Argonne

\title{
Improved Performance of U-Mo Dispersion Fuel by Si Addition in Al Matrix
}

Nuclear Engineering Division 


\section{About Argonne National Laboratory}

Argonne is a U.S. Department of Energy laboratory managed by UChicago Argonne, LLC under contract DE-AC02-06CH11357. The Laboratory's main facility is outside Chicago, at 9700 South Cass Avenue, Argonne, Illinois 60439. For information about Argonne and its pioneering science and technology programs, see www.anl.gov.

Availability of This Report

This report is available, at no cost, at http://www.osti.gov/bridge. It is also available on paper to the U.S. Department of Energy and its contractors, for a processing fee, from:

U.S. Department of Energy

Office of Scientific and Technical Information

P.O. Box 62

Oak Ridge, TN 37831-0062

Phone (865) 576-8401

Fax (855) 576-5728

reports@adonis.osti.gov

\section{Disclaime}

This report was prepared as an account of work sponsored by an agency of the United States Government. Neither the United States Government nor any agency thereof, nor UChicago Argonne, LLC, nor any of their employees or officers, makes any warranty, express or implied, or assumes any legal liability or responsibility for the accuracy, completeness, or usefulness of any information, apparatus, product, or process disclosed, or represents that its use would not infringe privately owned rights. Reference herein to any specific commercial product, process, or service by trade name, trademark, manufacturer, or otherwise, does not necessarily constitute or imply its endorsement, recommendation, or favoring by the United States Government or any agency thereof. The views and opinions of document authors expressed herein do not necessarily state or reflect those of the United States Government or any agency thereof, Argonne National Laboratory, or UChicago Argonne, LLC. 


\section{Improved Performance of U-Mo Dispersion Fuel by Si Addition in Al Matrix}

by

Y.S. Kim, G.L Hofman

Nuclear Engineering Division, Argonne National Laboratory

June 2011 



\section{Table of Contents}

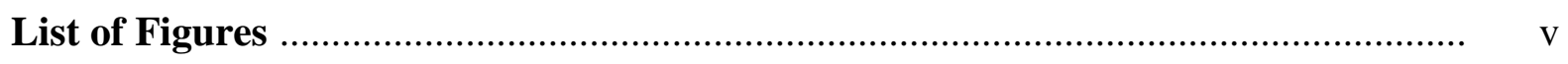

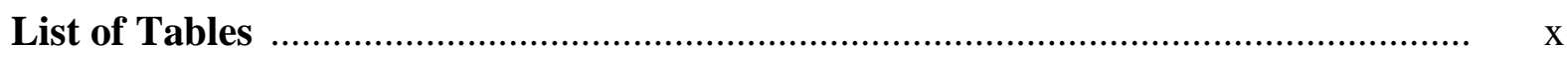

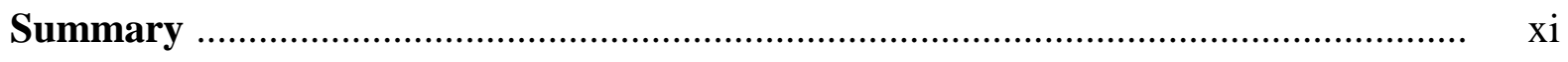

Nomenclature and acronyms .......................................................................... xii

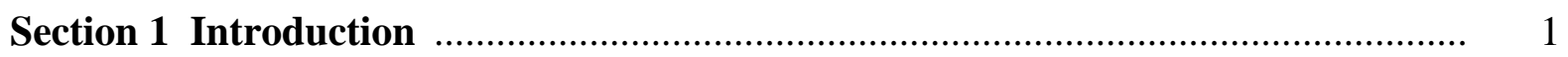

Section 2 Interaction layer growth and pore formation in plates with pure 3

Al matrix ...................................................................................................

2.1 Observations for U-Mo/Al dispersion ........................................................... 3

2.2 Cause for the pore formation in ILs ……………........................................... 6

2.2.1 Reaction in UAlx/Al dispersion ........................................................... 6

2.2.2 Al-to-U ratio .................................................................................... 7

2.2.3 Mo effect ....................................................................................... 8

2.2.4 Amorphization of IL .......................................................................... 9

Section 3 Remedy for interaction layer growth and pore formation .......................... 11

3.1 Alloying element addition in the matrix .......................................................... 11

3.1.1 Reaction between $\mathrm{U}$ and $\mathrm{Al}$................................................................ 11

3.1.2 Effect of alloy addition in Al to suppress UAl4 formation .................... 13

3.1.3 BFS atomistic model prediction of IL growth in U-Mo/Al with $\mathrm{Si}$ addition ....................................................................................... 14

3.1.4 Si effect on IL growth in U-Mo/Al during irradiation .......................... 16

3.1.5 Comparison of reaction layer thicknesses between $\mathrm{UAl} 3 / \mathrm{Al}$ and U(Al0.49Si0.11)3/Al from irradiated tests .......................................... 18

3.1.6 Effect of Si content on IL growth in U-Si compound/Al dispersions ... 19

3.2 Silicon effect on strengthening of interaction layers ......................................... 21

3.2.1 Effect of silicon content in U-Si intermetallics .................................... 21

3.2.2 Strengthening interaction layer ......................................................... 22

3.2.3 Minimum Si content in IL .................................................................. 24

3.2.4 Minimum as-fabrication Si content in matrix: prediction modeling ..... 26

3.3 Element addition in U-Mo ............................................................................ 29

Section 4 Out-of-pile tests................................................................................. 33

4.1 Interaction between U-Mo and Al-Si ........................................................ 33

4.2 Effect of $\mathrm{Zr}$ or Ti addition in U-Mo .............................................................. 35 


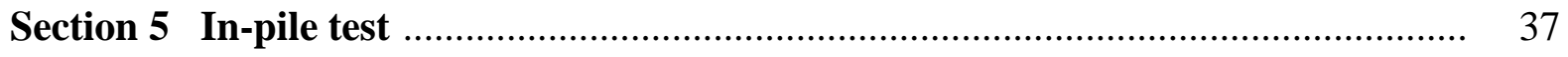

$5.1 \quad$ Test plate fabrication for RERTR tests................................................. 37

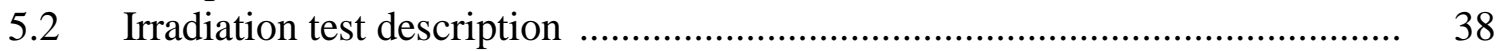

5.2.1 RERTR-3 test .................................................................... 39

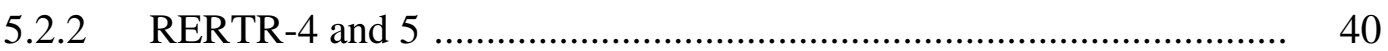

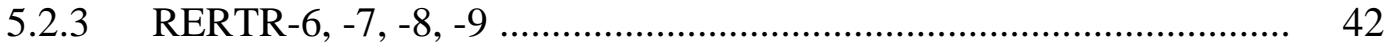

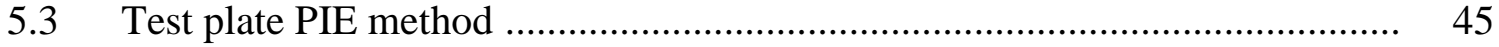

5.3.1. Optical Microscopy ..................................................................... 46

5.3.1.1 Interaction layer thickness measurement ....................... 47

5.3.1.2 Interaction layer volume measurement ......................... 47

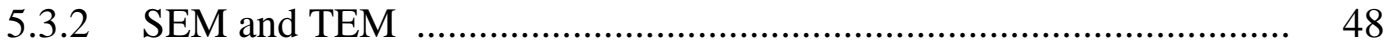

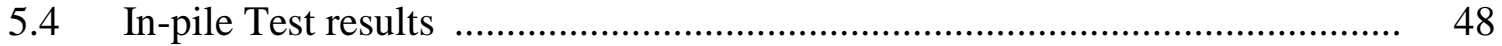

5.4.1 IL thickness reduction ................................................................ 48

5.4.2 Delayed pore formation in IL in U-Mo/Al-Si ................................ 54

5.4.3 Effect of $\mathrm{Ti}$ and $\mathrm{Zr}$ addition in $\mathrm{U}-\mathrm{Mo}$........................................... 57

5.4.4 Si diffusion to IL during irradiation ............................................ 59

5.4.5 KOMO test results from KAERI ................................................... 60

Section 6 Si effect on performance of U-Mo/Al .................................................. 71

6.1 Mechanism of Si effect on IL reduction ........................................................ 71

6.2 Mechanism of Si effect on pore formation in IL ........................................ 72

6.3 Interaction-layer-growth correlation for U-Mo/Al-Si plates .......................... 75

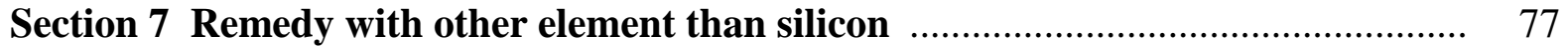

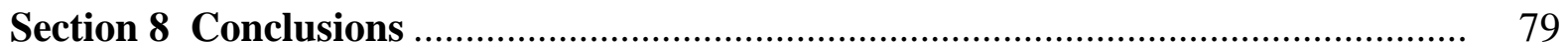

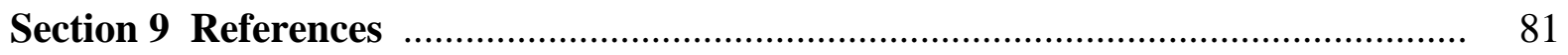

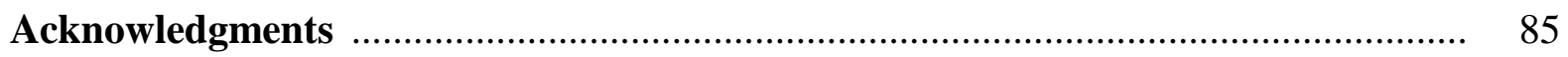

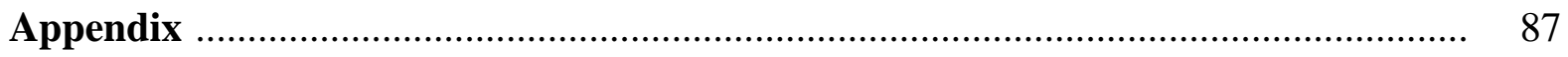




\section{List of Figures}

$\underline{\text { Figure }}$

$\underline{\text { Page }}$

1. SEM micrographs showing fission gas bubble morphology in $\mathrm{U}_{3} \mathrm{Si}_{2}$ and $\mathrm{U}$ 10Mo.

2. Comparison of interaction layer growth of U-Mo alloy particles in Al with Usilicide dispersion in $\mathrm{Al}$ (Redrawn from Ref. 2). $\mathrm{Y}$ is the IL thickness in $\mu \mathrm{m}$. ..

3. Optical micrographs of R04 from the RERTR-3 test irradiated to a fission density of $2.9 \times 10^{21} \mathrm{f} / \mathrm{cm}^{3}$. The darkest phase is pores, the brightest phase is the aluminum matrix, and the interaction product surrounds somewhat darker phase fuel particles.

4. Optical micrograph of transverse cross section of V6022M irradiated to $5.5 \times 10^{21} \mathrm{f} / \mathrm{cm}^{3}$ (77.8 LEU Equiv BU) from the RERTR-4 test.

5. SEM micrograph of fracture surface of Z03 irradiated to $2.2 \times 10^{21} \mathrm{f} / \mathrm{cm}^{3}$ in the RERTR-3 test. 1=Fuel particle, 2=interaction layer, 3=matrix $\mathrm{Al}$, $4=$ interaction layer on fuel surface showing pores formed there.

6. SEM (BSI) of a $93 \%$ enriched $\mathrm{UAl}_{\mathrm{x}} / \mathrm{Al}$ dispersion fuel after a $60 \% \mathrm{U}-235$ burnup (or $7.5 \times 10^{21} \mathrm{f} / \mathrm{cm}^{3}$ ). $\mathrm{A}$ is the $\mathrm{UAl}_{2}, \mathrm{~B}$ is the $\mathrm{UAl}_{3}, \mathrm{C}$ is the interaction product.

7. Pseudo-ternary diagram of U-Mo-Al-Si showing IL composition data from in-pile tests with pure $\mathrm{Al}$ matrix.

8. Heat of formation $\left(\Delta_{f} H_{298}^{o}\right)$ of $(\mathrm{U}, \mathrm{Mo}) \mathrm{Al}_{3}$ versus $\mathrm{Mo} /(\mathrm{U}+\mathrm{Mo})$ molar ratio [14].

9. Breakaway swelling of amorphous U-compounds. (a) $\mathrm{U}_{3} \mathrm{Si}$ (8\% HM burnup), (b) $\mathrm{U}_{6} \mathrm{Fe}$ (17\% HM burnup).

10. Comparison of interaction layer growth in U-Al and U-AlSi. Al-12Si is an alloy with $12 \mathrm{wt} \% \mathrm{Si}$ in $\mathrm{Al}$.

11. U-Al diffusion couple tests with a Mo-marker. (a) Test at $550{ }^{\circ} \mathrm{C}$, (b) test at $400{ }^{\circ} \mathrm{C}$. The Mo-marker bends into the Al. The value $\mathrm{x} 2 / \mathrm{x} 1$ is the ratio of the penetration of $\mathrm{U}$ into $\mathrm{Al}$ to the penetration of $\mathrm{Al}$ into $\mathrm{U}$ [27]. 
12. BFS model prediction of effect of Si addition to $\mathrm{Al}$ in U-Mo/Al IL growth. (a) U-5Mo/Al-5Si, (b) U-5Mo/Al, (c) U-10Mo/Al-5Si, (d) U-5Mo/Al-10Si, (e) U/Al-10Si, (f) U-10Mo/Al-10Si. The concentrations are in weight percent. ...

13. Optical micrograph showing interaction layer growth at interface between fuel zone and cladding. The IL thickness is thinner on the cladding side than on the fuel meat side.

14. U-Si-Al ternary phase diagram showing reaction products between $\mathrm{U}, \mathrm{Si}$, and Al.

15. $\mathrm{Y}^{2}$ versus time where $\mathrm{Y}$ is the IL thickness. $\mathrm{Y}^{2}$ is normalized with the square of the fission rate $\sqrt{\dot{\mathrm{f}}}$, and the IL thickness data are at $100^{\circ} \mathrm{C}$. Guided lines are also shown.

16. Elongation of sample by ion irradiation from Klaumunzer [47]. The data fitting curve with the Doolittle relation $\phi=15.4 \exp \left(-\mathrm{B} / \mathrm{v}_{\mathrm{f}}\right)$ is also included. .....

17. Fission gas bubble morphology in two U-Si compound fuels with different $\mathrm{Si} / \mathrm{U}$ ratios. Notice the difference in magnification, the image in (b) is 10 times higher in magnification.

18. Enthalpies of formation of compounds and alloys. Lines: predictions by the Miedema model, symbols: data in the literature.

19. Enthalpies of formation of interaction layers showing the effect of Mo and Si additions [12].

20. Minimum Si content in the IL to avoid the formation of $\mathrm{UAl}_{4}$

21. Schematic of modeling fission fragment recoil zone overlapping.

22. Prediction of Si concentration in IL for average fuel particle size of $70 \mu \mathrm{m}$ and $6 \mathrm{gU} / \mathrm{cm}^{3}$ meat U-density for four as-fabrication Si-contents in Al. This prediction is applicable for RERTR-6 test. This case is approximately applicable to the RERTR-7 test that has larger particle size but the same loading.

23. Prediction of Si concentration in IL for average fuel particle size of $70 \mu \mathrm{m}$ and $8 \mathrm{gU} / \mathrm{cm}^{3}$ meat U-density for four as-fabrication Si-contents in Al. This prediction is applicable for RERTR-9A test.

24. Prediction of Si concentration in IL for average fuel particle size of $70 \mu \mathrm{m}$ and $8.5 \mathrm{gU} / \mathrm{cm}^{3}$ meat U-density for four as-fabrication Si-contents in Al. This prediction is applicable for RERTR-9B test. 
25. Enthalpies of formation of binary alloys. ................................ 30

26. Schematic of design of alloying element additions in U-Mo/Al. ............... 31

27. Effect of $\mathrm{Zr}$ additions to U-7Mo alloy on isothermal transformation [56]. The $\gamma$ phase is stable at the left side of each curve while the $\alpha+\gamma^{\prime}$ is stable at the

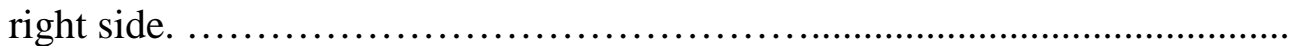

28. CNEA diffusion couple test result with U-Mo/Al-Si showing Si-precipitate depletion zone [57]

29. Diffusion couple tests with U-Mo-xZr versus Al-ySi at $600{ }^{\circ} \mathrm{C}$ for three hours, where $\mathrm{x}$ and $\mathrm{y}$ are concentrations in weight $\%$ [53].

30. Interaction layer growth kinetics $[57,58]$ and precipitate-free-zone (PFZ) growth kinetics from Mirandou tests [57].

31. Time to start $\gamma \rightarrow \alpha+\gamma^{\prime}$ transformation. Although the nominal Mo content is 7wt\%, R2R010 and R2R020 have $8.2 \mathrm{wt} \%$ Mo whereas R3R030 has $6.8 \mathrm{wt} \%$ Mo. An IRIS-3 test plate is shown for comparison that uses a lower hot rolling temperature than RERTR plates.

32. Comparison of nanoplate and miniplate sizes.

33. Schematic of test plate loading scheme used for RERTR-4, -5, -6, -7, -8 and 9 tests.

34. ATR core diagram showing the locations of RERTR-4 (B-11) and -5 (B-12) irradiation and plate loading direction in the test vehicle. (a) ATR core diagram, (b) Detailed description of the quarter core and neutron flux contours. (c) Test basket B-11 showing plate loading direction. In B-12 hole for RERTR-5, the basket is turned $90^{\circ}$.

35. Changes in plate direction and power peaking factors across the plate width by flipping of basket between cycles (RERTR-4 and -5).

36. EOL burnup distributions across the meat width for RERTR-3, -4, -5, -6, -7, 8 , and -9 .

37. Fission rate histories (meat average in the fuel particles) of RERTR-3, $-4,-5$, 6, $-7,-8$ and -9 tests. Fission by Pu not included.

38. Schematic diagrams showing PIE locations for miniplates.

39. Schematic of metallographic surface to obtain interaction layer thickness. A and $\mathrm{B}$ are cutting planes. 
40. Schematic of an optical micrograph with superimposed grids.

41. Optical micrographs of test plates from RERTR-6. IL is IL thickness. The number in front of Si represents Si concentration in weight \%. BU is given LEU Equiv.

42. Optical micrographs of test plates from RERTR-7. BU is U-235 LEU equivalent burnup. IL is IL thickness. The number in front of Si represents $\mathrm{Si}$ concentration in weight \%. BU is given LEU Equiv.

43. Optical micrographs of test plates from RERTR-9A. BU is U-235 LEU equivalent burnup. IL is IL thickness. The number in front of Si represents $\mathrm{Si}$ concentration in weight \%. BU is given LEU Equiv.

44. OM taken from the cold side of test plates from RERTR-9B. BU is U-235

LEU equivalent burnup. IL is IL thickness. The number in front of $\mathrm{Si}$ represents Si concentration in weight \%. BU is given LEU Equiv.

45. Effect of Si addition on IL thickness for RERTR-6 plates.

46. Optical micrographs showing fuel microstructures.

47. Comparison of pore morphology in dispersion plates at different burnups......

48. Change in $\mathrm{Zr} / \mathrm{Mo}$ ratio as a function of burnup and time of $\gamma \rightarrow \alpha+\gamma^{\prime}$ transformation for U-7Mo and U-7Mo-2Zr alloys at $450^{\circ} \mathrm{C}$. (No irradiation effects considered.)

49. Comparison of post-irradiation microstructures in U-7Mo/Al-5Si, U-7Mo1Ti/Al-5Si and U-7Mo-2Zr/Al-5Si. FD is the fission density in $10^{21} \mathrm{f} / \mathrm{cm}^{3}$ fuel particle.

50. Precipitate free zones observed in R3R030 from RERTR-6.

51. Si X-ray map of as-fabricated U-7Mo/Al-3.5Si used for RERTR-9B [67]. The right side image is for $\mathrm{Si}$.

52. U-7Mo/Al-2Si irradiated to $3.7 \times 10^{21} \mathrm{f} / \mathrm{cm}^{3}$ (51\% LEU equiv burnup) at 195

${ }^{\circ} \mathrm{C}$ for 132 EFPD in the HANARO [74].

53. U-7Mo/Al-5Si irradiated to $3.6 \times 10^{21} \mathrm{f} / \mathrm{cm}^{3}$ (49\% LEU equiv burnup) at 190 ${ }^{\circ} \mathrm{C}$ for 132 EFPD in the HANARO [74].

54. U-7Mo/Al-8Si irradiated to $3.5 \times 10^{21} \mathrm{f} / \mathrm{cm}^{3}$ (48\% LEU equiv burnup) at 190 ${ }^{\circ} \mathrm{C}$ for $132 \mathrm{EFPD}$ in the HANARO [74]. 
55. U-7Mo/Al-5Si with heating before irradiation (for 1 hour at $580{ }^{\circ} \mathrm{C}$ ) and subsequently irradiated to $4.0 \times 10^{21} \mathrm{f} / \mathrm{cm}^{3}$ (54\% LEU equiv burnup) at $190{ }^{\circ} \mathrm{C}$ for 132 EFPD in the HANARO [74] ..........................................

56. Concentration profiles of pre-heated U-7Mo/Al-5Si sample before irradiation. 63

57. EPMA data showing composition in IL from KOMO-3 irradiation test of U$7 \mathrm{Mo} / \mathrm{Al}-2 \mathrm{Si}$ in a fuel rod [75].

58. Concentration profiles and Al flux in the IL calculated for the U-7Mo/Al-2Si sample described in Fig. 51, irradiated to $3.7 \times 10^{21} \mathrm{f} / \mathrm{cm}^{3}$ (51\% LEU equiv burnup) at $195{ }^{\circ} \mathrm{C}$ for $132 \mathrm{EFPD}$ in the HANARO.

59. Concentration profiles and Al flux in the IL calculated for the U-7Mo/Al-5Si sample described in Fig. 52, irradiated to $3.6 \times 10^{21} \mathrm{f} / \mathrm{cm}^{3}$ (49\% LEU equiv burnup) at $195{ }^{\circ} \mathrm{C}$ for $132 \mathrm{EFPD}$ in the HANARO.

60. Concentration profiles and Al flux in the IL calculated for the U-7Mo/Al-8Si sample described in Fig. 53, irradiated to $3.5 \times 10^{21} \mathrm{f} / \mathrm{cm}^{3}$ (48\% LEU equiv burnup) at $190{ }^{\circ} \mathrm{C}$ for $132 \mathrm{EFPD}$ in the HANARO.

61. Concentration profiles and Al flux in the IL calculated for the U-7Mo/Al-5Si sample with pre-heating before irradiation described in Fig. 54, irradiated to $4.0 \times 10^{21} \mathrm{f} / \mathrm{cm}^{3}$ (54\% LEU equiv burnup) at $190{ }^{\circ} \mathrm{C}$ for $132 \mathrm{EFPD}$ in the HANARO.

62. $\mathrm{Si} / \mathrm{Al}$ ratio in the $\mathrm{IL}$ versus $\mathrm{Si} / \mathrm{Al}$ ratio in the matrix.

63. Microstructures of R5R020 (Al-0.2Si) irradiated in the RERTR-6 test and R3R050 (Al-4.8Si) irradiated in RERTR-7. See table 9 for irradiation conditions.

64. Comparison of IL reduction factors obtained for the low-temperature RERTR-6 test and the high-temperature KOMO-4 test, where IL reduction factor is defined as the square of IL divided by the square of IL for pure Al matrix at the same temperature.

65. Comparison of heats of formation of binary alloys of candidate elements with $\mathrm{U}, \mathrm{Mo}$, and $\mathrm{Al}$.

66. Comparison of diffusion coefficients of U/Al, U/Al-Si and U/Al-Be diffusion couples. 


\section{List of Tables}

$\underline{\text { Table }}$

$\underline{\text { Page }}$

1. Fundamental differences observed between out-of-pile and in-reactor tests for interaction in U-Mo/Al dispersion ..........................................

2. Thermal neutron absorption cross-sections for some elements

3. Compositions of two frequently used aluminum cladding alloys

18

4. Comparison of reaction layer thicknesses between $\mathrm{UAl}_{3} / \mathrm{Al}$ and

$\mathrm{U}\left(\mathrm{Al}_{0.49} \mathrm{Si}_{0.11}\right)_{3} / \mathrm{Al}$ from irradiated tests

5. Measured IL thickness and predicted threshold IL thickness for minimum Sicontent in the IL for RERTR-test plates

6. Hot rolling parameters used for test plate fabrication

7. IL thickness and time of $\alpha+\gamma^{\prime}$ transformation

8. Summary of irradiation test data for plates of RERTR-3, -4, -5, -6, -7, -8, -9A, and $-9 B$ tests

9. Total amount of $\mathrm{Al}$ and $\mathrm{Si}$ in the IL and average effective interdiffusion coefficient of $\mathrm{Al}$ in the IL after 132 days of irradiation in HANARO

10. Post-irradiation fuel microstructure data for RERTR tests 


\section{Summary}

The purpose of this report is to collect in one publication and fit together work fragments presented in many conferences in the multi-year time span starting 2002 to the present dealing with the problem of large pore formation in $\mathrm{U}-\mathrm{Mo} / \mathrm{Al}$ dispersion fuel plates first observed in 2002. Hence, this report summarizes the excerpts from papers and reports on how we interpreted the relevant results from out-of-pile and in-pile tests and how this problem was dealt with. This report also provides a refined view to explain in detail and in a quantitative manner the underlying mechanism of the role of silicon in improving the irradiation performance of $\mathrm{U}$ $\mathrm{Mo} / \mathrm{Al}$.

This report comprises eight sections. The major contents of each section are as follows:

Section 1: an overall introduction and objectives of the report.

Section 2: description of problems related to interaction layer growth in U-Mo dispersion fuel in an Al matrix and formation of large scale pores in the interaction layer (IL).

Section 3: explanation of how and why we selected Si addition to solve the problems stated in Section 2. This section describes the accumulated experimental data and theoretical predictions to seek a remedy.

Section 4: out-of-pile test results to scan and confirm the predictions, and to supplement the inpile tests also.

Section 5: in-pile test design, PIE methods, results from the RERTR test campaigns and some data from international collaboration are also used.

Section 6: mechanism of the effect of Si addition.

Section 7: alternative element other than Si that has potential to replace Si.

Section 8: conclusions. 


\section{Nomenclature and acronyms}

$\begin{array}{ll}\text { ANL } & \text { Argonne National Laboratory } \\ \text { AGHCF } & \text { Alpha Gamma Hot Cell Facility } \\ \text { BU } & \text { burnup of U-235 } \\ \text { BOL } & \text { beginning of life } \\ \text { EOL } & \text { end of life } \\ \text { EPMA } & \text { electron probe micro analysis } \\ \text { FD } & \text { fission density in fuel particles } \\ \text { FR } & \text { fission rate in fuel particles } \\ \text { HEU } & \text { Highly enriched uranium (with enrichment } \geq 20 \% \text { U-235) } \\ \text { HM } & \text { heavy metal } \\ \text { IL } & \text { interaction layer } \\ \text { INL } & \text { Idaho National Laboratory } \\ \text { KAERI } & \text { Korea Atomic Energy Research Institue } \\ \text { LEU } & \text { low enrivhed uranium (with enrichment }<20 \% \text { U-235) } \\ \text { MFC } & \text { materials and fuel complex } \\ \text { OM } & \text { optical microscope } \\ \text { RERTR } & \text { reduced enrichment for research and test reactors } \\ \text { SEM } & \text { scanning electron microscopy } \\ \text { TEM } & \text { tramsmission electron microscopy }\end{array}$

\section{Units}

LEU equiv. BU U-235 burnup normalized for enrichment of $19.5 \%$ 


\section{Section 1 Introduction}

The need for conversion of HEU-using high-power research reactors that cannot be met with the use of developed LEU $\mathrm{U}_{3} \mathrm{Si}_{2}$ resulted in development of U-Mo alloy. Since 1996, the U-Mo alloys in dispersion form first and monolithic form later have been under development in the RERTR (Reduced Enrichment for Research and Test Reactors) program in the United Sates and foreign programs in Argentina, Canada, France, South Korea, and Russia.

U-Mo has predictable stable swelling by fission products at typical operation temperatures of the reactors (see for example Ref. 1 and references therein). Gas bubble morphology between $\mathrm{U}_{3} \mathrm{Si}_{2}$ and U-10Mo is compared in Fig. 1.

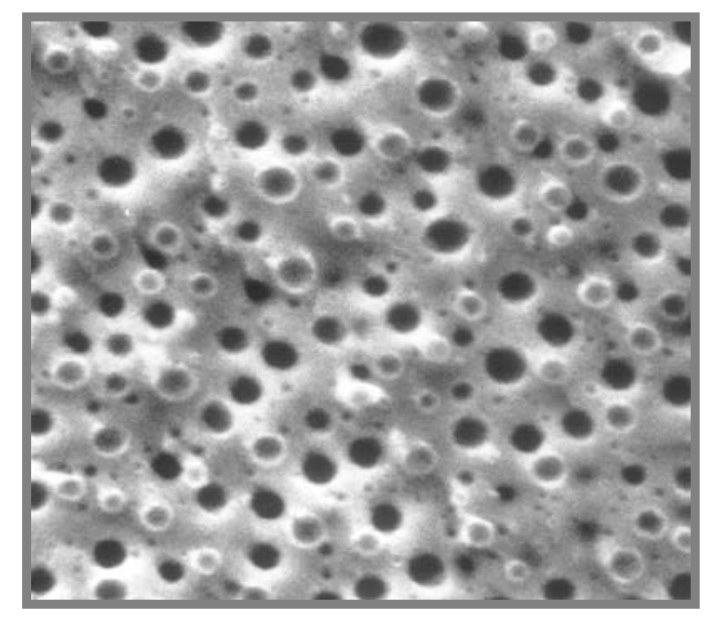

(a) $\mathrm{U}_{3} \mathrm{Si}_{2}$ irradiated to $\mathrm{FD}=5.1 \times 10^{21} \mathrm{f} / \mathrm{cm}^{3}$

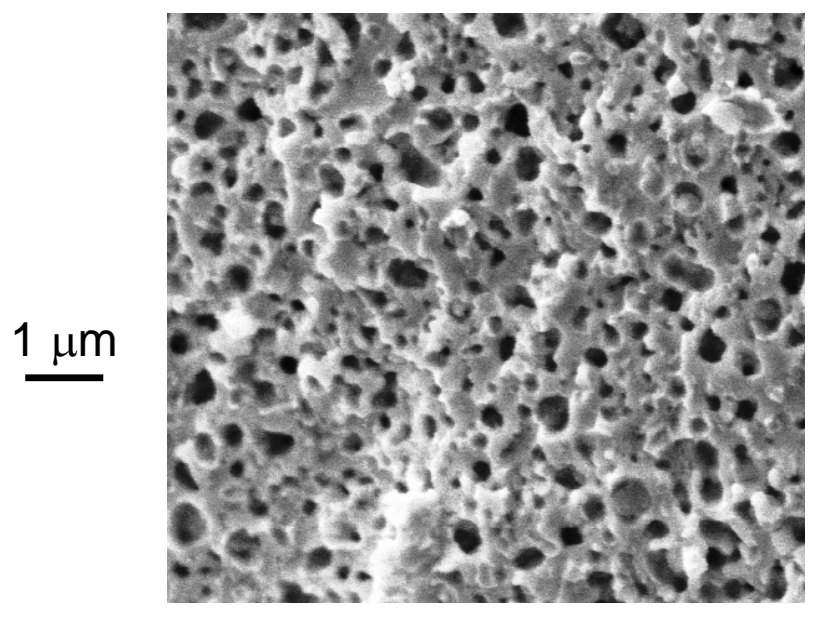

(b) U-10Mo irradiated to $\mathrm{FD}=5.7 \times 10^{21} \mathrm{f} / \mathrm{cm}^{3}$

Fig. 1 SEM micrographs of fuel particle fracture surface showing fission gas bubble morphology in irradiated $\mathrm{U}_{3} \mathrm{Si}_{2}$ and $\mathrm{U}-10 \mathrm{Mo}$.

However, the formation of an interaction layer between the fuel particles and matrix aluminum presented a problem in the course of qualification of this fuel. The formation of interaction layers (ILs) results in a reduction in thermal conductivity of the fueled zone (i.e., fuel meat) because of the thermal conductivity of the ILs is much lower than that of the matrix $\mathrm{Al}$ it is consuming. The IL growth poses a more serious effect. For some irradiated at a high fission rate and a high fission density, pores were observed in the thick ILs, much larger than the fission gas bubbles typically observed in U-Mo. The surface of the pores are generally smooth and round, suggesting the ILs that surround the pores have low viscosity allowing plastic flow. The shape and extent of pores implied that strengthening of the ILs is the key to improve the stability of the fuel meat and prevent connection between the pores that can lead to a potential failure mechanism such as plate pillowing. Although U-Mo alloy fuel showed stable swelling behavior comparable with the existing qualified fuel $\mathrm{U}_{3} \mathrm{Si}_{2}$, the above mentioned problem had to be solved to allow qualification of this type of fuel to proceed. 
In the RERTR program at ANL, silicon alloying addition in the matrix was proposed as a remedy to suppress IL growth and increase the IL stability. Titanium and zirconium additions in U-Mo were also suggested to reduce the amount of Si addition.

Since ANL proposed Si addition to the Al matrix, there have been numerous out-of-pile tests and in-pile tests to examine the efficacy of the remedy in the US and foreign programs as well. In general, consistent results have been reported, all of which show beneficial effect of Si addition. IL growth is indeed drastically reduced and pore formation in the ILs was significantly delayed from irradiation tests. However, in some cases, there also have been inconsistent results that confused the fuel developers mostly because of still scarce data and, therefore, limitation in characterization that hinders thorough interpretation of the available data.

The idea of adding Si is based on ANL's experience garnered in the development of silicide dispersion fuel and earlier studies on U-Al fuel [2].

This report carries the record of the multi-year effort to overcome the obstacle caused by excessive IL growth and pore formation in U-Mo dispersion in $\mathrm{Al}$, designated as U-Mo/Al hereafter. Some out-of-pile test results mostly obtained at KAERI and CNEA are also used. The irradiation test results from the RERTR test campaigns are used. The KOMO tests performed at KAERI were also very significantly used.

From the data available to present, we explain how and why Si addition is effective in solving the problems, and other remedies are also suggested. 


\section{Section 2 Interaction layer growth and pore formation in plates with pure Al matrix}

\subsection{Observations for U-Mo/Al dispersion}

Formation of interaction layers between dispersant fuel particles and the matrix resulting from fission induced interdiffusion, is a common occurrence. From low temperature $\left(\sim 65{ }^{\circ} \mathrm{C}\right)$ tests, RERTR-1 and -2, interaction layer (IL) growth of U-Mo dispersion in $\mathrm{Al}$ was shown to be comparable to that of $\mathrm{U}_{3} \mathrm{Si}_{2}$ compound dispersion in $\mathrm{Al}$ as shown in Fig. 2. Based on this promising result together with stable swelling performance of the fuel, further tests were planned.

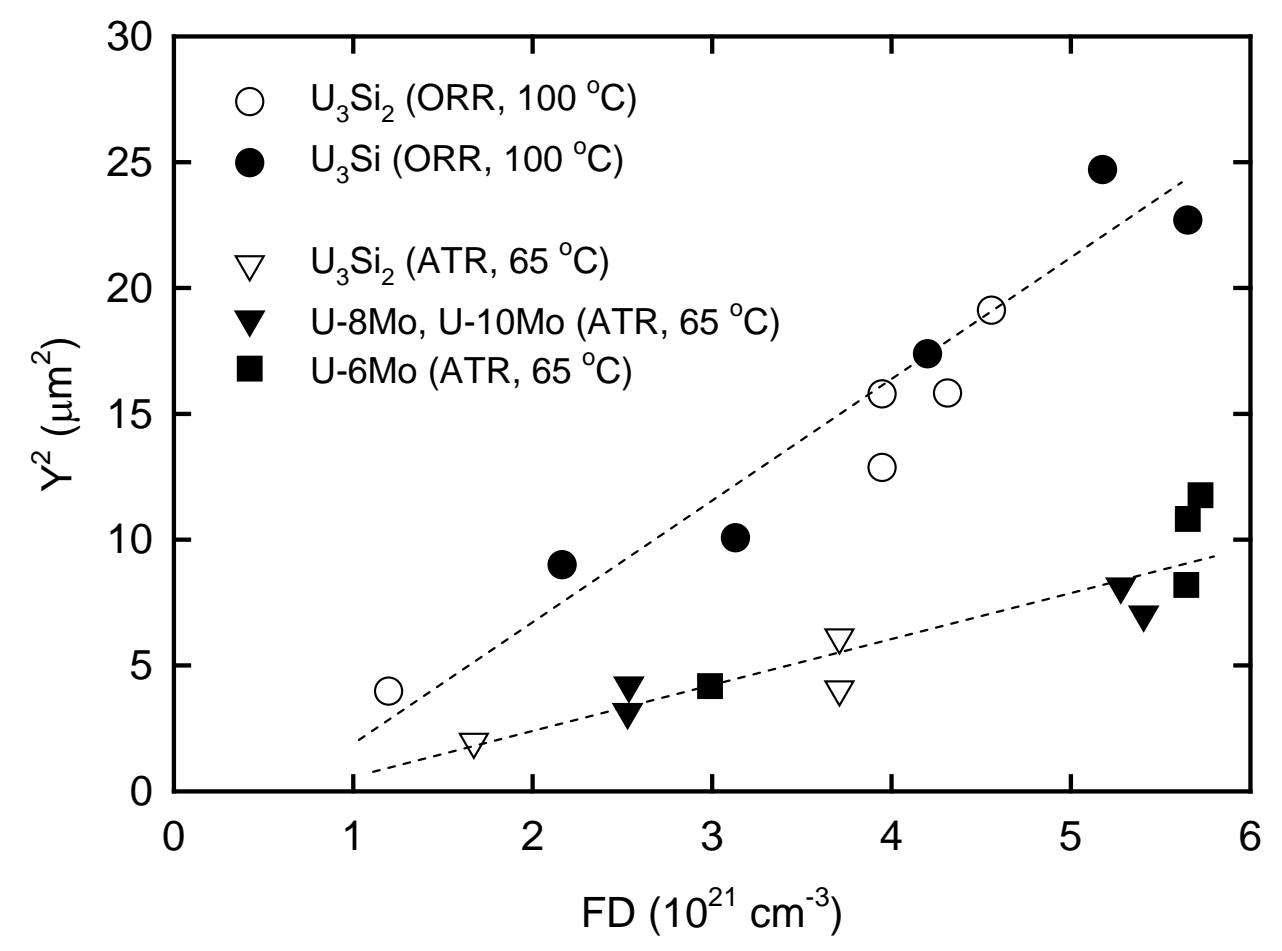

Fig. 2 Comparison of interaction layer growth of U-Mo alloy particles in Al with Usilicide dispersion in $\mathrm{Al}$ (Redrawn from Ref. 2). $\mathrm{Y}$ is the IL thickness in $\mu \mathrm{m}$.

However, from the RERTR-3 test, which was a short but higher temperature test than RERTR-1 and -2 , much higher IL growth rate was found at the plate centers where power was highest. The BOL fuel temperatures of the test plates were designed to be higher than $100{ }^{\circ} \mathrm{C}$ (see Table 8 in Section 5 for the details of in-pile test data). It was the first test that showed such a high rate of IL growth for this fuel.

At the same location where the thick ILs are found, pores were also observed as shown in Fig. 3. These pores occur in the ILs and at the IL-Al interface. A more detailed description of the irradiation tests is given in later section. 


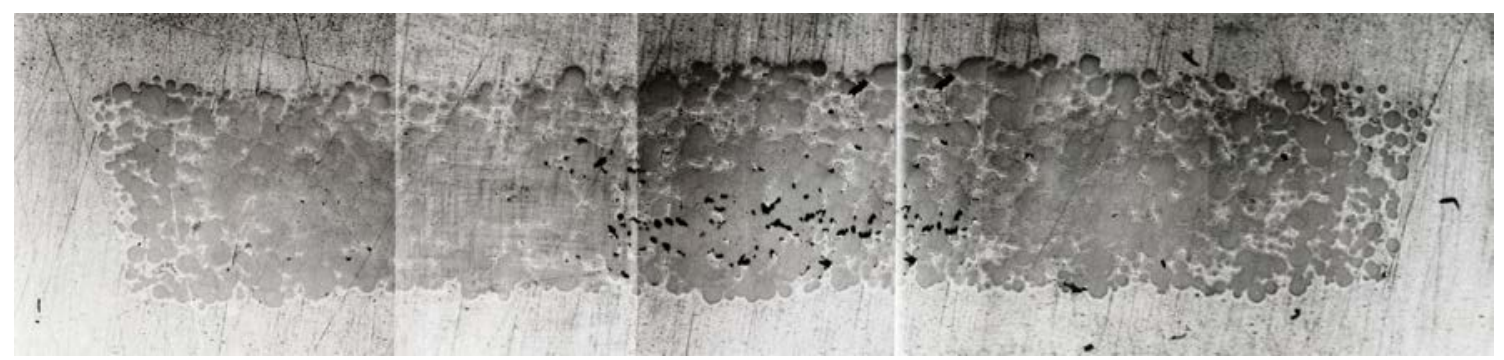

(a) Transverse cross section at axial center plane

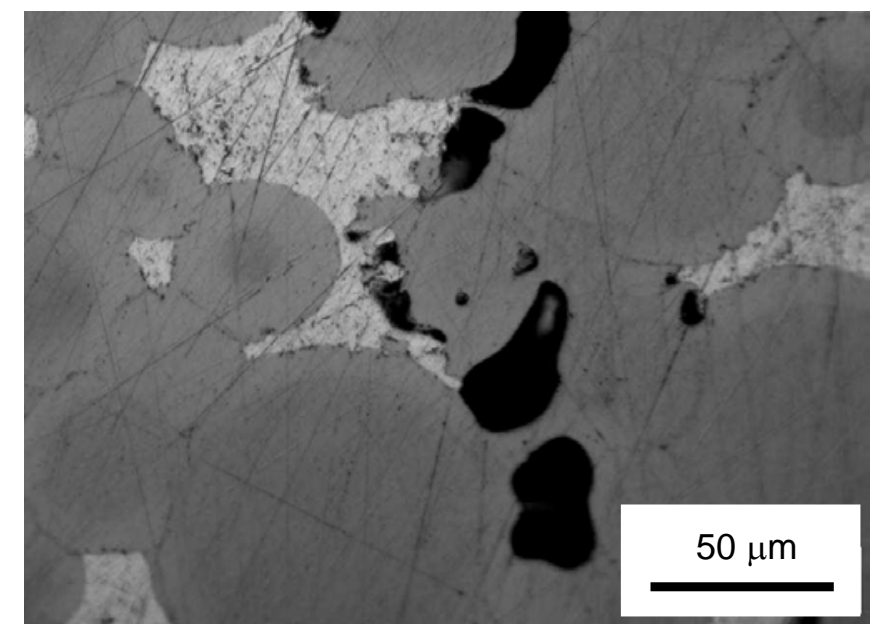

(b) Higher magnification of micrograph shown in (a)

Fig. 3 Optical micrographs of test plate R04 from the RERTR-3 test irradiated to a fission density of $2.9 \times 10^{21} \mathrm{f} / \mathrm{cm}^{3}$. The BOL fuel temperature was $155^{\circ} \mathrm{C}$. The darkest phase is pores, the brightest phase is the aluminum matrix, and the interaction product surrounds somewhat darker phase fuel particles.

Later the RERTR-5 and -4 experiments tested to higher burnups than the RERTR-3 found similar results as shown in Fig.4. For these longer tests, the IL growth was extensive. Near complete consumption of the Al matrix was observed. Large scale pores were prominent. This observation, particularly, the pore formation phenomenon, was reported by Hofman et al. in 2003 [3] and became an issue for fuel development in the RERTR community. A high power test by the French showed inter-connected pore growth that was considered a pre-stage of a pillowing failure [4]. Also a high power Russian test with U-Mo/Al tubular dispersion fuel failed by pillowing.

Regardless of the tests, the pores formed at the interface between the interaction layer and Al matrix, as shown in Fig. 4. This finding precludes the possibility that the pores are solely due to agglomeration of fission gas bubbles in the fuel. 
(a) Transverse cross section.

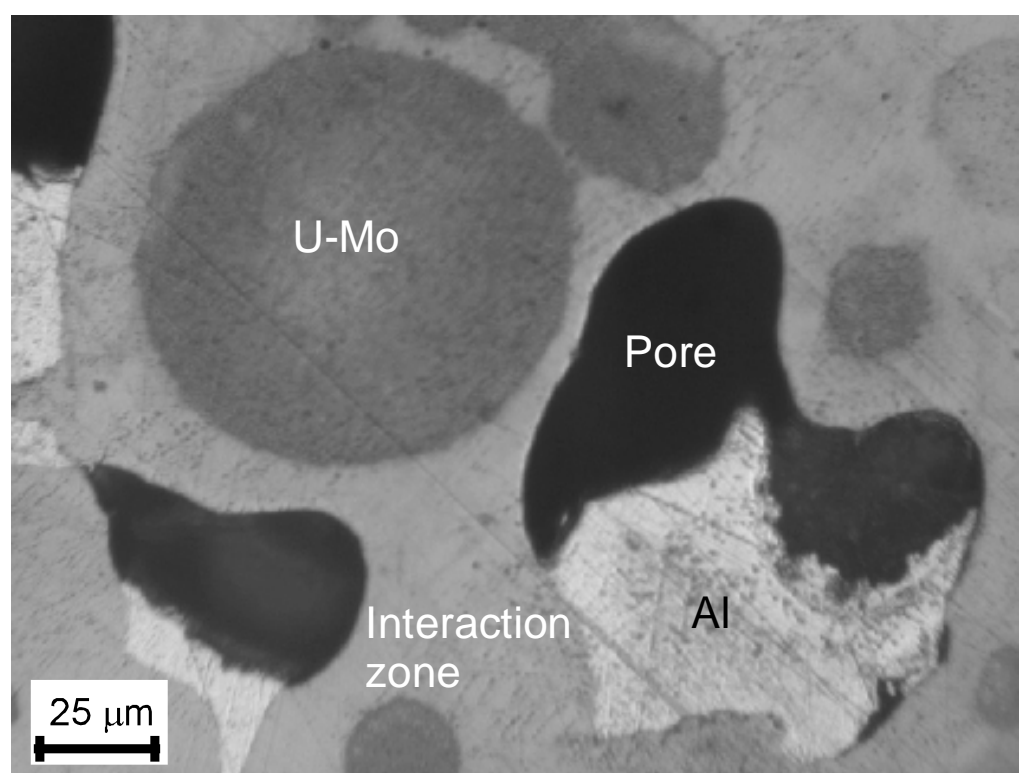

(b) Higher magnification of pore formation location shown in (a).

Fig. 4 Optical micrograph of transverse cross section of V6022M irradiated to $5.5 \times 10^{21} \mathrm{f} / \mathrm{cm}^{3}$ (77.8 LEU Equiv BU) from the RERTR-4 test.

The pore morphology was investigated more in detail by SEM. The SEM micrograph shown in Fig. 5 was taken on a fracture surface of irradiated U-Mo/Al at fission density of $2.2 \times 10^{21} \mathrm{f} / \mathrm{cm}^{3}$. As indicated in the image, some fracture surfaces of U-Mo particles are visible together with ILs on them. The ILs appear to be tightly bonded to the particles. Some areas of the Al matrix were pulled off and some show relatively ductile fracture surfaces. Some U-Mo particles were pulled off and rough $\mathrm{Al}$ surfaces are exposed. The most interesting feature is the pit-like indentations marked in the image by 4 . These are believed to be the clusters of pores in the ILs on the particle surfaces. The maximum size of this feature is $\sim 5 \mu \mathrm{m}$. The size of fission gas bubbles in U-Mo alloy is about an order of magnitude smaller than this. At higher burnup, these pores will grow to the larger sized pores shown such as in Fig. 4. 


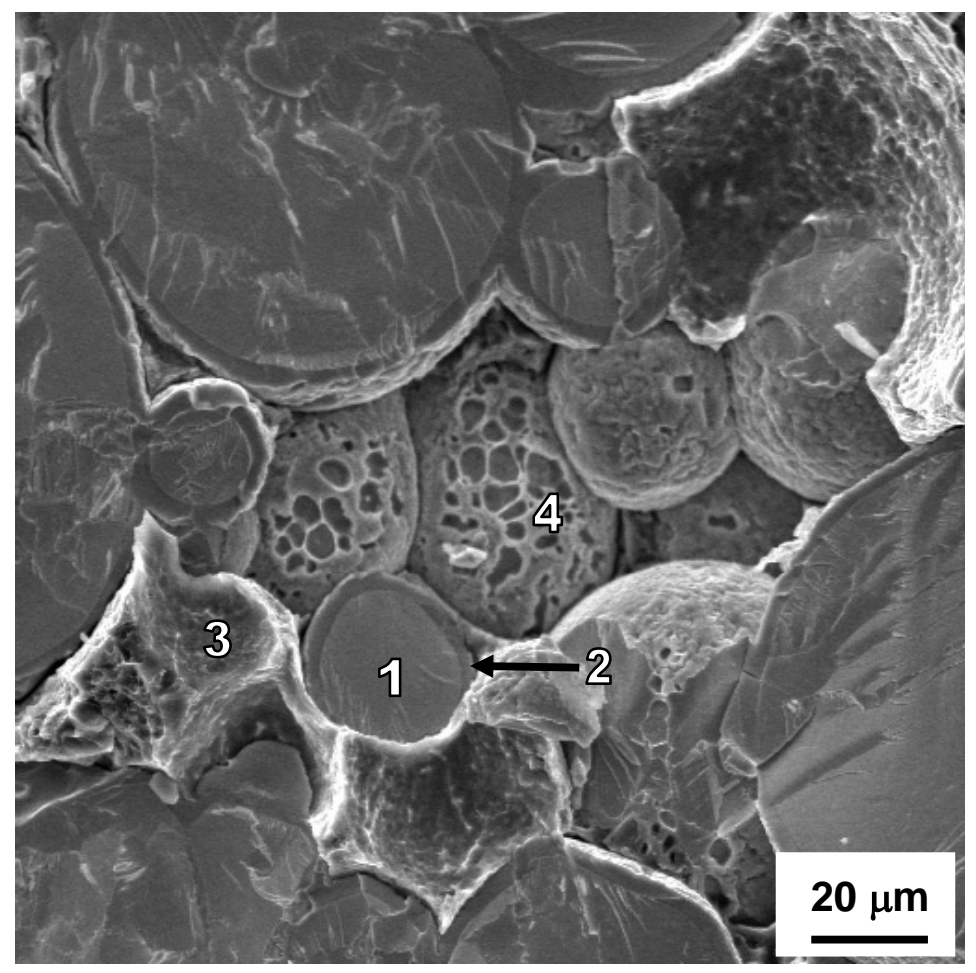

Fig. 5 SEM micrograph of fracture surface of Z03 irradiated to $2.2 \times 10^{21} \mathrm{f} / \mathrm{cm}^{3}$ in the RERTR-3 test. $1=$ Fuel particle, $2=$ interaction layer, $3=$ matrix $\mathrm{Al}$, $4=$ interaction layer on fuel surface showing pores formed there.

\subsection{Cause for the pore formation in ILs}

\subsubsection{Reaction in UAlx/Al dispersion}

Dienst et al. [5] and Hofman [6] showed that the interaction products formed in a $\mathrm{UAl}_{\mathrm{X}} / \mathrm{Al}$ dispersion fuel, where UAlx represents a mixture of two or three uranium aluminides, i.e., $\mathrm{UAl}_{2}$, $\mathrm{UAl}_{3}$, and $\mathrm{U}_{0.9} \mathrm{Al}_{4}$, are very stable in fission gas swelling. There are only three compounds in the $\mathrm{U}-\mathrm{Al}$ system. $\mathrm{UAl}_{2}$ is formed from liquid; the other two are formed by peritectoid reactions. The final reaction product is therefore probably $\mathrm{U}_{0.9} \mathrm{Al}_{4}$.

As shown in Fig. 6, the fission gas bubbles (or pores) in the interaction layer (labeled C) are so small that they are invisible in the SEM. Considering the working resolution $(\sim 0.1 \mu \mathrm{m})$ for SEM in those days, it is apparent that fission gas bubbles larger than $0.1 \mu \mathrm{m}$ do not form in UAlx to that high burnup. 


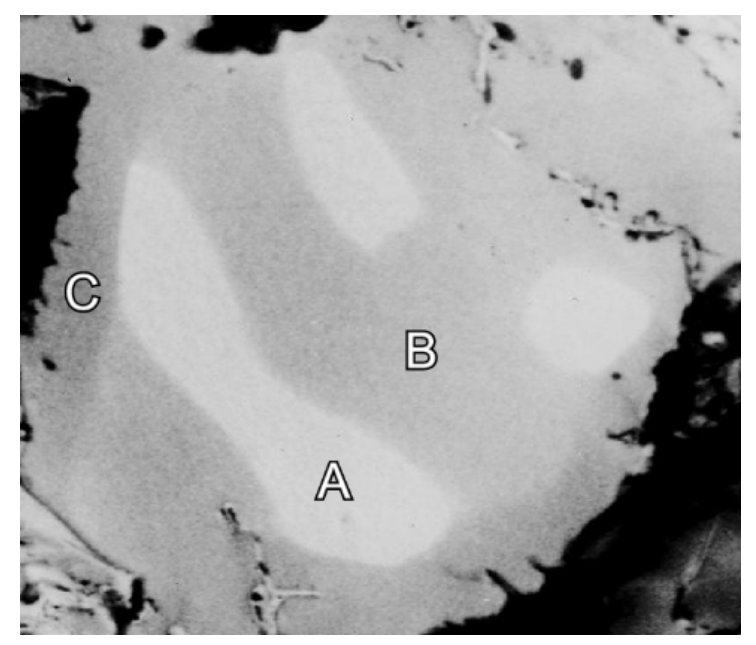

Fig. 6 A SEM (BSI) of a 93\% enriched $\mathrm{UAl}_{\mathrm{x}} / \mathrm{Al}$ dispersion fuel after a $60 \% \mathrm{U}$ 235 burnup (or $7.5 \times 10^{21} \mathrm{f} / \mathrm{cm}^{3}$ ). A is the $\mathrm{UAl}_{2}, \mathrm{~B}$ is the $\mathrm{UAl}_{3}, \mathrm{C}$ is the interaction product.

\subsubsection{Al-to-U ratio}

Knowledge accumulated regarding the differences between the ILs from out-of-pile and in-pile tests are summarized in Table 1.

Table 1 Fundamental differences observed between out-of-pile and in-reactor tests for interaction in U-Mo/Al dispersion

\begin{tabular}{|l|c|c|}
\hline & Out-of-pile & In-pile \\
\hline Temperature $\left({ }^{\circ} \mathrm{C}\right)$ & $\sim 550$ & $<200$ \\
\hline Time (hr) & $<100$ & $720-7200$ \\
\hline IL morphology & $\begin{array}{c}\text { Multi layers [7] } \\
\text { Crystalline } \\
\text { Intermetallic compound } \\
\text { mixtures [7-10] }\end{array}$ & $\begin{array}{c}\text { Single layer } \\
\text { Amorphous }\end{array}$ \\
\hline $\mathrm{x}$ (=Al/U ratio) & $\begin{array}{c}\text { Discrete value in each } \\
\text { layer ranging 2 - 7 [11] }\end{array}$ & $\begin{array}{c}\text { Variable in the layer and } \\
\text { varies on test condition } \\
\text { ranging 3-7 [11] }\end{array}$ \\
\hline
\end{tabular}

Only three compounds exist in the $\mathrm{U}-\mathrm{Al}$ system, i.e., $\mathrm{UAl}_{2}, \mathrm{UAl}_{3}$ and $\mathrm{UAl}_{4}$. The formation of reaction products with the $\mathrm{Al} /(\mathrm{U}+\mathrm{Mo})$ ratio (x) higher than 4 may be therefore promoted by the presence of Mo in the fuel.

Figure 7 shows the composition data from in-pile tests. 


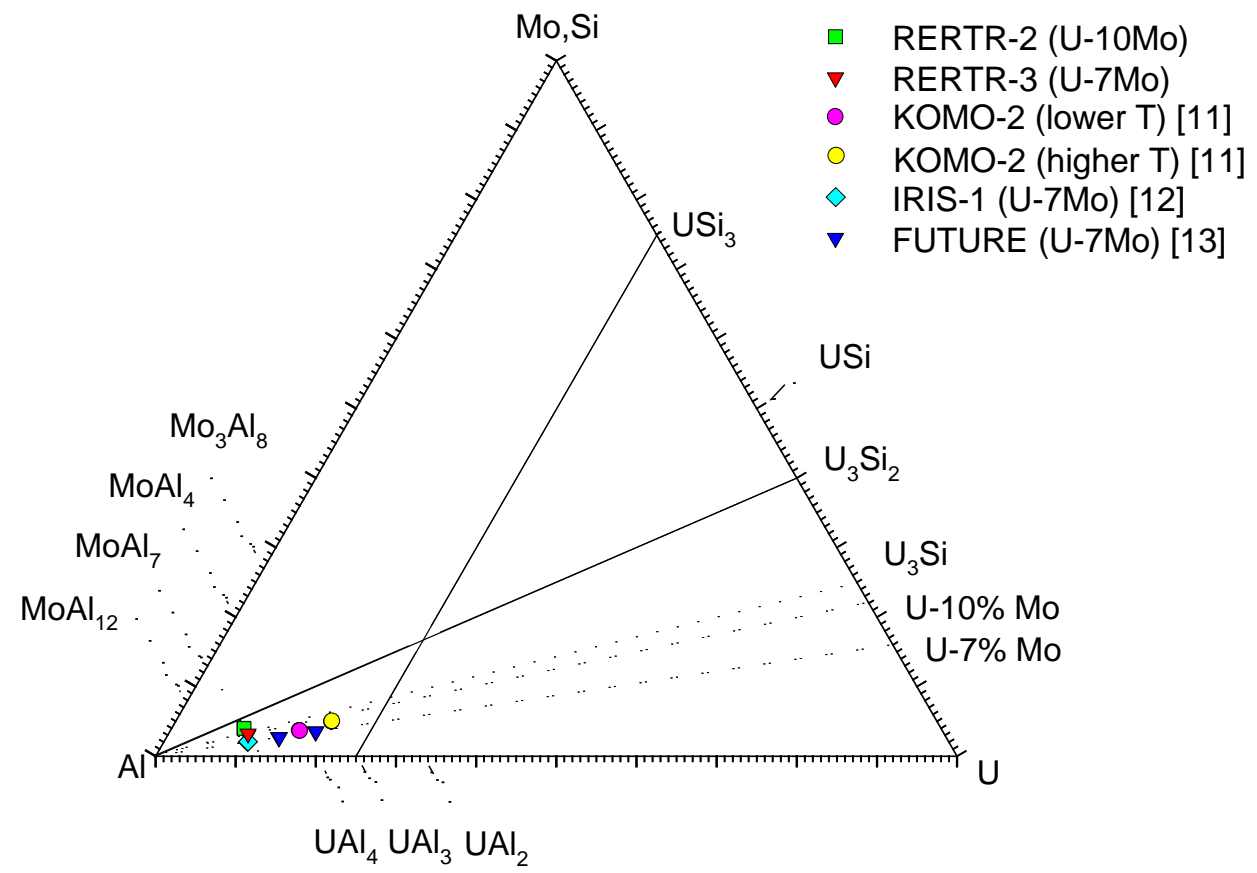

Fig. 7 Pseudo-ternary diagram of U-Mo-Al-Si showing IL composition data from in-pile tests with pure $\mathrm{Al}$ matrix.

\subsubsection{Mo effect}

From subsections 2.2.1 and 2.2.2, it is arguable that Mo in fuel promotes the formation of compounds with a high $\mathrm{x}$ in the out-of-pile tests. During irradiation these interaction products facilitate development of large fission gas pores to the extent that is not observed in UAlx.

The effect of addition of Mo in the fuel was examined thermodynamically [14]. Gibbs free energy of formation of a compound ( $\Delta \mathrm{G}=\Delta \mathrm{H}-\mathrm{T} \Delta \mathrm{S})$ is the measure of the stability of a compound and spontaneity of the reaction. Since enthalpy is the dominant part of Gibbs free energy at the relatively low temperatures, knowing enthalpy of formation of a compound provides an approximate measure of how stable the compound is relative to other comparable compounds. Although non-equilibrium conditions prevail during irradiation, the thermodynamic analysis is still a method to predict the real situations.

As can be seen in Fig. 8, the enthalpy of formation (U,Mo) $\mathrm{Al}_{3}$ becomes less negative with the Mo content in the interaction product, suggesting that the interaction product becomes less stable with the addition of Mo. 


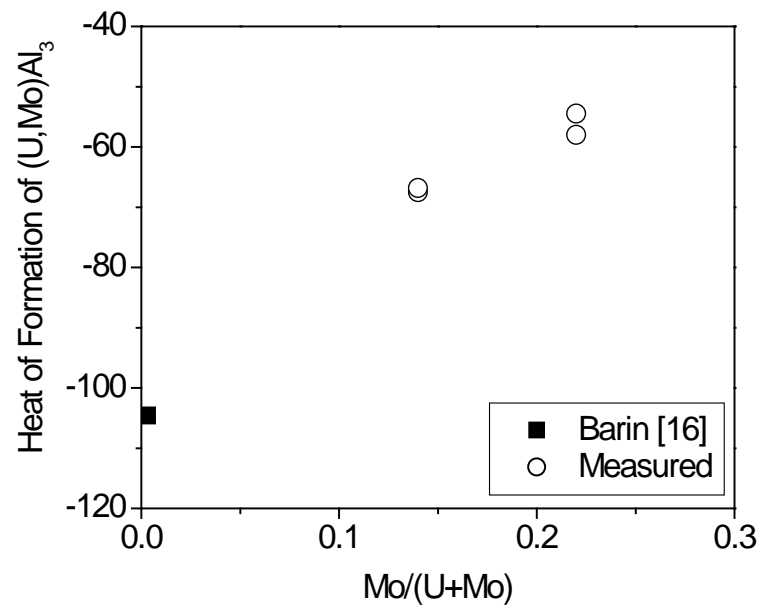

Fig. 8 Heat of formation $\left(\Delta_{f} H_{298}^{o}\right)$ of $(\mathrm{U}, \mathrm{Mo}) \mathrm{Al}_{3}$ versus $\mathrm{Mo} /(\mathrm{U}+\mathrm{Mo})$ molar ratio [15].

\subsubsection{Amorphous IL}

Ryu et al. [11] showed that the ILs forming in U-Mo/Al are amorphous during irradiation. In two other papers, experimental confirmation followed that the ILs in U-Mo/Al are indeed amorphous during irradiation [17,18]. The high fission rate and low temperature irradiation are the prerequisite for amorphization of the ILs. The higher the $\mathrm{Al} / \mathrm{U}$ ratio in the IL, the more readily the IL can be amorphized. In this sense, the presence of Mo in the IL promotes the amorphization of the ILs in that Mo increases formation of ILs with higher $\mathrm{x}$ as discussed in subsection 2.2.2, and that Mo reduces the stability of the IL products as discussed in subsection 2.2.3. However, U-Mo fuel and matrix aluminum remain crystalline during irradiation.

A large number and variety of compounds and alloys have been found to become amorphous and have "glass-like" behavior, when exposed to various types of irradiation (see Ref. 1 and references therein). In fact, the primary damage to the crystal structure is due to the highly energetic fission fragments, not by neutrons. Amorphization is clearly a low temperature phenomenon as amorphized materials devitrify (recrystallize) at the so called glass transition temperature. Above this temperature, amorphization is not possible and the fuel in question has the familiar crystalline irradiation behavior. However, the behavior, particularly of fission gases, can be quite different in amorphized fuels. For example, shown in Fig. 9 are micrographs of two irradiated compounds, $\mathrm{U}_{3} \mathrm{Si}$ and $\mathrm{U}_{6} \mathrm{Fe}$. Uranium compounds such as $\mathrm{U}_{3} \mathrm{Si}, \mathrm{U}_{6} \mathrm{Fe}$ and $\mathrm{U}_{6} \mathrm{Mn}$ become amorphous at a relatively low damage dose [19,20].

The fission gas bubble morphology appears to be characteristic of that of alloys at high temperatures. Yet, these fuels were irradiated at $\sim 100^{\circ} \mathrm{C}$. Evidently the fission gas was highly mobile and the fuel material was easily deformed by the growing gas bubbles. Post-irradiation hardness tests showed that these fuels had retained their relatively hard and brittle pre-irradiation properties. The observed fluid-like behavior thus only exists during irradiation. Klaumunzer [21] has demonstrated this irradiation behavior with heavy ion beam irradiations of borosilicate 
glasses and Pd-Si metallic glasses. He was able to correlate the measured increase in fluidity in these tests with the excess free-volume that was independently measured on these metallic glasses. Work on quenched metallic, glasses, has shown that the viscosity, $\eta$, during annealing tests can be described by the Doolittle equation [22]:
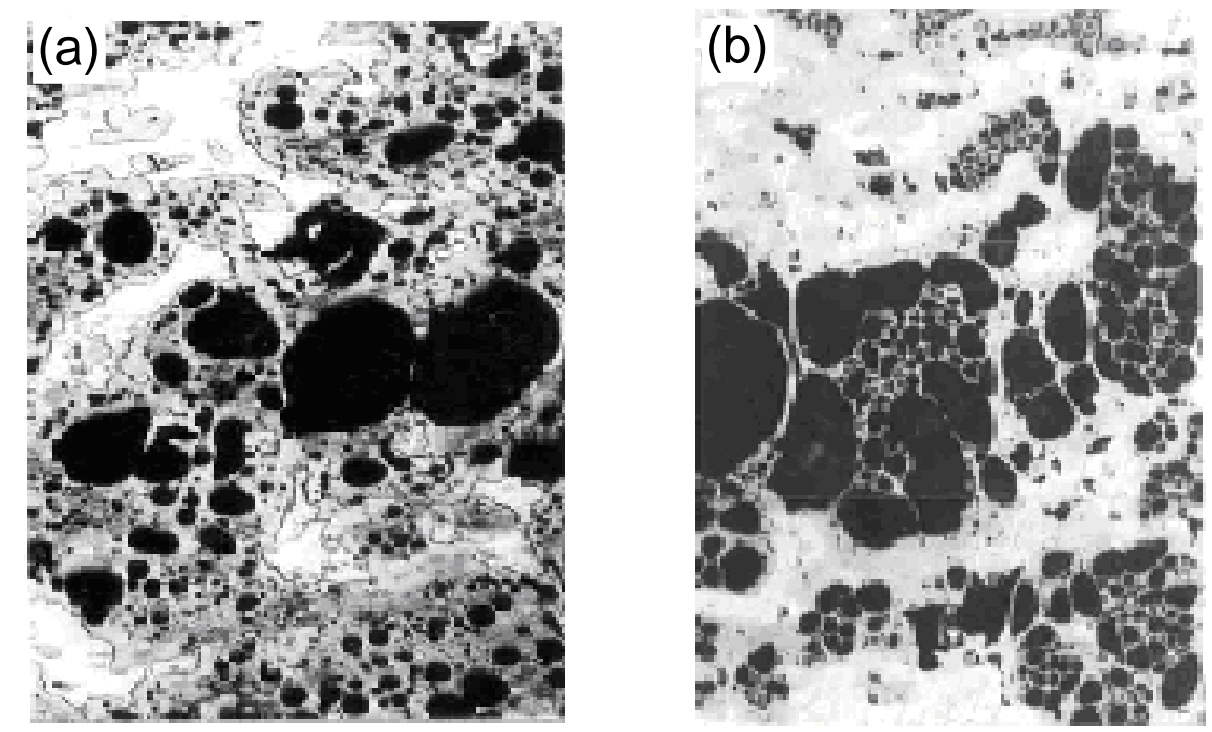

Fig. 9 Breakaway swelling of amorphous U-compounds. (a) $\mathrm{U}_{3} \mathrm{Si}$ (8\% $\mathrm{HM}$ burnup), (b) $\mathrm{U}_{6} \mathrm{Fe}$ (17\% HM burnup).

$\eta=\eta_{0} \exp \left(\frac{C}{\Delta V_{R}}\right)$

where $\mathrm{C}$ is a constant and $\Delta \mathrm{V}_{\mathrm{R}}$ is the part of the quenched-in free-volume associated with structural relaxation that is recovered during annealing of the glass prior to recrystallization.

In the paper given as Ref. 1, we proposed that during continuing irradiation of an amorphized fuel this excess free-volume is maintained at a value proportional to the damage rate. This results in a commensurate decrease in viscosity, or increase in fluidity, $\phi=\eta^{-1}$, as long as fission events are occurring in the fuel. Likewise, the diffusivity in the fuel that is related to the viscosity through the Nernst-Einstein equation, $\mathrm{D} \propto \eta^{-1}$, is enhanced by the magnitude of the fission-induced excess free-volume.

It is worth noting that U-Mo and $\mathrm{Al}$ are crystalline while the ILs between them are amorphous during irradiation. Therefore, the growth of the more readily flowing ILs between U-Mo and Al appears to facilitate pore formation with released fission gases. 


\section{Section 3 Remedy for interaction layer growth and pore formation}

A remedy to prevent large pore formation in the ILs was sought at ANL. Because a method to enable a complete prevention of interdiffusion between fuel constituents and matrix $\mathrm{Al}$ is practically non-existent, improving the stability of the ILs is instead aimed. We have focused on modifying the IL property by alloying additions in the matrix Al. After reviewing the literature, considering experience obtained from the development of U-Si dispersion fuel in $\mathrm{Al}$, and some thermodynamic assessment, silicon was selected for the candidate element. This remedy was presented in two international meetings $[23,24]$. This section summarizes the above mentioned presentations.

\subsection{Alloying element addition in the matrix}

\subsubsection{Reaction between $\mathrm{U}$ and $\mathrm{Al}$}

The addition of $\mathrm{Si}$ to $\mathrm{Al}$ at the eutectic composition of $12 \mathrm{wt} \% \mathrm{Si}$ reduced significantly the diffusion of uranium into aluminum in a U-AlSi diffusion couple test in the temperature range of $200-300^{\circ} \mathrm{C}$ [25]. Compared to the data obtained by the same authors using the same experimental setup but without silicon addition [26], the effect of Si addition is clearly noticeable.

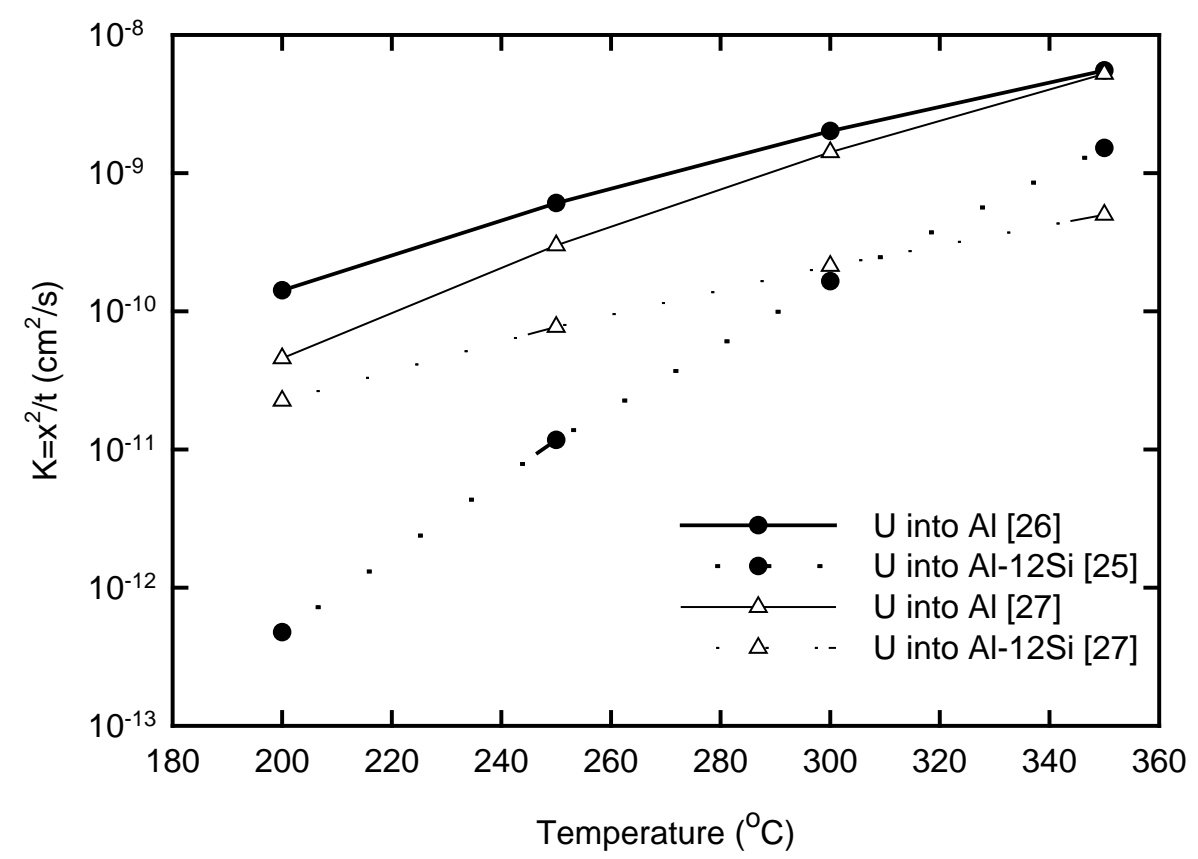

Fig. 10 Comparison of interaction layer growth in U-Al and U-AlSi. Al-12Si is an alloy with $12 \mathrm{wt} \% \mathrm{Si}$ in Al.

As shown in Fig. 10, U-Al has a two orders of magnitude larger reaction constant than U-AlSi at $200^{\circ} \mathrm{C}$, meaning that the time to obtain the same reaction penetration takes about two orders of magnitude longer for the U-AlSi than the U-Al. At temperatures higher than $400^{\circ} \mathrm{C}$, however, diffusion of $\mathrm{U}$ into the $\mathrm{Al}$ becomes smaller than that of $\mathrm{U}$ into the AlSi, suggesting that 
extrapolation to lower temperatures of the results of diffusion studies generally performed at higher temperatures might be unreliable. In any case, at low temperature applications where U$\mathrm{Mo} / \mathrm{Al}$ is typically used, this information provides favorable prediction for using Si addition.

The effect of Mo in $\mathrm{U}$ on diffusion can be assessed from data in the literature. Comparing the diffusion coefficients at $600^{\circ} \mathrm{C}$ [29], the diffusivity of $\mathrm{U}$ is six orders of magnitude higher than that of Mo. Extrapolating the equations to the lower temperatures where research reactor fuel is operating, the difference becomes even larger. This low Mo diffusivity was recognized in early studies, and DeLuca and Sumsion [27] used Mo as a marker for their U-Al diffusion tests. As shown in Fig. 11, there was no indication of diffusion of the Mo markers at $400-500^{\circ} \mathrm{C}$.
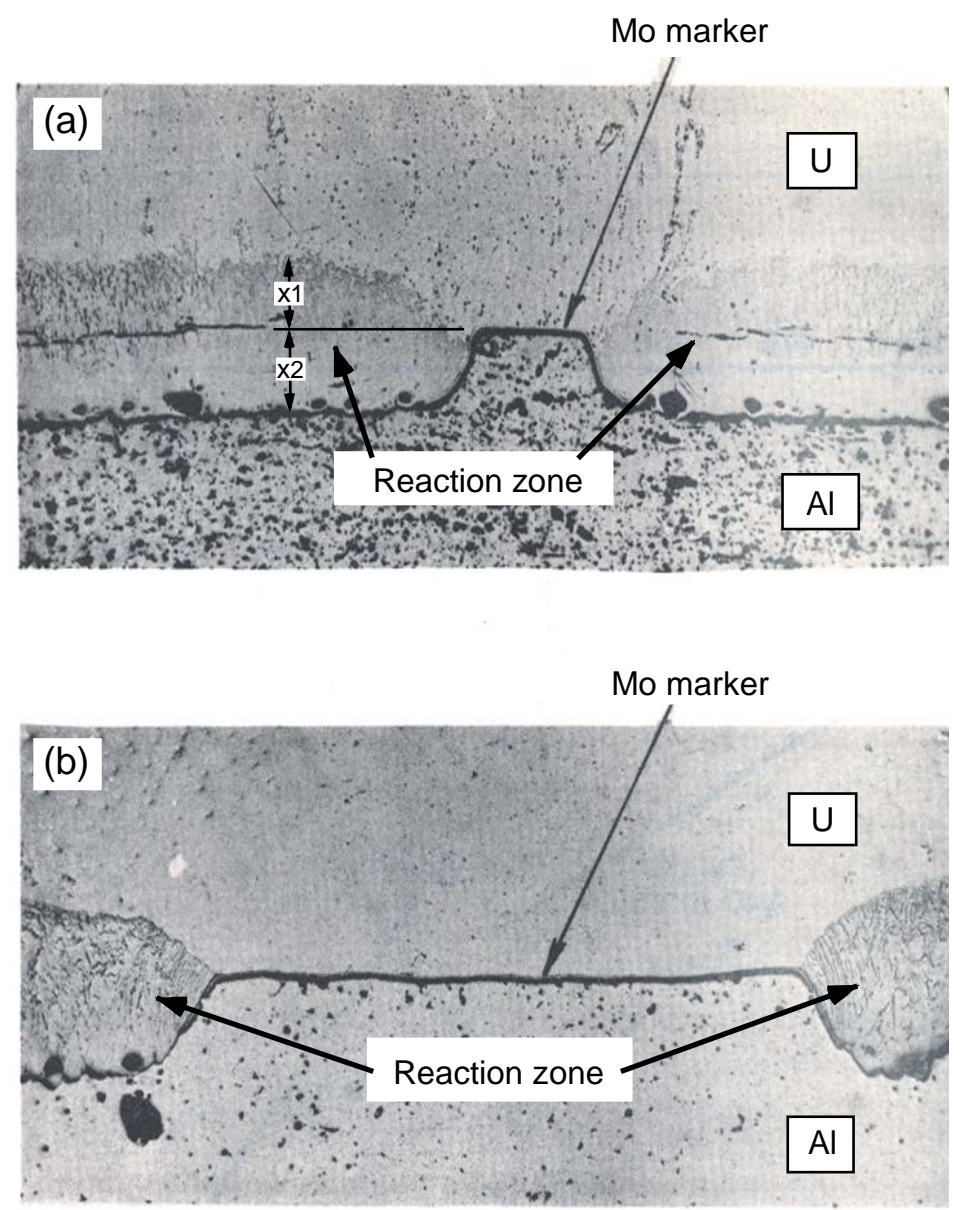

Fig. 11 U-Al diffusion couple tests with a Mo-marker. (a) Test at $550{ }^{\circ} \mathrm{C}$, (b) test at 400 ${ }^{\circ} \mathrm{C}$. The Mo-marker bends into the Al. The value $\mathrm{x} 2 / \mathrm{x} 1$ is the ratio of the penetration of $\mathrm{U}$ into $\mathrm{Al}$ to the penetration of $\mathrm{Al}$ into $\mathrm{U}$ [27].

The effect of the presence of Mo in $\mathrm{U}$ is to decrease the reaction rate between U-Mo and $\mathrm{Al}$ from the reaction between $\mathrm{U}$ and Al. Ugajin et al [30] reported that a small amount of Mo (0.5wt\% $\mathrm{Mo}$ ) in $\mathrm{U}_{3} \mathrm{Si}_{2}$ was effective to lower the reaction between the $\mathrm{U}_{3} \mathrm{Si}_{2}$ and $\mathrm{Al}$ matrix. This observation shows that Mo has a synergistic effect when it is present with Si. In addition, it is 
commonly observed from irradiation tests that the presence of Mo in U-Mo reduces reaction in U$\mathrm{Mo} / \mathrm{Al}$ dispersion.

Nevertheless, the harmful role of the presence of Mo to promote the formation of high Al-content compounds and, more importantly, to enhance pore formation in the ILs overwhelms the slight benefit in reducing the reaction rate.

\subsubsection{Effect of alloy addition in $\mathrm{Al}$ to suppress $\mathrm{UAl}_{4}$ formation}

There have been several studies seeking remedies to reduce $\mathrm{UAl}_{4}$ formation, all of these efforts were focused on alloying of elements such as Si, Ge, Zr, Sn, or Ti into Al.

Thurber and Beaver [31] found that the addition of $3 \mathrm{wt} \% \mathrm{Si}, \mathrm{Ge}, \mathrm{Zr}, \mathrm{Sn}$, or Ti in $48 \mathrm{wt} \% \mathrm{U}-\mathrm{Al}$ alloys $\left(\mathrm{UAl}_{3}-\mathrm{Al}\right)$ completely suppressed $\mathrm{UAl}_{4}$ formation. The role of the ternary addition was to suppress the peritectic reaction $\mathrm{UAl}_{3}+\mathrm{Al} \rightarrow \mathrm{UAl}_{4}$ and permits $\mathrm{UAl}_{3}$ to coexist with $\mathrm{Al}$ during prolonged heating. Thurber and Beaver found that the silicon addition was associated with aluminum in the $\mathrm{UAl}_{3}$ lattice, forming compounds of the $\mathrm{U}(\mathrm{Al}, \mathrm{Si})_{3}$ type in which the lattice parameters are a function of the silicon content of the alloy. No reversion of $\mathrm{UAl}_{3}$ to $\mathrm{UAl}_{4}$ occurred in the silicon-modified alloy after extensive thermal treatment at $605^{\circ} \mathrm{C}$. Exner and Petzow [32] investigated and proposed similar elements for effective addition.

DeLuca and Sumsion [27] also found that in the U-AlSi diffusion couple the formation of $\mathrm{UAl}_{4}$ was supressed. Chakraborty et al. [33] studied the effect of ternary additions on the suppression of $\mathrm{UAl}_{4}$ formation more thoroughly and showed similar results given by Thurber and Beaver. The ternary additions of Si, Ge, and Zr were effective. A brief summary of their work is given below.

$\underline{S i}$

Additions of $4-6$ wt $\% \mathrm{Si}$ in $\mathrm{UAl}_{3}$ did inhibit transformation of $\mathrm{UAl}_{3}$ to $\mathrm{UAl}_{4}$. Si replaces $\mathrm{Al}$ in $\mathrm{UAl}_{3}$, forming $\mathrm{U}(\mathrm{Al}, \mathrm{Si})_{3}$. However, $1.5 \mathrm{wt} \% \mathrm{Si}$ showed $\mathrm{UAl}_{4}$ transformation. In this case, Si migrated from $\mathrm{UAl}_{3}$ to $\mathrm{UAl}_{4}$ and replaced $\mathrm{Al}$ lattice sites because of the similar atom size between Si and Al.

$\underline{Z r}$

$\mathrm{UAl}_{3}$ containing $14 \mathrm{wt} \% \mathrm{Zr}$ coexists with $\mathrm{Al}$ in equilibrium and extends down to room temperature. In addition, $\mathrm{Zr}$ did not diffuse into $\mathrm{Al}$ and allow $\mathrm{Al}$ diffuse into $\mathrm{UAl}_{3}$ in a test for two hours at $610^{\circ} \mathrm{C}$. $\mathrm{Zr}$ atoms replace $\mathrm{U}$ lattice sites forming (U,Zr) $\mathrm{Al}_{3}$ compound. This is similar to Mo that also form (U,Mo) $\mathrm{Al}_{3}$ compound. Kutty et al. [34] showed that, if the $\mathrm{Zr}$ content is small such as $3 \mathrm{wt} \%$, (U, Zr) $\mathrm{Al}_{3}$ phase is not stable allowing formation of $\mathrm{UAl}_{4}$.

$\underline{\text { Ge }}$

Similar to $\mathrm{Si}$, however, a high Ge concentration (4.4 - 6 wt\%) in $\mathrm{UAl}_{3}$ was effective in suppressing $\mathrm{UAl}_{4}$ formation.

$\underline{\mathrm{Sn}}$ 
The effect of Sn addition was negligible, which contradicted the results of Thurber and Beaver [27].

$\underline{T i}$

Titanium was not considered in this study. However, because of its similarity (in its bonding electron structure to $\mathrm{Zr}$ ), it is likely to have an effect similar to $\mathrm{Zr}$.

Therefore, Chakraborty [33] and Thurber and Beaver [31] agree on the positive effects of Si, Ge and Zr. In Table 2, the neutron absorption cross-sections for some elements are given. Si and $\mathrm{Zr}$ have advantageous neutron absorption characteristics, but Ge does not. Using $\mathrm{Zr}$ as an addition in $\mathrm{Al}$, however, has a disadvantage over Si because the addition of $\mathrm{Zr}$ in the amount of $14 \mathrm{wt} \%$ reduces the thermal conductivity of the alloy much more than $\mathrm{Si}$.

Table 2 Thermal neutron absorption cross-sections for some elements

\begin{tabular}{|l|l|l|l|l|l|l|l|l|l|l|l|l|}
\hline & $\mathrm{Al}$ & $\mathrm{Si}$ & $\mathrm{Fe}$ & $\mathrm{Cu}$ & $\mathrm{Mn}$ & $\mathrm{Cr}$ & $\mathrm{Mg}$ & $\mathrm{Zn}$ & $\mathrm{Ge}$ & $\mathrm{Sn}$ & $\mathrm{Zr}$ & $\mathrm{Ti}$ \\
\hline $\begin{array}{l}\sigma_{a} \\
\text { (barns) }\end{array}$ & 0.23 & 0.16 & 2.55 & 3.79 & 13.3 & 3.1 & 0.063 & 1.1 & 2.3 & 0.63 & 0.2 & 6.1 \\
\hline
\end{tabular}

Chiotti and Kateley [35] developed the free energy of formation of $\mathrm{UAl}_{3}$ and $\mathrm{UAl}_{4}$ and calculated the concentration of $\mathrm{UAl}_{3}$ or the concentration of the ternary addition element necessary to suppress $\mathrm{UAl}_{4}$ formation. For example, at $500^{\circ} \mathrm{C}$ the mole fraction of $\mathrm{UAl}_{3}$ in $\mathrm{U}(\mathrm{Al}, \mathrm{Si})_{3}$ necessary to suppress $\mathrm{UAl}_{4}$ formation is 0.82 or the fraction of $\mathrm{USi}_{3} 0.18$. This corresponds to the data by Thurber and Beaver [27], where $3 \mathrm{wt} \% \mathrm{Si}$ suppresses $\mathrm{UAl}_{4}$ formation in the $48 \mathrm{wt} \% \mathrm{U}-\mathrm{Al}$ alloys $\left(\mathrm{UAl}_{3}-\mathrm{Al}\right)$. Although, at low temperatures, the formation of $\mathrm{UAl}_{4}$ becomes more favorable by free energy calculations, the diffusion and nucleation rates of the reaction are too small to permit a significant $\mathrm{UAl}_{4}$ formation.

In the literature, there has been no attempt to alloy a third element additionally from the individually beneficial elements. Setting aside other effects, alloying other elements simultaneously may not produce an advantageous result because thermal conductivity reduction would be considerable.

\subsubsection{BFS atomistic model prediction of IL growth in U-Mo/Al with Si addition}

A more sofistigated modeling was commissioned to predict the behavior of Si added to the Al matrix by using the BFS model [36]. The description of this modeling is available elsewhere [37]. A brief summary for this modeling is given here.

The model is a quantum approximate method that provides an efficient and accurate way to compute the total energy of arbitrary atomic systems in term of their geometrical configuration, combining first-principles calculations for its parameterization and Monte Carlo statistical methods for its implementation to large scale samples. It is built on the basis of completely transferable parameters and can deal with the complexity of the problem at hand because of its lack of theoretical constraints regarding the type and number of elements, or on the number or 
type of phases it can handle. In spite of its approximate nature, it has been shown to be equivalent to first principles methods in its description of multicomponent systems near or at equilibrium. The modeling work performed dealt with the application of the BFS-based atomistic modeling software package ADWTOOLS [38], which performs detailed atom-by-atom calculations as well as large scale atomistic simulations using different statistical methods for performing "computer experiments," all using the BFS method for alloys as the engine for the calculation of the energetics.

Figure 12 shows typical results obtained with the proposed methodology. Visual analysis of the T $=400 \mathrm{~K}$ cells and the corresponding concentration profiles provide valuable information on the role of each element and the effect of changing concentrations of each element.

The IL is described as a mixture of blue circles ( $\mathrm{U}$ atoms) and yellow circles ( $\mathrm{Al}$ atoms) in the figure. The results can be summarized as follows:

- (a) shows that Si atoms completely absorbed in the U side. Comparing (a) and (d), there are some $\mathrm{Si}$ atoms remain in the $\mathrm{Al}$ if the $\mathrm{Si}$ concentration is increased from $5 \%$ to $10 \%$.

- Comparing (a) and (b), the addition of Si in the Al reduces the IL growth.

- Comparing (a) and (d), the Si content higher than 5\% has a nearly neglible additional reduction power from $5 \%$.

- Comparing (d) and (e), the synergistic role of Mo is suggestive.

In general, the results are consistent with experimental results that showed the effect of Si in the U/Al system. The presence of Mo does not change the trend of the effect of Si, instead it may have a positive effect on IL growth. As is discussed later, however, Mo seems to have a disadvantageous effect by degrading the property of the IL. 


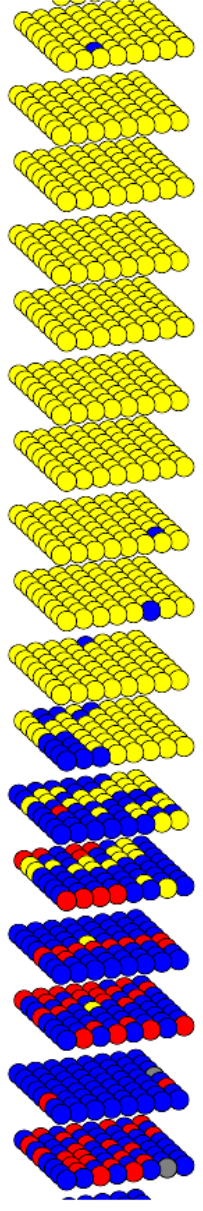

(a)

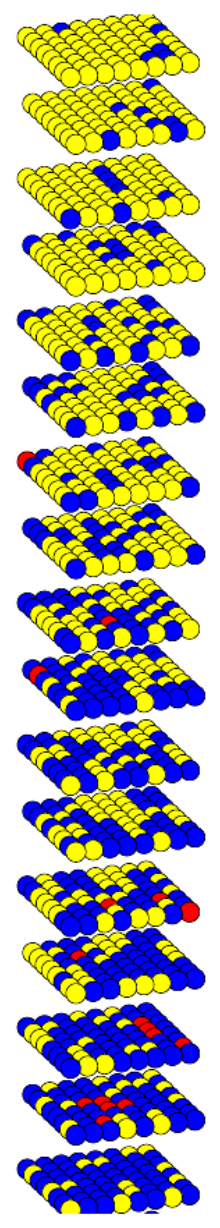

(b)

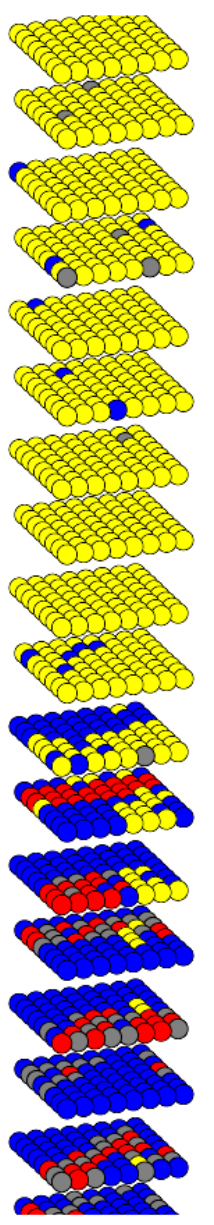

(c)
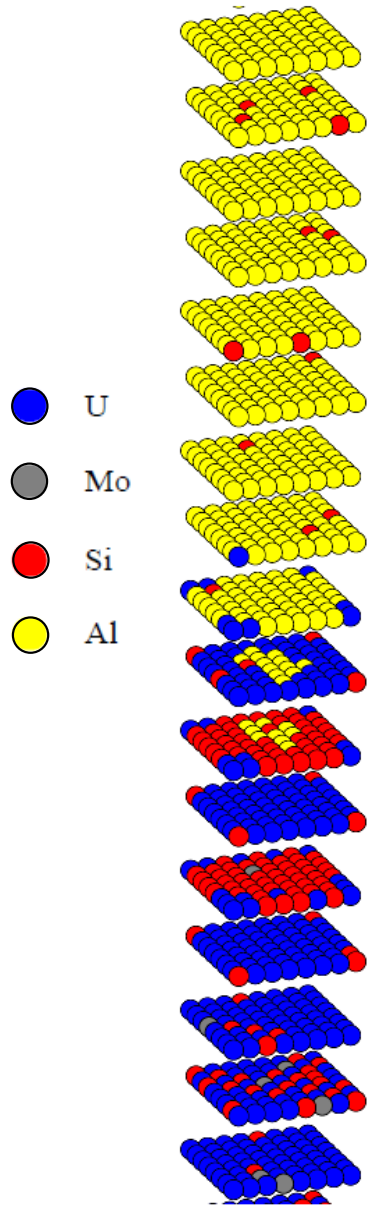

(d)

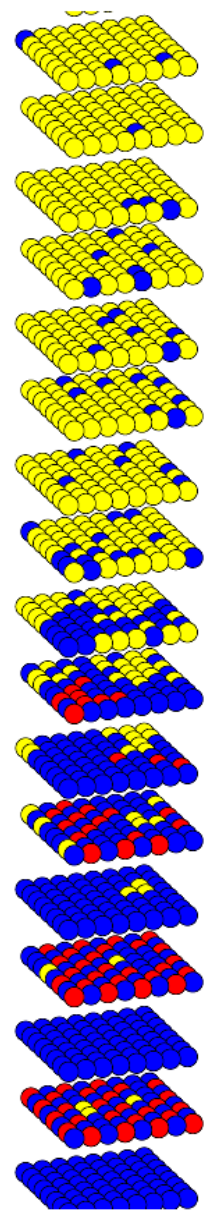

(e)

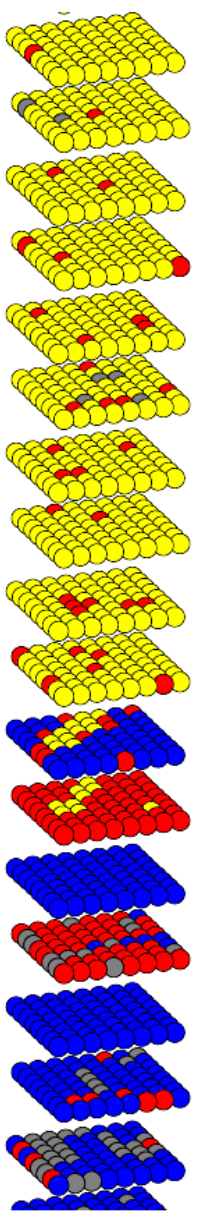

(f)

Fig. 12 BFS model prediction of effect of Si addition to $\mathrm{Al}$ in U-Mo/Al IL growth. (a) U-5Mo/Al-5Si, (b) U-5Mo/Al, (c) U-10Mo/Al-5Si, (d) U-5Mo/Al-10Si, (e) $\mathrm{U} / \mathrm{Al}-10 \mathrm{Si}$, (f) U-10Mo/Al-10Si. The concentrations are in weight percent.

\subsubsection{Si effect on IL growth in U-Mo/Al during irradiation}

A cross-section view of irradiated fuel of a RERTR-3 test plate is shown Fig. 13. The reaction layers on the fuel particle surfaces contacting the cladding are thinner than those of fuel particles at the interior of the fuel zone (Fig. 13 (a)). The temperature difference between these two locations is probably less than $3{ }^{\circ} \mathrm{C}$ because of the short heat transfer path in aluminum and high thermal conductivity of Al. The matrix is pure Al while $6061 \mathrm{Al}$ alloy is for cladding. This suggests that the alloying elements in 6061 alloy reduce interaction layer growth (Fig. 13 (b)). No such effect was observed from the test with Ag3NE alloy cladding used in French tests. The compositions of 6061 and Ag3NE alloys used in the respective tests are compared in Table 3. More Mg, Mn and Fe are included in Ag3NE and more Si, Cu and $\mathrm{Cr}$ in 6061, confirming that the effect of $\mathrm{Mg}, \mathrm{Mn}$ and Fe are negligible whereas $\mathrm{Si}, \mathrm{Cu}$ and $\mathrm{Cr}$ may be effective. 


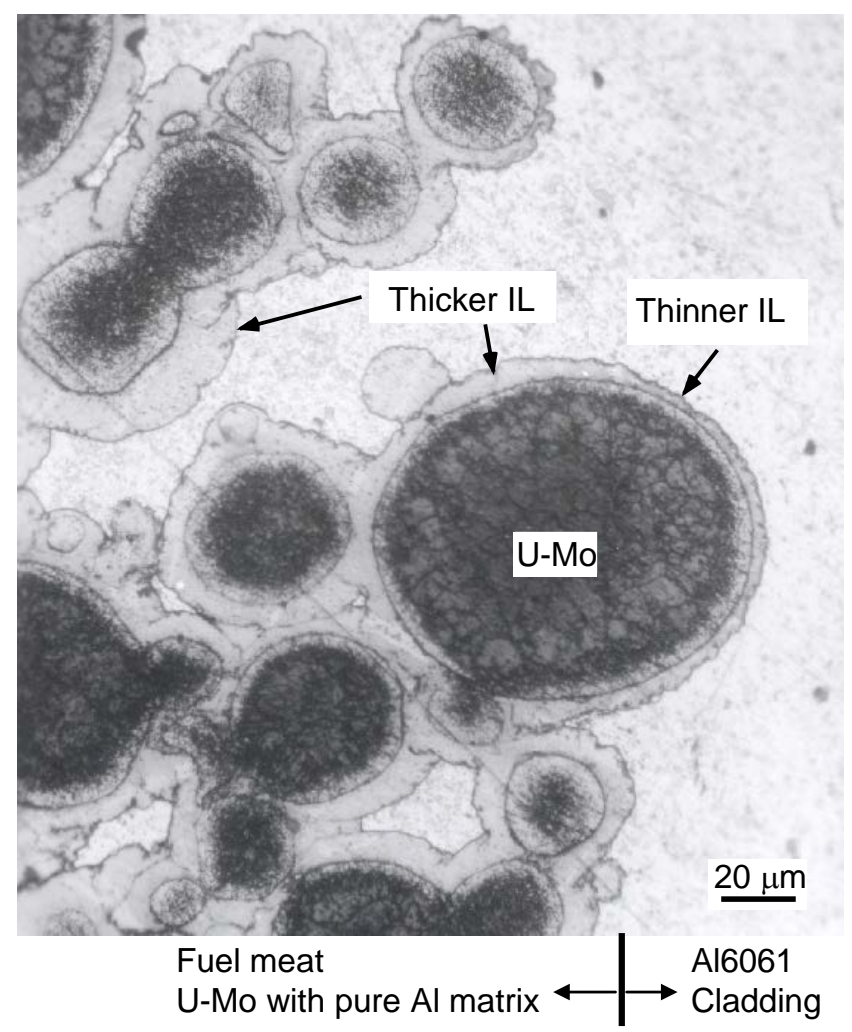

(a) Optical micrograph showing interaction layer growth at interface between fuel zone and cladding. The IL thickness is thinner on the cladding side than on the fuel meat side.

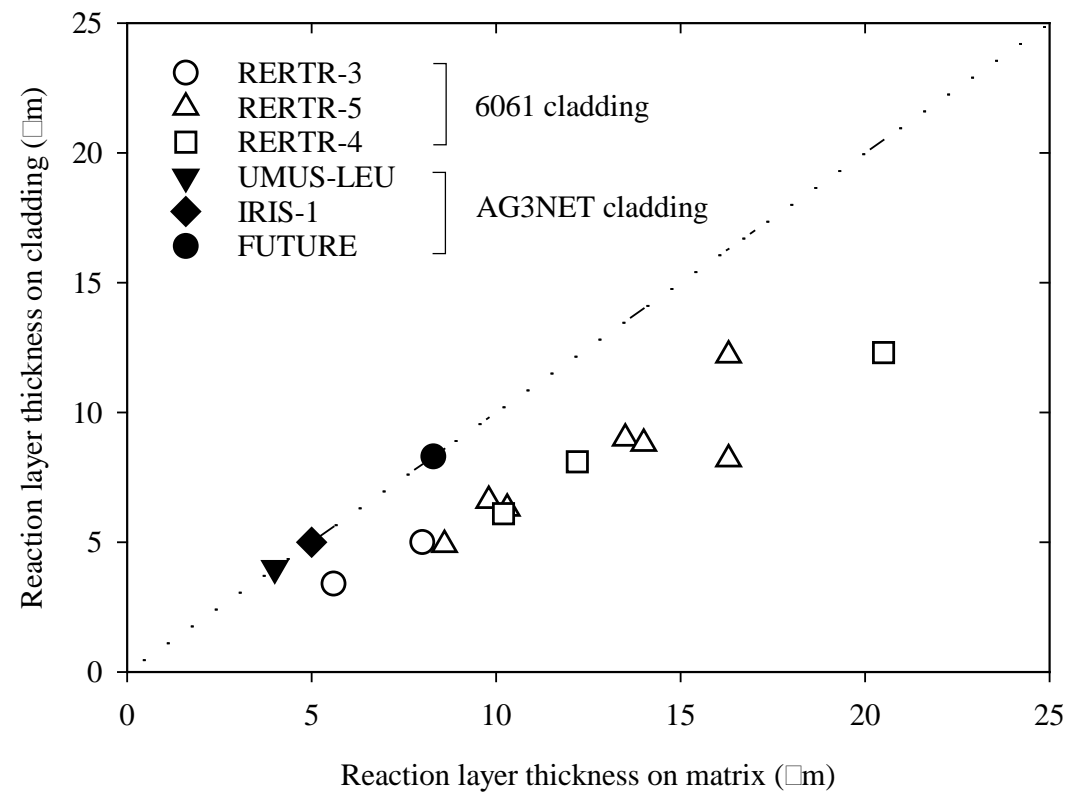

(b) Comparison of reaction layer thickness on cladding side and Al matrix. The 6061 cladding contains $0.6 \% \mathrm{Si}$ and the AG3NET cladding includes $0.2 \% \mathrm{Si}$ as alloying element.

Fig. 13 Si effect on IL growth rate observed from irradiation tests. 
It is also noteworthy that $\mathrm{Si}$ in Ag3NE has no beneficial effect, probably because of the high concentration of $\mathrm{Mg}$ in Ag3NE depriving the beneficial effect of Si. $\mathrm{Mg}$ forms $\mathrm{Mg}_{2} \mathrm{Si}$ removing $\mathrm{Si}$ from the Al alloy matrix, resulting in Si-free zones around [39]. The Mg content in Ag3NE is three times greater than that of 6061 whereas the Si content is about one half of 6061. This means that Si in Ag3NE will be completely consumed by Mg while some of Si will be left free in 6061. The large amount of $\mathrm{Mg}$ in Ag3NE is rather deleterious than beneficial in this regard. Fe also forms Fe rich phases $\mathrm{Fe}_{3} \mathrm{SiAl}_{12}, \mathrm{Fe}_{2} \mathrm{Si}_{2} \mathrm{Al}_{9}$, and a mixture of the two, depending on the propositions of $\mathrm{Mg}, \mathrm{Si}$ and Fe. $\mathrm{Cr}$ and $\mathrm{Mn}$ stabilize (Fe,Mn,Cr) ${ }_{3} \mathrm{SiAl}_{12}$. Therefore, Fe, $\mathrm{Cr}$ and $\mathrm{Mn}$ reduce the effective Si concentration in the alloy matrix.

Table 3 Compositions of two frequently used aluminum cladding alloys

\begin{tabular}{|l|l|l|l|l|l|l|l|l|l|}
\hline Alloy & Test & $\mathrm{Si}$ & $\mathrm{Fe}$ & $\mathrm{Cu}$ & $\mathrm{Mn}$ & $\mathrm{Mg}$ & $\mathrm{Cr}$ & $\mathrm{Zn}$ & Al \\
\hline Al6061 (wt\%) & RERTR & 0.6 & 0.5 & 0.2 & 0.1 & 0.9 & 0.2 & 0.1 & Balance \\
\hline Ag3NE (wt\%) & French & 0.2 & 1.1 & 0 & 0.7 & 2.8 & 0 & 0 & Balance \\
\hline
\end{tabular}

Because reprocessing Si-containing dispersion fuel is somewhat troublesome, the amount of Si addition in $\mathrm{Al}$ should be limited to the least amount desirable. At the present time, the necessary Si amount ranges $4-12 \mathrm{wt} \%$. The $12 \mathrm{wt} \% \mathrm{Si}$ forms a eutectic alloy with $\mathrm{Al}$.

\subsubsection{Comparison of reaction layer thicknesses between $\mathrm{UAl}_{3} / \mathrm{Al}$ and $\mathrm{U}\left(\mathrm{Al}_{\mathbf{0 . 4 9}} \mathrm{Si}_{0.11}\right)_{3} / \mathrm{Al}$ from irradiated tests}

In Table 4, the reaction layer thicknesses from several irradiation tests are compared. The specimen of the RLB data was fabricated from $48 \mathrm{wt} \% \mathrm{U}+49 \mathrm{wt} \% \mathrm{Al}+3 \mathrm{wt} \% \mathrm{Si}$ alloy, allowing $\mathrm{U}\left(\mathrm{Al}_{0.49} \mathrm{Si}_{0.11}\right)_{3}$ to precipitate out during cooling. As a result, the specimen was composed of $\mathrm{U}\left(\mathrm{Al}_{0.49} \mathrm{Si}_{0.11}\right)_{3}$ in the $\mathrm{Al}$ matrix. It is considered that, during precipitation, the negligible amount of silicon was included in the $\mathrm{Al}$ matrix because the solubility of $\mathrm{Si}$ in $\mathrm{Al}$ at the temperature of interest $\left(\sim 300^{\circ} \mathrm{C}\right)$ is 0.05 at\%.

Table 4 Comparison of reaction layer thicknesses between $\mathrm{UAl}_{3} / \mathrm{Al}$ and $\mathrm{U}\left(\mathrm{Al}_{0.49} \mathrm{Si}_{0.11}\right)_{3} / \mathrm{Al}$ from irradiated tests

\begin{tabular}{lccc}
\hline & $\mathrm{RLB}$ data [40] & $\mathrm{DNT}$ data [41] & $\mathrm{ANL}$ data \\
\hline Fuel & $\mathrm{U}\left(\mathrm{Al}_{0.49} \mathrm{Si}_{0.11}\right)_{3}$ & $\mathrm{UAl}_{3}$ & $\left(\mathrm{U}_{0.91} \mathrm{Mo}_{0.09}\right) \mathrm{Al}_{3}$ \\
Matrix & $\mathrm{Al}$ & $\mathrm{Al}$ & $\mathrm{Al}$ \\
Fuel volume fraction (\%) & 44 & 28 & 30 \\
Irradiation temp $\left({ }^{\circ} \mathrm{C}\right)$ & 80 & 70 & 65 \\
Enrichment (\% U-235) & 19.5 & 93 & 19.5 \\
Burnup (at\% U-235) & 73 & 16 & 70 \\
Burnup (at\% HM) & 14.2 & 14.9 & 13.7 \\
Fuel particle fission density & 1.7 & 1.8 & 1.7 \\
$\left(10^{21}\right.$ f/cm $\left.{ }^{3}\right) *$ & & 5 \\
Interaction layer thickness & 5 & 13 & \\
$(\mu \mathrm{m})$ & & & \\
\hline \multicolumn{2}{c}{ * Based on density of $\mathrm{UAl}_{3} 6.8 \mathrm{~g} / \mathrm{cm}^{3}, 10 \%$ fission by Pu included. }
\end{tabular}


The DNT specimen consisted of $\mathrm{UAl}_{3}$ dispersed in an $\mathrm{Al}$ matrix. The ANL data were made with $\mathrm{U}-4 \mathrm{wt} \% \mathrm{Mo}$ dispersion in an $\mathrm{Al}$ matrix.

As shown in the table, the reaction layer thickness of the RLB test with Si addition is lower than that of DNT, even with the higher test temperature. The beneficial effect of Mo addition in $U$ can be seen in the ANL result.

This leads us to a conclusion that Si will also have a beneficial effect on reducing reaction layer growth in (U-Mo)/Al.

\subsubsection{Effect of Si content on IL growth in U-Si compound/Al dispersions}

In this subsection, the IL growth rates between $\mathrm{U}_{3} \mathrm{Si} / \mathrm{Al}, \mathrm{U}_{3} \mathrm{Si}_{2} / \mathrm{Al}$ and $\mathrm{USi} / \mathrm{Al}$ are compared to examine the effect of Si content in U-Si compound fuels.

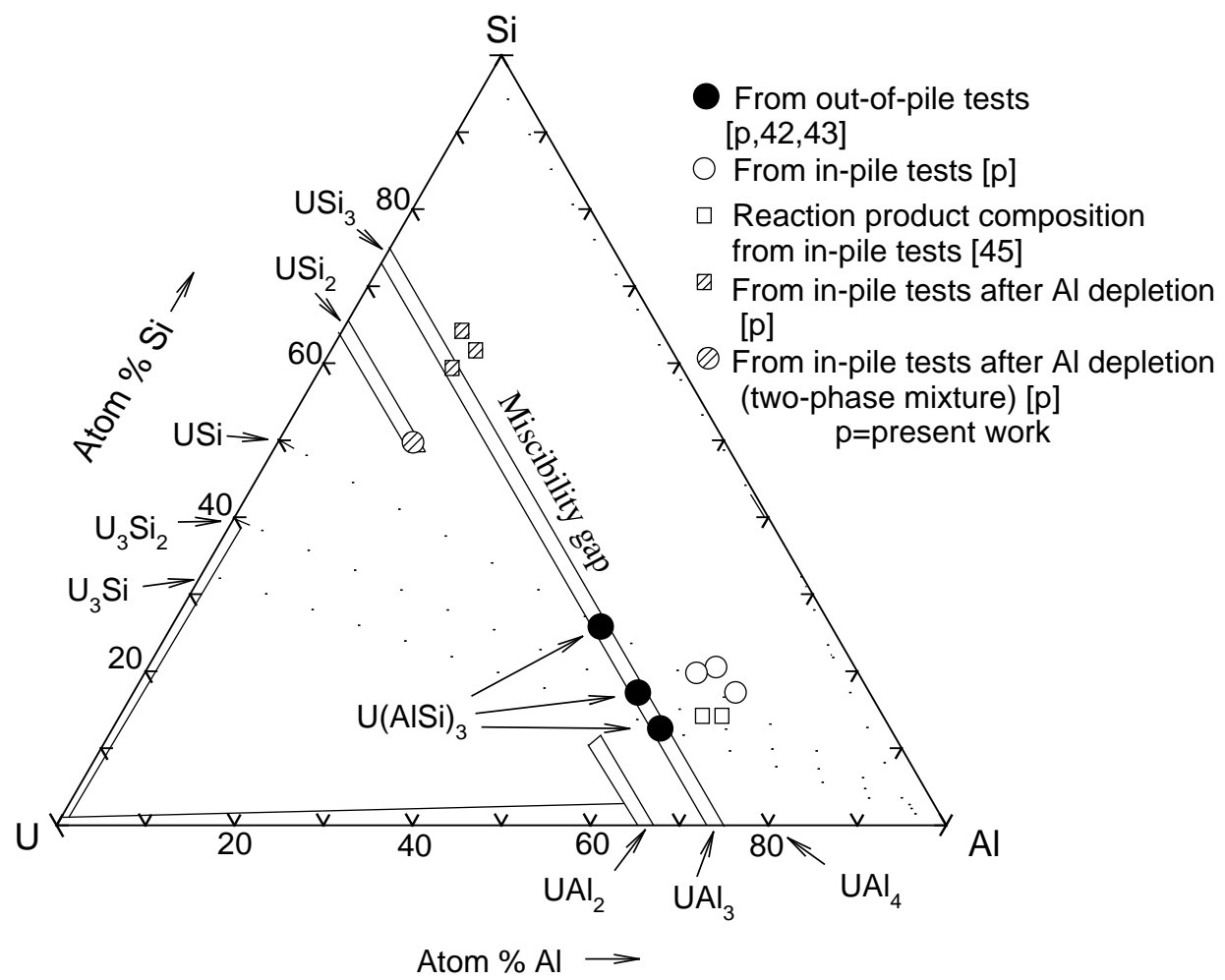

Fig. $14 \mathrm{U}-\mathrm{Si}$-Al ternary phase diagram showing reaction products between $\mathrm{U}, \mathrm{Si}$, and $\mathrm{Al}$.

$\mathrm{U}_{3} \mathrm{Si}, \mathrm{U}_{3} \mathrm{Si}_{2}$ and $\mathrm{USi}$ react with Al to form a single intermetallic compound, U(AlSi), in out-ofpile tests of which the test temperatures are typically much higher than the in-pile tests [42]. Rhee et al. [43] reported from out-of-pile $\mathrm{U}_{3} \mathrm{Si}-\mathrm{Al}$ diffusion tests that they observed a thin layer of $\mathrm{U}(\mathrm{AlSi})_{2}$ at the interface between $\mathrm{Al}$ and IL that turned into $\mathrm{U}(\mathrm{AlSi})_{3}$. The solubilities of $\mathrm{Al}$ in 
$\mathrm{U}_{3} \mathrm{Si}, \mathrm{U}_{3} \mathrm{Si}_{2}$ and USi themselves are very small (<<1at\%) [44]. U(AlSi) $)_{3}$ has a composition intermediate between $\mathrm{UAl}_{3}$ and $\mathrm{USi}_{3}$. These two cubic compounds are mutually soluble. The $\mathrm{Al} / \mathrm{Si}$ ratio in the $\mathrm{IL}$ is the highest for $\mathrm{U}_{3} \mathrm{Si}-\mathrm{Al}$, lower for $\mathrm{U}_{3} \mathrm{Si}_{2}-\mathrm{Al}$ and the lowest for USi-Al, which is approximately proportional to the U/Si ratio in the fuel. The compositions of the compounds lie on the tielines between the uranium-silicides and $\mathrm{Al}$, as shown in the isothermal section of the ternary phase diagram (Fig. 14). For all cases, the reaction compounds have a density of $\sim 7.1 \mathrm{~g} / \mathrm{cm}^{3}$, and approximately equal volumes of uranium-silicide and $\mathrm{Al}$ are used in its formation. There is only a small volume change, $\sim 4 \%$, involved in the reaction of uraniumsilicide and Al.

The compositions deviate from the exact stoichiometry, i.e., $(\mathrm{Al}+\mathrm{Si}) / \mathrm{U}=3$. This indicates that the reaction products became amorphous during irradiation. The amorphous nature of the ILs in $\mathrm{U}_{3} \mathrm{Si}_{2}-\mathrm{Al}$ dispersion fuels from in-pile tests have been reported previously [10,45]. Since the IL is amorphous, $\mathrm{U}, \mathrm{Al}$, and $\mathrm{Si}$ atoms exist in a mixture without crystalline restriction of stoichiometry.

A graph is shown in Fig. 15, where the square of the IL thickness $\left(\mathrm{Y}^{2}\right)$ divided by the square root of the fission rate is plotted versus time. Division by the square root of the fission rate is necessary to remove the difference in the fission rate among the data. $\mathrm{U}_{3} \mathrm{Si} / \mathrm{Al}$ has the fastest $\mathrm{IL}$ growth kinetics, the slower is $\mathrm{U}_{3} \mathrm{Si}_{2} / \mathrm{Al}$, and the slowest is $\mathrm{USi} / \mathrm{Al}$. The $\mathrm{Si} / \mathrm{U}$ ratio in fuel particles is preserved in the IL, implying that the higher the $\mathrm{Si} / \mathrm{U}$ ratio in the $\mathrm{IL}$, the slower is the growth rate.

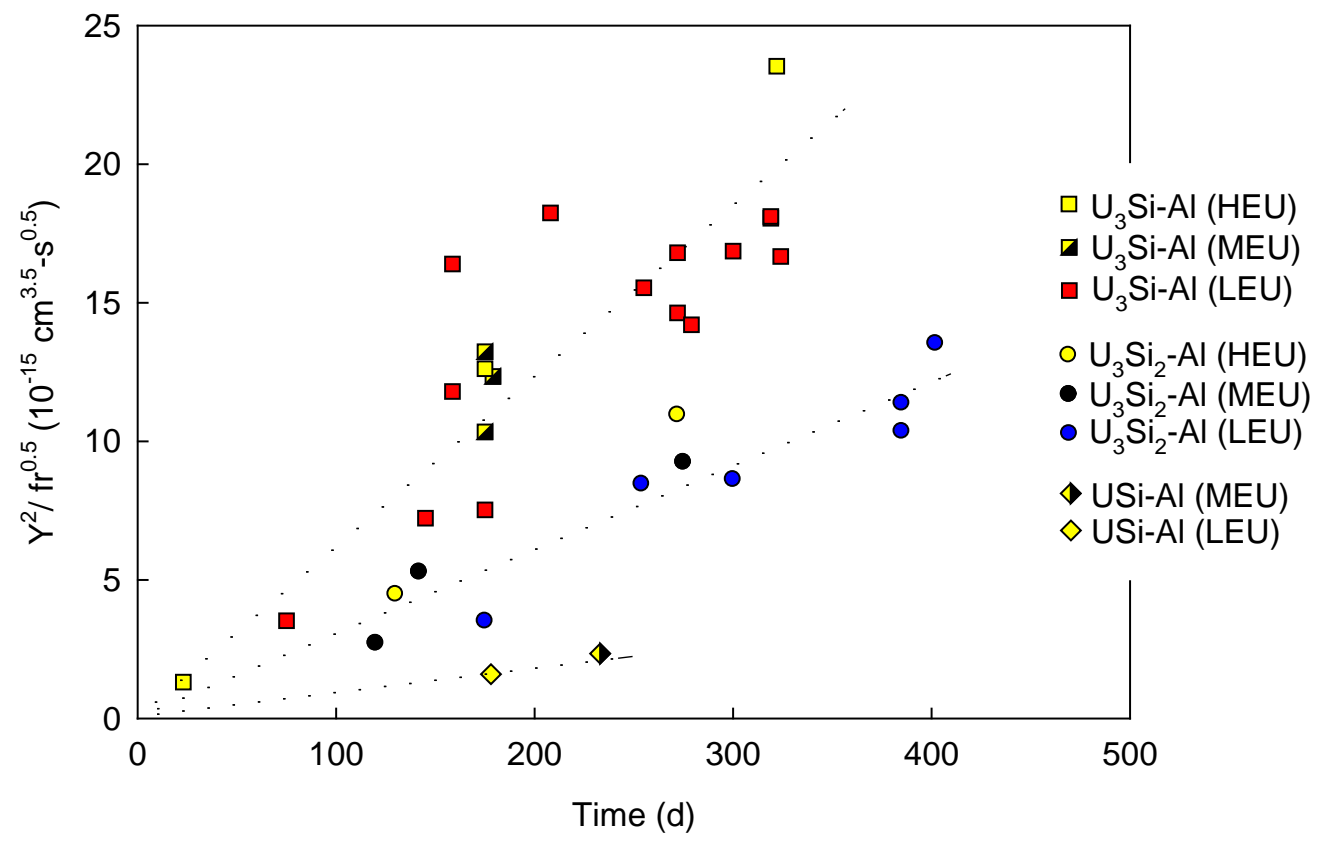

Fig. $15 \mathrm{Y}^{2}$ versus time where $\mathrm{Y}$ is the IL thickness. $\mathrm{Y}^{2}$ is normalized with the square of the fission rate $\sqrt{\dot{\hat{f}}}$, and the IL thickness data are at $100^{\circ} \mathrm{C}$. Guided lines are also shown. 


\subsection{Silicon effect on strengthening of interaction layers}

It is reasonable to suppose that the extent of pore formation in the ILs in size and population can be reduced as IL growth is suppressed. As long as ILs grow, however, a complete prevention is impossible. The second best solution is naturally strengthening the ILs to prevent pore formation. The solution lies in the reduction of free volume in the amorphous ILs. This parameter is primarily dependent on the composition of the IL, in essence, on the strength of the chemical bonds of the ILs. The theoretical basis of argument is given in the next subsection. The possible modification would be an appropriate alloy addition.

\subsubsection{Effect of silicon content in U-Si intermetallics}

It has been shown that the free-volume of an amorphous intermetallic compound is strongly affected by composition, because short range bonding character of an alloy is maintained in the glass state. A good example was shown by Komatzu for an intermetallic glass (see for example Fig. 13 of Ref. 46). For U-Si intermetallic compounds, the relation between the fluidity (typically measured by sample elongation during ion beam irradiation) and the free volume was correlation using the so-called Doolittle equation [22], as shown in Fig. 16 [24]. The free volume, and the resulting fluidity are clearly dependent on the Si content.

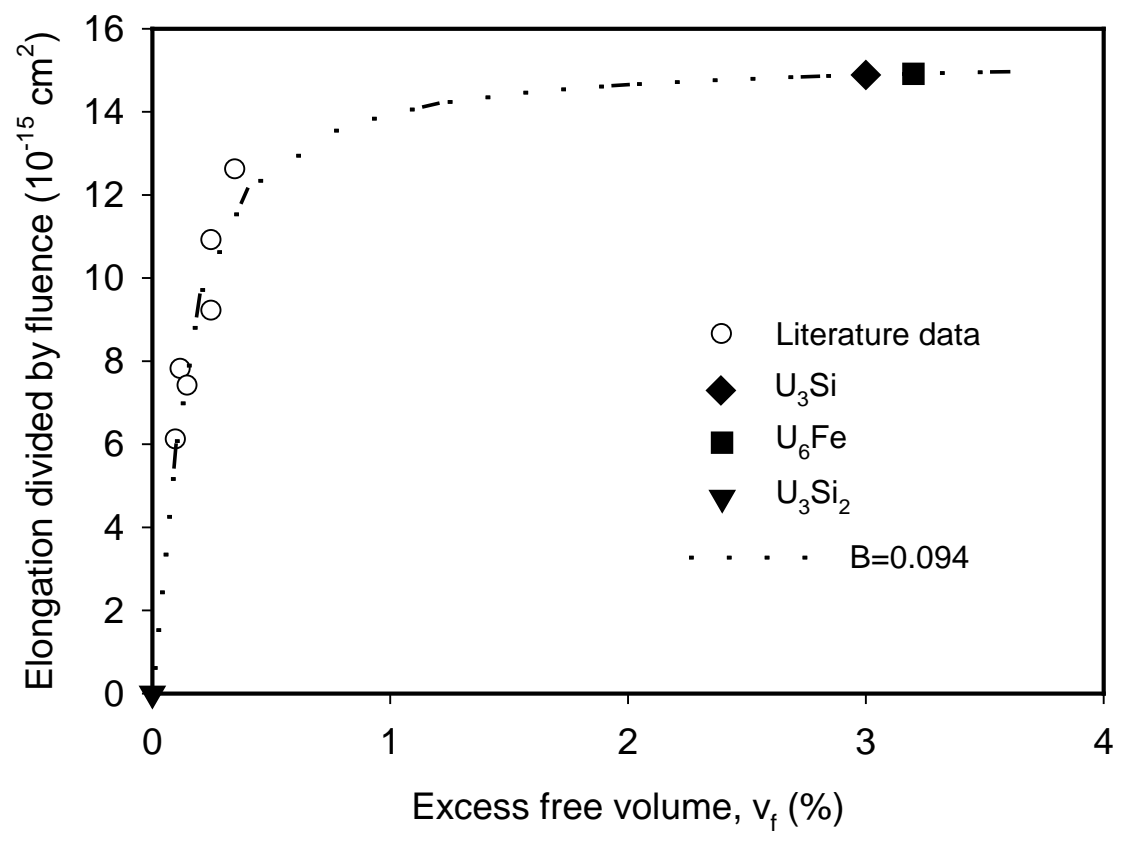

Fig. 16 Elongation of sample by ion irradiation from Klaumunzer [47]. The data fitting curve with the Doolittle relation $\phi=15.4 \exp \left(-\mathrm{B} / \mathrm{v}_{\mathrm{f}}\right)$ is also included.

The effect of the composition, the Si content in the U-Si compounds, on the pore growth of two uranium silicide fuels is shown in Fig. 17 [1]. Both $\mathrm{U}_{3} \mathrm{Si}$ and $\mathrm{U}_{3} \mathrm{Si}_{2}$ are amorphized at a low damage dose $[48,49]$. Whereas amorphization of $\mathrm{U}_{3} \mathrm{Si}$ is accompanied by a relatively large 
increase in free volume, the corresponding change for $\mathrm{U}_{3} \mathrm{Si}_{2}$ was found to be negligibly small. Apparently the additional $\mathrm{Si}$ bonds in $\mathrm{U}_{3} \mathrm{Si}_{2}$ have an extra benefit by reducing the amount of freevolume in the glassy state, reducing the fluidity of the fuel - the fission gas diffusivity - and the resulting swelling behavior. By analogy, this led us to conclude that the higher Si content in a Sicontaining amorphous material should be beneficial in reducing free volume and resulting fluidity.

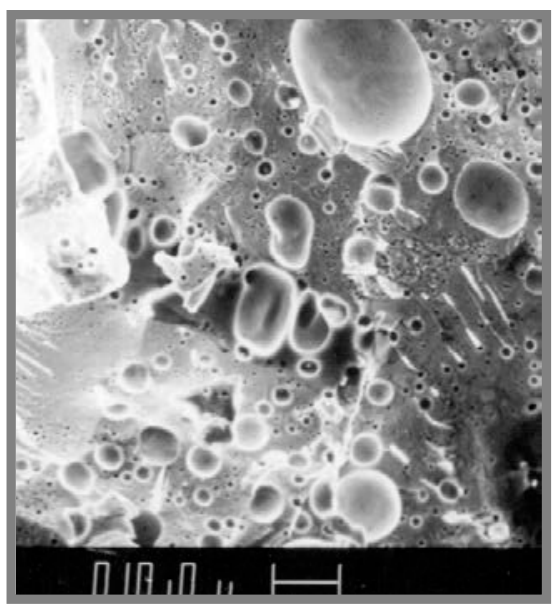

(a) $U_{3}$ Si with $F D=5.2 \times 10^{21} \mathrm{f} / \mathrm{cm}^{3}$

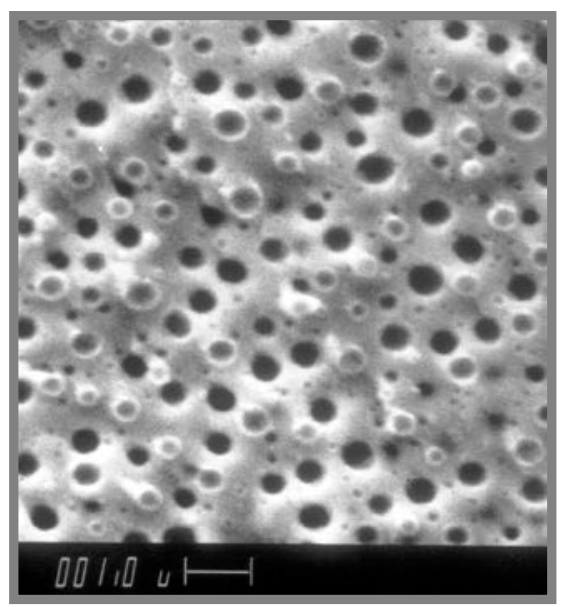

(b) $\cup_{3} \mathrm{Si}_{2}$ with $F D=5.1 \times 10^{21} \mathrm{f} / \mathrm{cm}^{3}$

Fig. 17 Fission gas bubble morphology in two U-Si compound fuels with different $\mathrm{Si} / \mathrm{U}$ ratios. Notice the difference in magnification, the image in (b) is 10 times higher in magnification.

\subsubsection{Strengthening interaction layer}

Gibbs free energy formation of a compound $(\Delta \mathrm{G}=\Delta \mathrm{H}-\mathrm{T} \Delta \mathrm{S})$ is the measure of the stability of a compound and spontaneity of a reaction. Since enthalpy is the dominant part of Gibbs free energy, particularly at low temperatures, knowing enthalpy of formation of a compound provides an approximate measure of how stable the compound is relative to other comparable compounds. In general, the heat of formation of a compound is considered as the bond enthalpy, a measure of (average) bond strength. The more heat release during a reaction, the larger negative value of the heat of formation is related. In this regard, examining the change in the heat of formation of a compound accompanied by an element addition is a convenient method to estimate the effect of that element addition on the bond strength of the compound. We deduce that a material with a high (average) bond strength tends to be more stable. By a stable material, we mean that the viscosity of the material is high.

The Miedema model analytically assesses the enthalpy change during mixing of two elements by using an empirical correlation [50]. The correlation for the formation enthalpy of an AB binary is given by 
$\Delta \mathrm{H}^{\mathrm{f}}=c_{A} f_{B}^{A} \frac{2 V_{A}^{2 / 3}}{\left(n_{w s ~}^{-1 / 3}+n_{w s B}^{-1 / 3}\right)}\left\{-P(\Delta \varphi)^{2}+Q\left(\Delta n_{w s}^{1 / 3}\right)^{2}-R\right\}$

where $\Delta H^{\mathrm{f}}$ is given in $\mathrm{kJ} / \mathrm{mol}$ of atoms of $\mathrm{A}$ and $\mathrm{B}$ with concentrations in the mixture, and $c_{A}$ the concentration of $\mathrm{A}$. $f_{B}^{A}$ is the degree to which $\mathrm{A}$ atoms are in contact with $\mathrm{B}$ atoms. $V$ is the atomic volume, $n_{w s}$ is the electron density, $\varphi$ is the electronic charge. $P, Q$ and $R$ are constants fitted to experimental data (see Ref. 47 for more in details).

The data for enthalpy of formation of compounds at $298 \mathrm{~K}$ were collected and reviewed. Because the Miedema model predicts at $0 \mathrm{~K}$, the literature data were to be revised to apply at $0 \mathrm{~K}$. However, the difference between $0 \mathrm{~K}$ and $298 \mathrm{~K}$ is around $1 \mathrm{~kJ} / \mathrm{mole}$ of atoms in compound so that the data at $298 \mathrm{~K}$ can be also applicable to $0 \mathrm{~K}$.

Figure 18 provides a collection of measured data and the prediction results of the Miedema method. The U-Si and U-Al data generally follow the trend calculated with the Miedema model, although the Miedema model over predicts. As seen in the figure, the heats of formation of the compounds decrease, or become more negative, with the increasing Si content. The trend is reversed for the $\mathrm{U}-\mathrm{Al}$ compounds, implying that the compound stability decreases with the increasing $\mathrm{Al}$ content. It is also noticeable that the U-Si compounds are more stable than the U-Al compounds. Comparing between the $\mathrm{UAl}_{3}, \mathrm{U}(\mathrm{Al}, \mathrm{Si})_{3}$ and $\mathrm{USi}_{3}$, the compound stability increases with the Si content.

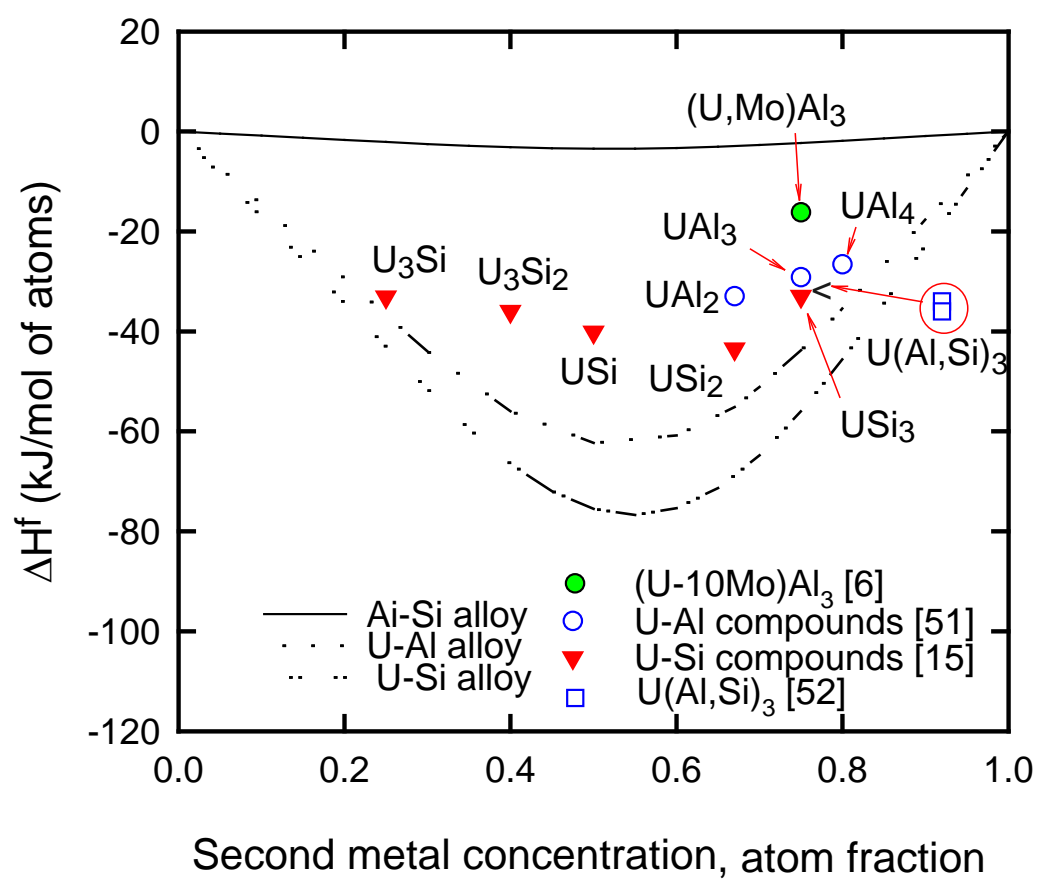

Fig. 18 Enthalpies of formation of compounds and alloys. Lines: predictions by the Miedema model, symbols: data in the literature. 
The heat formation of the $\mathrm{UAl}_{3}$ type IL was reported [51]. The effect of the presence of Mo on the stability of the ILs can be examined in Fig. 19. The more Mo added to the UAl , the less negative enthalpy of formation the compound becomes, meaning that it becomes less stable. From these analyses, Mo in the IL appears to decrease the stability of the IL. Conversely, as also shown in Fig. 19, the addition of Si stabilizes the $\mathrm{UAl}_{3}$ compound, which is consistent with the finding in Fig. 17. A similar trend was also found for the effect of Si addition to (U,Mo) $\mathrm{Al}_{3}$ [13,14]. It should be pointed out that the above reasoning does not account for the amorphous nature of the material and does not include the effect of high fission damage. It can therefore only serve as a guide.

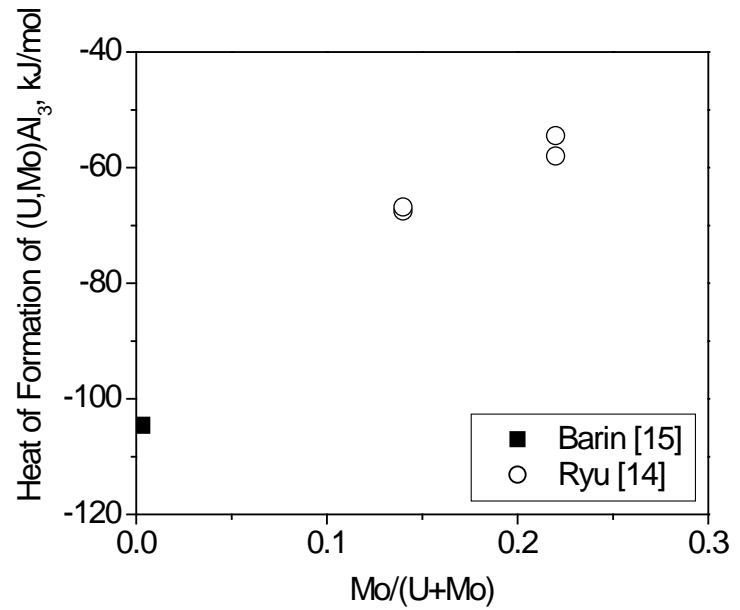

(a) Heat of formation of $(\mathrm{U}, \mathrm{Mo}) \mathrm{Al}_{3}$ shown in Fig. 7.

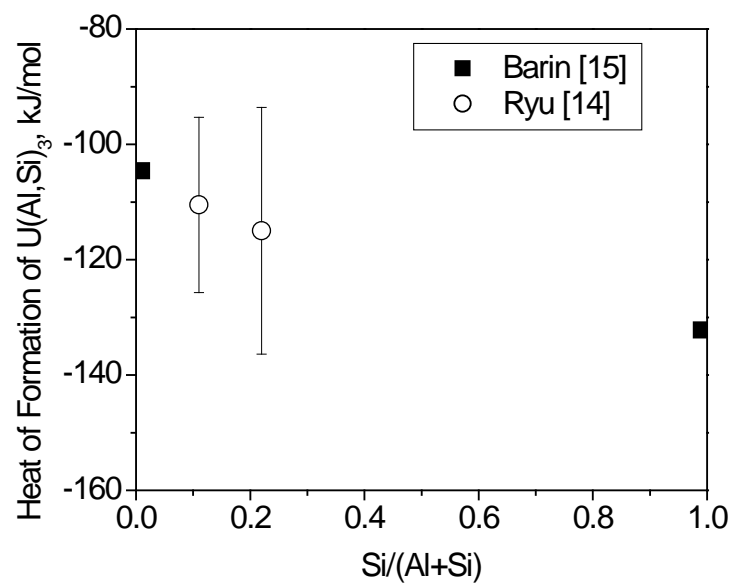

(b) Heat of formation of $\mathrm{U}(\mathrm{Al}, \mathrm{Si})_{3}$

Fig. 19 Enthalpies of formation of interaction layers showing the effect of Mo and Si additions [12].

\subsubsection{Minimum Si content in IL}

The minimum Si content in the IL for the Si to be effective is estimated in this subsection. This is a difficult problem requiring a large test matrix. The only literature data [31,33] concern the amount of Si necessary to prevent the formation of $\mathrm{UAl}_{4}$ from $\mathrm{UAl}_{3}$ during annealing at $605^{\circ} \mathrm{C}$. The compositions of the reaction products are in the range $\mathrm{U}\left(\mathrm{Al}_{0.86} \mathrm{Si}_{0.14}\right)_{3}-\mathrm{U}\left(\mathrm{Al}_{0.75} \mathrm{Si}_{0.25}\right)_{3}$. To more accurately find the minimum value, a thermodynamic consideration was given.

A pseudo-ternary diagram shown in Fig. 20(a) provides IL compositions observed from in-pile tests with pure $\mathrm{Al}$ matrixes and out-of-pile tests with addition of $\mathrm{Si}$ in the matrixes. The ternary phase diagram for the U-Al-Si system at $400{ }^{\circ} \mathrm{C}$ in Fig. 20(b) shows the phase field of U(Al,Si) IL product and $\mathrm{UAl}_{4}$. The Si content necessary to stabilize $\mathrm{UAl}_{3}$ and prevent the formation of $\mathrm{UAl}_{4}$ is at $5 \%$. Below this concentration, $\mathrm{UAl}_{4}$ is formed. This is applicable only for the out-ofpile annealing, where the reaction product is crystalline and, therefore, behaves abiding by thermodynamics. During irradiation, the ILs are amorphous, which may make the minimum Si concept different. In addition, the in-pile reaction products frequently have the $\mathrm{Al} / \mathrm{U}$ ratio higher than 4 because of the presence of Mo as discussed in subsects. 2.2.2 and 2.2.3. However, the exact value can only be determined by tests. 


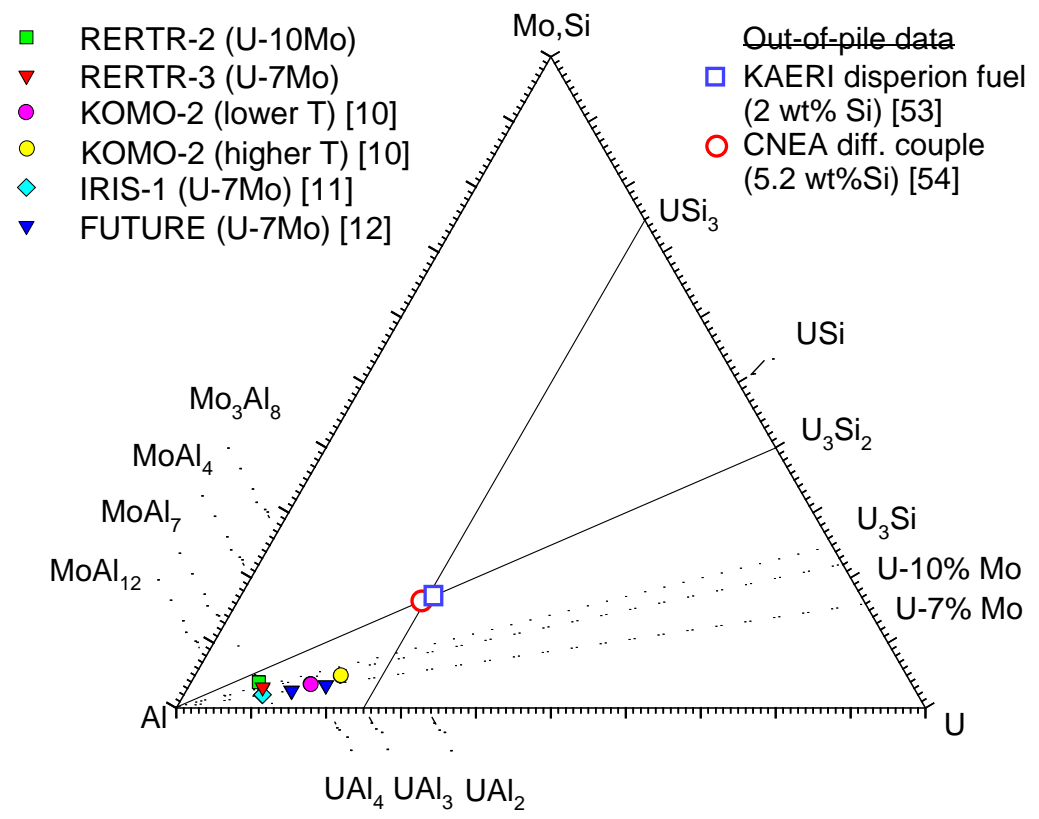

(a) Pseudo-ternary diagram of U-Mo-Al-Si showing IL composition data from in-pile tests with pure $\mathrm{Al}$ matrix and out-of-pile tests with Si-added Al.

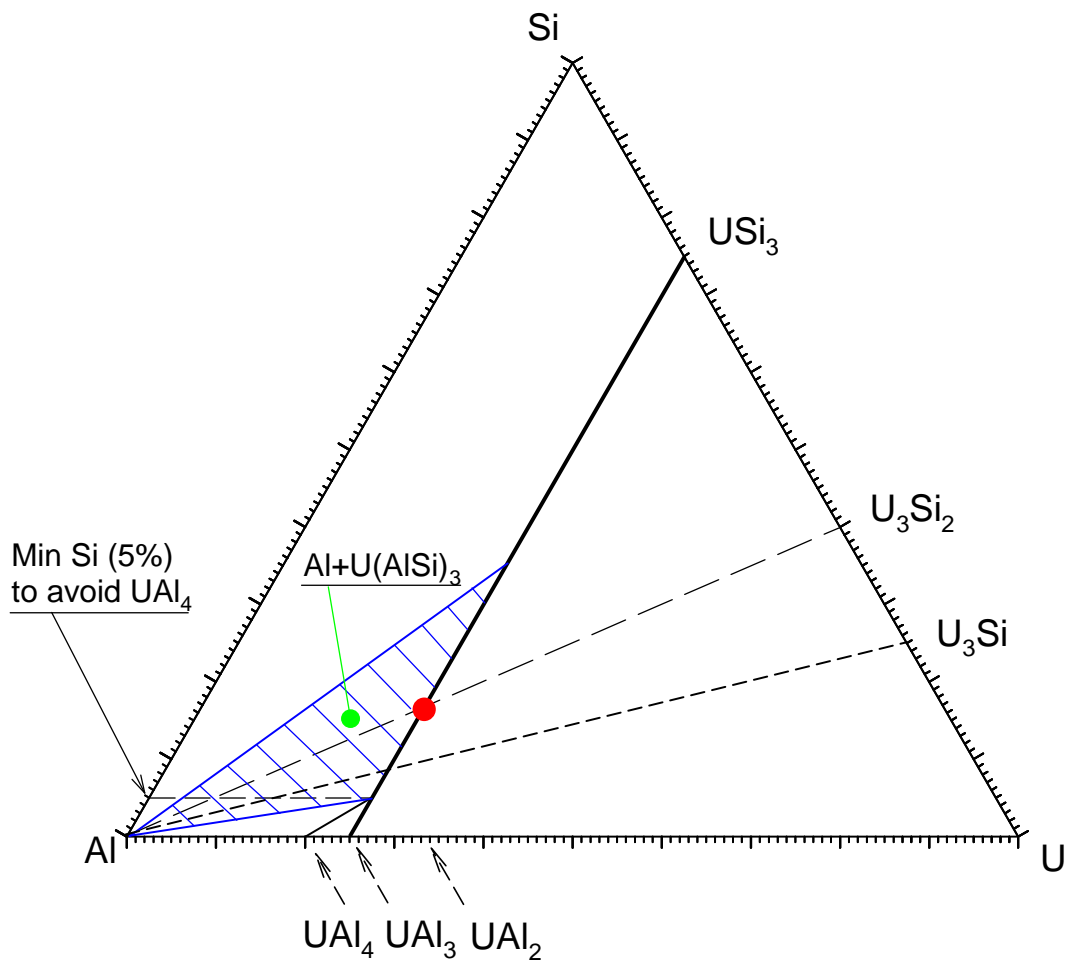

(b) U-Al-Si ternary phase diagram at $400{ }^{\circ} \mathrm{C}$.

Fig. 20 Minimum Si content in the IL to avoid the formation of $\mathrm{UAl}_{4}$. 


\subsubsection{Prediction model for Si content in IL}

A prediction model was developed to calculate the Si content in an IL. The following assumptions were used in this model: (1) Fuel particles have a uniform size. (2) Si diffusion is only from the fission fragment recoil zones with width of $13 \mu \mathrm{m}$. The $13 \mu \mathrm{m}$ recoil zone width is chosen based on the most energetic fission fragment range in Al. The Si diffusion mechanism and range are discussed later in section 6. (3) Fission density in the ILs is much smaller than that in the U-Mo. Hence, no contribution by fissions in the ILs to the recoil range is considered. (4) A complete depletion of as-fabricated Si contained in the recoil zone is assumed.

The extent of overlapping of recoil zones can be estimated by considering that fuel particles are positioned in an FCC array. Fig. 21 illustrates the configuration of two neighboring fuel particles and recoil zones around them. The distance, d, between two neighboring particles from their surfaces is $d=a / \sqrt{2}-2 r$ where $a$ is the unit cell edge length, $r$ is the fuel radius. By definition of fuel volume fraction in the meat, $\mathrm{V}_{\mathrm{f}}=\mathrm{V}_{\mathrm{f}} / \mathrm{V}_{\mathrm{m}}=\mathrm{V}_{\mathrm{f}} / \mathrm{a}^{3}$ where $\mathrm{V}_{\mathrm{f}}=4\left(4 \pi \mathrm{r}^{3} / 3\right)$ and $\mathrm{V}_{\mathrm{m}}$ is the meat volume. From these relations, $\mathrm{d}$ can be found as

$\mathrm{d}=\left(\frac{1}{\sqrt{2}} \sqrt[3]{\frac{16 \pi}{3} \frac{1}{\mathrm{v}_{\mathrm{f}}}}-2\right) \mathrm{r}$

where the applicable range of $\mathrm{v}_{\mathrm{f}}$ is less than $0.74 . \mathrm{v}_{\mathrm{f}}$ is usually known from the fabrication data.

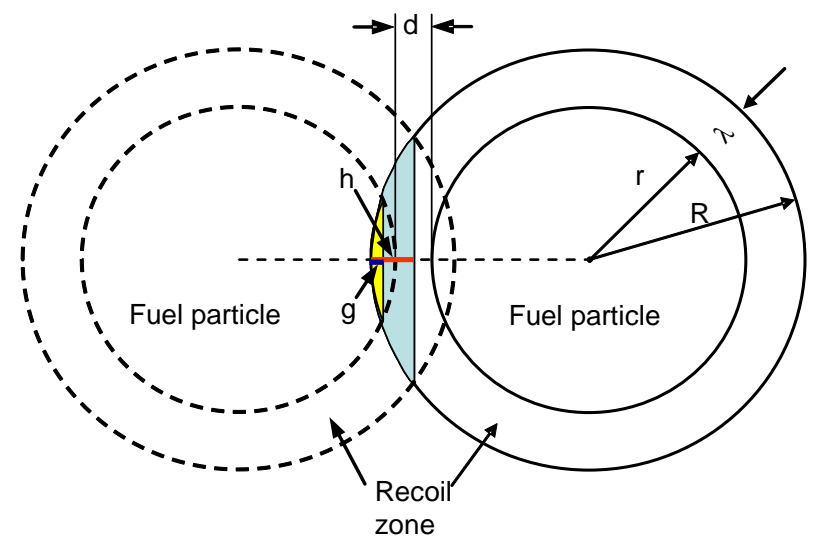

Fig. 21 Schematic of modeling fission fragment recoil zone overlapping.

In Fig. 21, the overlapping part of the recoil zone of the right-hand-side fuel particle by the neighbor particle is a partial sphere with height, $h$, of which the volume is

$\mathrm{V}_{\mathrm{c}}=\frac{1}{3} \pi \mathrm{h}^{2}(3 \mathrm{R}-\mathrm{h})$

where $\mathrm{h}=\lambda-\mathrm{d} / 2$ and $\mathrm{R}=\mathrm{r}+\lambda$. Here $\lambda$ is the fission fragment recoil range in aluminum known as $13 \mu \mathrm{m}$. When the recoil zone overlaps with neighboring fuel particles, i.e., $\lambda$ is greater than $\mathrm{d}$, 
as shown by the yellow region in Fig. 21, this volume must be subtracted from the large cap volume given in Eq. (10a). Because there are two symmetric caps, two of these small caps must be considered.

$\mathrm{v}_{\mathrm{c}}=\frac{1}{3} \pi \mathrm{h}^{2}(3 \mathrm{R}-\mathrm{g})$

where $g=(\lambda-d) / 2$.

The recoil zone volume can be calculated considering only one fuel particle surrounded by 12 neighboring ones by

$\mathrm{V}_{\mathrm{r}}=\frac{4 \pi \mathrm{R}^{3}}{3}-\frac{4 \pi \mathrm{r}^{3}}{3}-12\left(\mathrm{~V}_{\mathrm{c}}-2 \mathrm{v}_{\mathrm{c}}\right)$

The recoil zone volume fraction $\mathrm{v}_{\mathrm{r}}$ in the fuel meat can be calculated by

$\mathrm{v}_{\mathrm{r}}=\frac{\mathrm{V}_{\mathrm{r}}}{\mathrm{V}_{\mathrm{f}}} \mathrm{v}_{\mathrm{f}}$

where $V_{r}$ is the recoil zone volume. For the fuel particle size $70 \mu \mathrm{m}$, the model predicts recoil zone volume fractions of 53,47 , and $43 \%$ for the fuel loadings of 6,8 , and $8.5 \mathrm{gU} / \mathrm{cm}^{3}$ in the meat, respectively. At $6 \mathrm{gU} / \mathrm{cm} 3$ fuel loading, the recoil zone volume fractions are 58, 53, and $43 \%$ for the fuel particle sizes of 60,70 , and $90 \mu \mathrm{m}$, respectively. This shows that less Si is available for ILs as the fuel loading increases, whereas more Si is available as the fuel particle size increases.

Table 5 shows some examples of predictions for RERTR test plates.

Table 5 Measured IL thickness and predicted Si-concentration in the IL for RERTRtest plates

\begin{tabular}{|c|c|c|c|c|c|}
\hline Plate ID & Test & $\begin{array}{c}\text { As-fabrication } \\
\text { Si-content in } \\
\text { Al (wt\%) }\end{array}$ & $\begin{array}{c}\text { U-loading } \\
\left(\mathrm{gU} / \mathrm{cm}^{3}\right)\end{array}$ & $\begin{array}{c}\text { Measured IL } \\
\text { thickness } \\
(\mu \mathrm{m})\end{array}$ & $\begin{array}{c}\text { Si } \\
\text { concentration } \\
\text { in IL (\%) }\end{array}$ \\
\hline R5R020 & RERTR-6 & 0.2 & 6 & 13 & 0.3 \\
R2R010 & RERTR-6 & 2.0 & 6 & 4 & 7.6 \\
\hline R0R010 & RERTR-7 & 0.0 & 6 & 9 & 0 \\
R2R040 & RERTR-7 & 2.0 & 6 & 3 & 10.6 \\
\hline R2R078 & RERTR-9A & 2.0 & 8 & 6 & 3.5 \\
R3R108 & RERTR-9A & 4.8 & 8 & 4 & 13.0 \\
\hline R2R088 & RERTR-9B & 2.0 & 8.5 & 9 & 1.8 \\
R6R018 & RERTR-9B & 3.5 & 8.5 & 8 & 2.6 \\
\hline
\end{tabular}

In Figs. 22 - 24, the predicted Si contents in the IL are shown for three U-loadings, or U-densities in the meat, as a function of IL volume fraction and average IL thickness in the meat. It is common for all U-loadings that as the amount of the Si addition in the Al increases, the Si concentration in the IL also increases. 


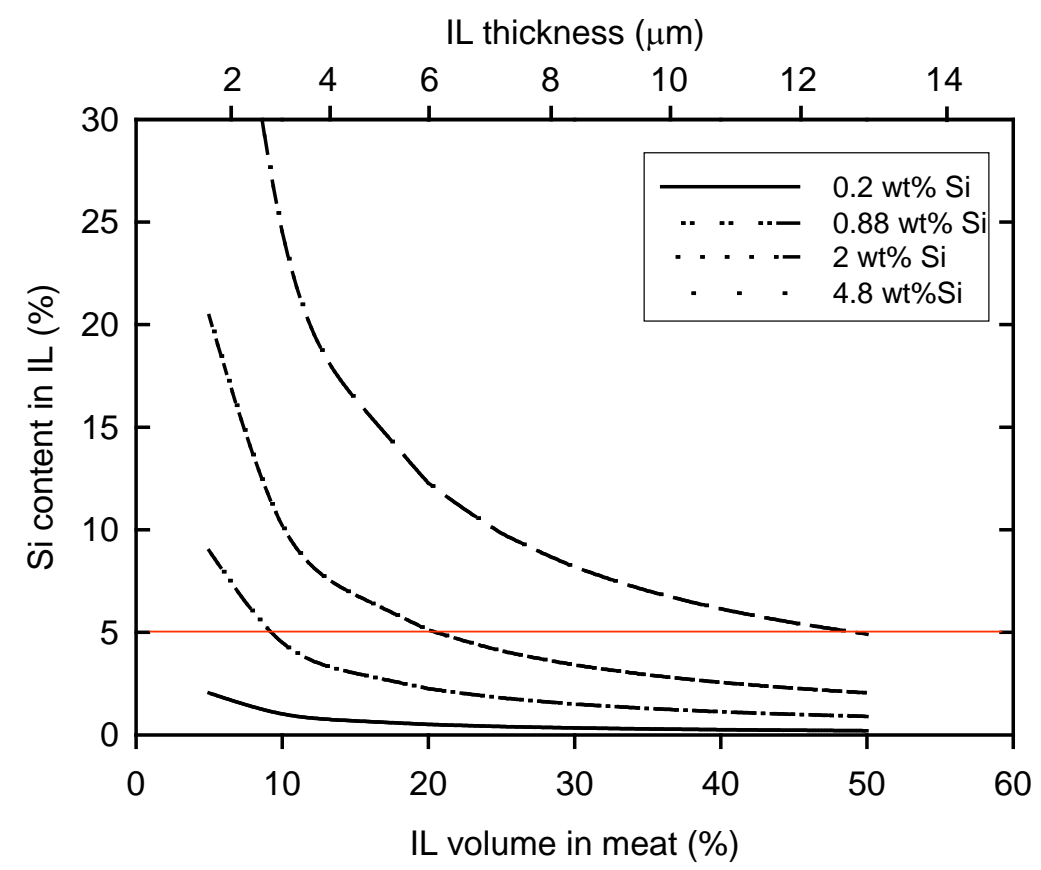

Fig. 22 Prediction of Si concentration in IL for average fuel particle size of $70 \mu \mathrm{m}$ and $6 \mathrm{gU} / \mathrm{cm}^{3}$ meat U-density for four as-fabrication Si-contents in Al. This prediction is applicable for RERTR-6 test. This case is approximately applicable to the RERTR-7 test that has larger particle size but the same loading.

IL thickness $(\mu \mathrm{m})$

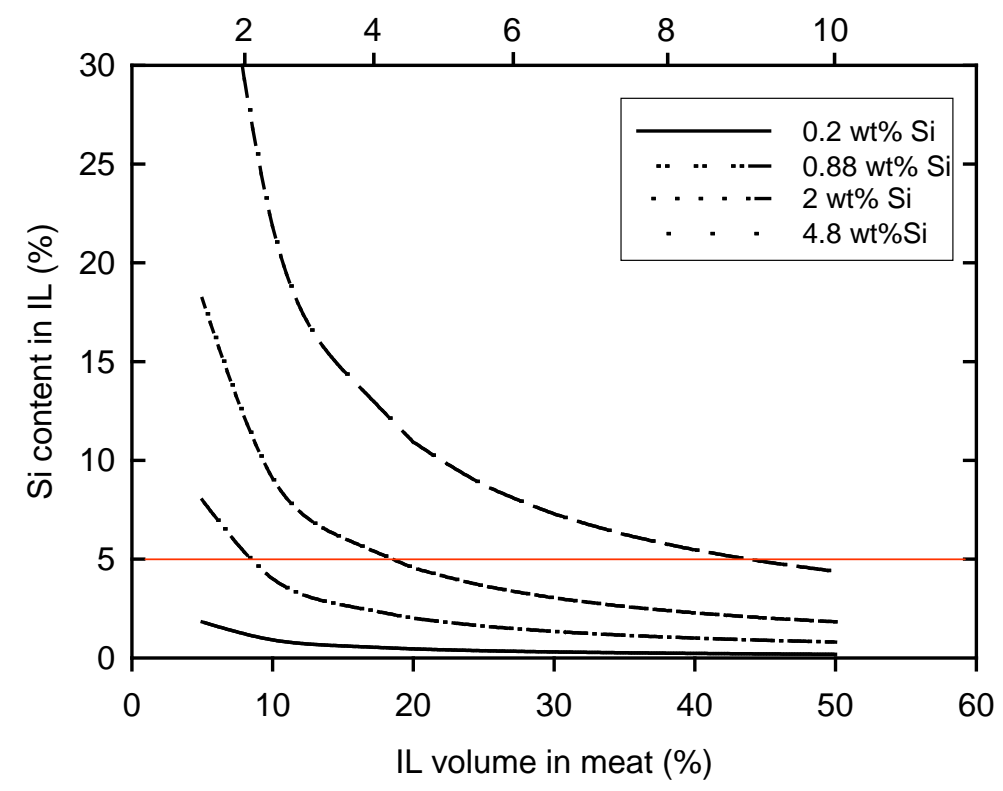

Fig. 23 Prediction of Si concentration in IL for average fuel particle size of $70 \mu \mathrm{m}$ and $8 \mathrm{gU} / \mathrm{cm}^{3}$ meat U-density for four as-fabrication Si-contents in Al. This prediction is applicable for RERTR-9A test. 


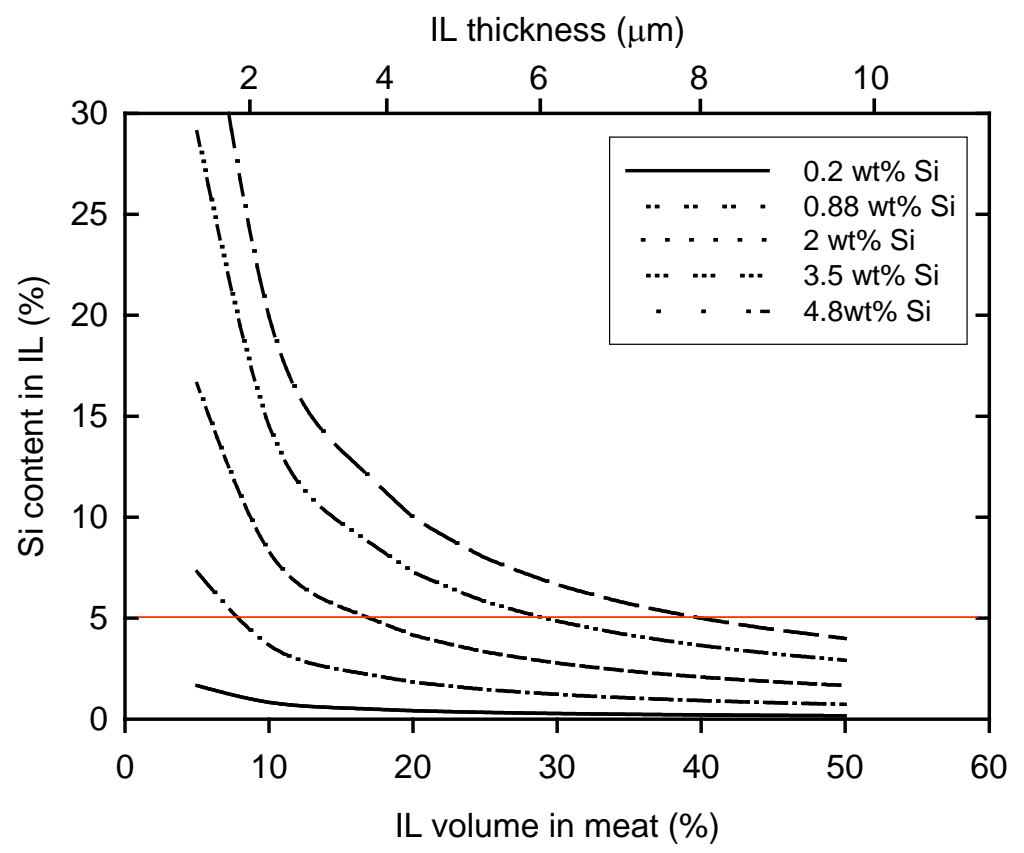

Fig. 24 Prediction of Si concentration in IL for average fuel particle size of $70 \mu \mathrm{m}$ and $8.5 \mathrm{gU} / \mathrm{cm}^{3}$ meat U-density for four as-fabrication Si-contents in Al. This prediction is applicable for RERTR-9B test.

\subsection{Element addition in U-Mo}

In order to reduce the amount of alloying element in the matrix, in particular the addition of $\mathrm{Si}$, a third element addition in the fuel side was considered. The candidates are transition metal elements such as $\mathrm{Zr}, \mathrm{V}, \mathrm{Ti}$ and $\mathrm{Nb}$, which suppress the formation of $\mathrm{U}-\mathrm{Al}$ compounds with a high $\mathrm{Al} / \mathrm{U}$ ratio.

Enthalpies of formation of binary alloys with the new element were estimated using the Miedema method. Since it is to be added in the U-Mo, the desirable element should have property that it has a high affinity to Si or aluminum and a low affinity to U. The high affinity to Si is beneficial to enhance the Si diffusion to the IL. Figure 25(a) shows that in contrast to Si and Al, the transition elements have positive heats of formation with U. Conversely, in Fig. 25(b) all of the candidate transition elements have negative heats of formation with $\mathrm{Si}$. Al and Si have positive heat of formation for all concentrations, suggesting no chemical affinity between them. The ability of the candidate element to stabilize the desirable interaction phase is predicted best if it has the largest negative enthalpy of formation with $\mathrm{Si}$. 


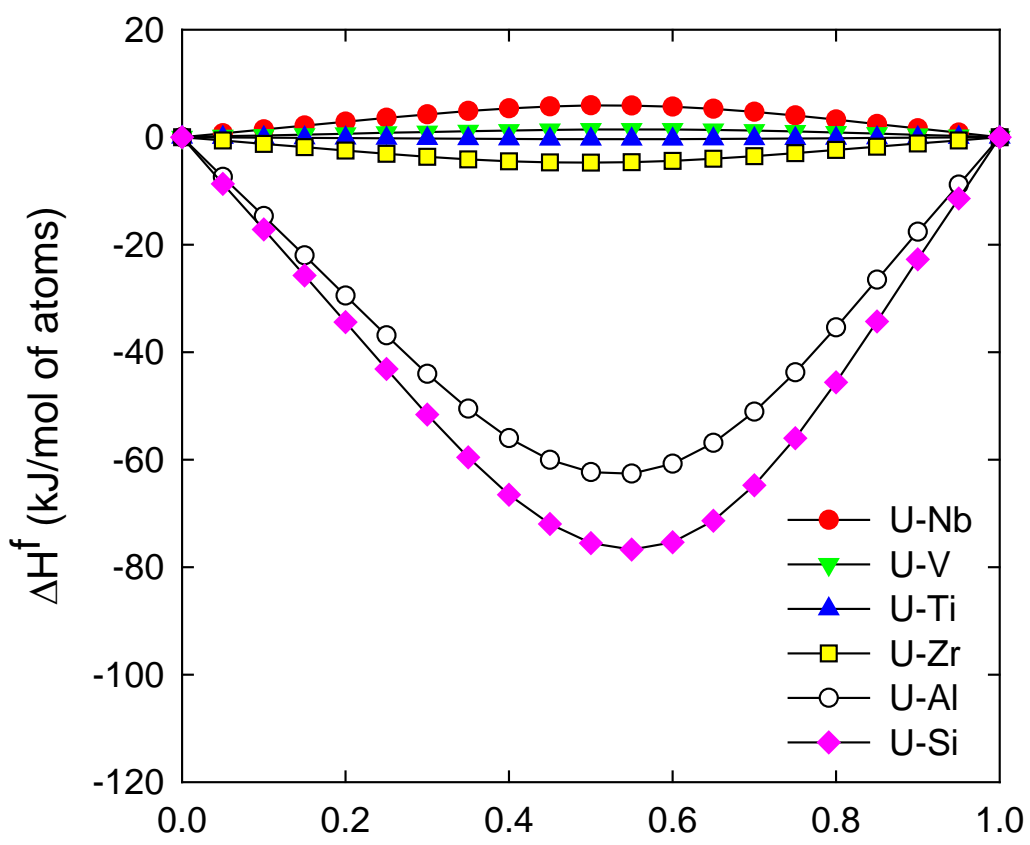

Second element concentration (atom fraction)

(a) $\mathrm{U}$ with $\mathrm{Nb}, \mathrm{V}, \mathrm{Ti}, \mathrm{Zr}, \mathrm{Al}$ and $\mathrm{Si}$

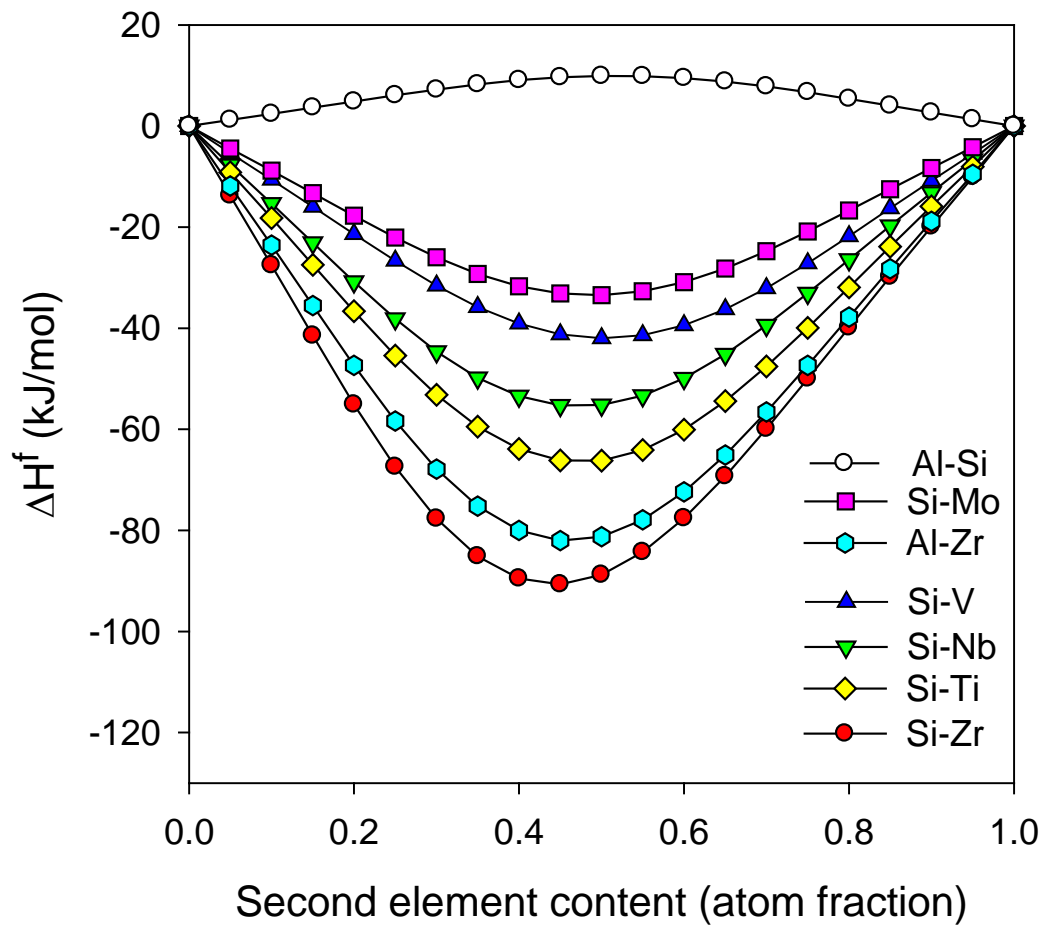

(b) Si with V, Nb, Ti and Zr. Si with Mo, Al with Si and Zr are also included.

Fig. 25 Enthalpies of formation of binary alloys. 
This analysis predicts that the candidate elements will diffuse from the fuel side to the matrix whereas Si diffuses to the fuel side because of the chemical affinities to Si and $\mathrm{Al}$. $\mathrm{Zr}$ and Ti have the strongest affinities to Si. Using this result, a positive effect can be anticipated when a transition element is added to $\mathrm{U}-\mathrm{Mo}$, and $\mathrm{Si}$ is added to the $\mathrm{Al}$ matrix.

Figure 26 illustrates a schematic of the likely stabilizing action for the case with $\mathrm{Si}$ in the $\mathrm{Al}$ matrix and $\mathrm{Zr}$ in the U-Mo. Si is attracted to the U-Mo because of its affinity for $\mathrm{U}$ and repulsion by $\mathrm{Al}$ while $\mathrm{Zr}$ is interacted to the $\mathrm{Al}$ by its affinity for $\mathrm{Al}$ and $\mathrm{Si}$.

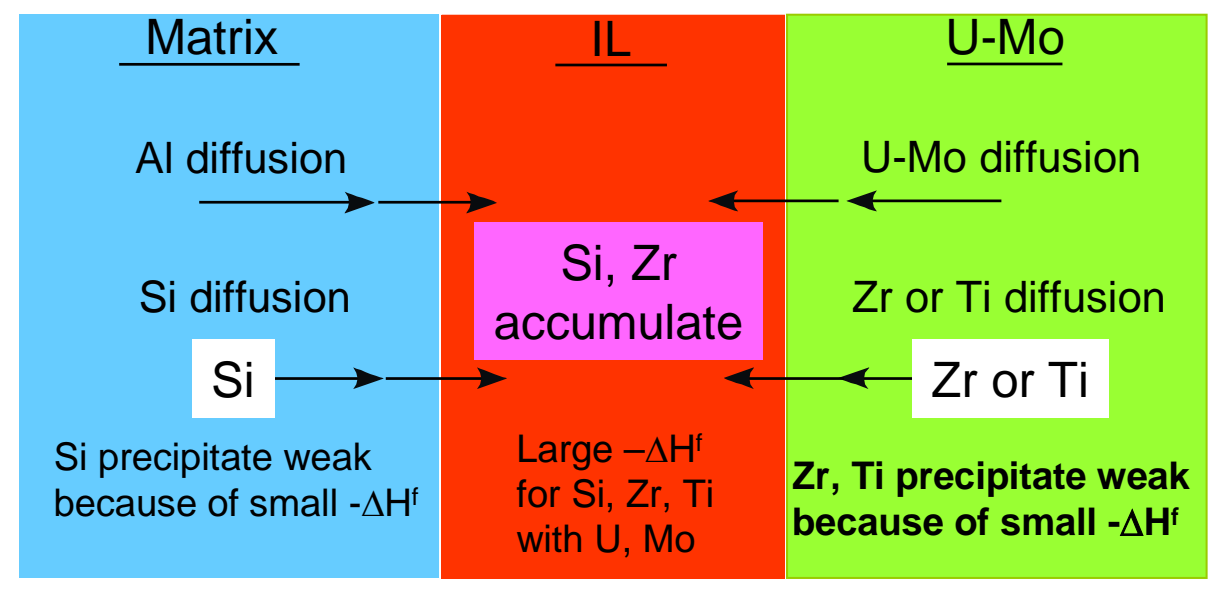

Fig. 26 Schematic of design of alloying element additions in U-Mo/Al.

Zirconium seems to have the strongest effect and Ti is the next. However, $\mathrm{Zr}$ reduces the $\gamma$-phase stabilizing power of Mo by forming $\mathrm{Mo}_{2} \mathrm{Zr}$ as shown in Fig. 27. As seen in the figure, a small amount of $\mathrm{Zr}$, say $1 \mathrm{wt} \%$, reduces the time of $\gamma$-to- $\alpha$ phase transformation almost one order of magnitude. Although it is not shown here, $\mathrm{Nb}$ and $\mathrm{V}$ have a similar effect. Ti apparently has the least harmful effect: if the amount is $1 \mathrm{wt} \%$, the effect on the $\gamma$-stability of U-Mo is negligible. Considering the higher neutron absorption cross section, Ti is unfavorable. Ti is lighter element than $\mathrm{Zr}$, so the Ti addition can be a half of $\mathrm{Zr}$ amount in weight \% to have the similar effect. Overall, Ti appears to be the best choice. In order not to deleteriously reduce U-loading, the amount of an element addition to the U-Mo is restricted below approximately $3 \mathrm{wt} \%$. 


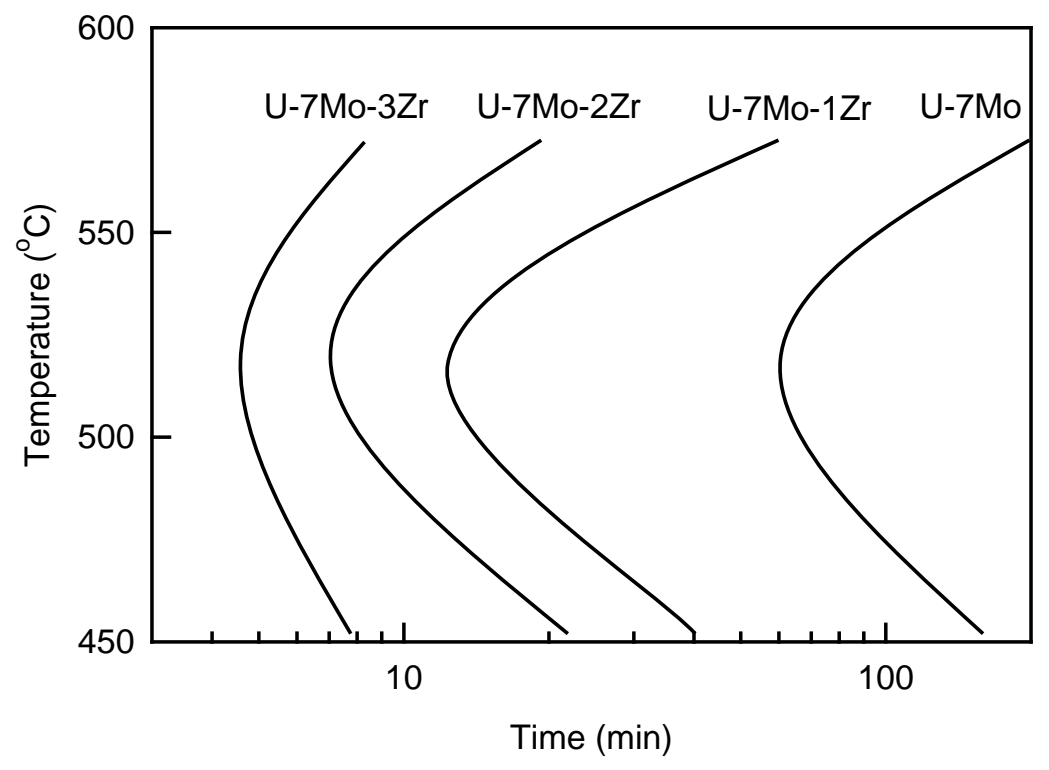

Fig. 27 Effect of Zr additions to U-7Mo alloy on isothermal transformation [55]. The $\gamma$ phase is stable at the left side of each curve while the $\alpha+\gamma^{\prime}$ is stable at the right side. 


\section{Section 4 Out-of-pile tests}

\subsection{Interaction between U-Mo and Al-Si}

Experimental evidence to support the thermodynamic predictions and deduction from the analogy of $\mathrm{U}-\mathrm{Al}$ system to U-Mo dispersion in $\mathrm{Al}$ was sought at CNEA and KAERI. Figure 28 shows the cross section of CNEA diffusion couple specimen annealed at $550^{\circ} \mathrm{C}$ for two hours. The asfabricated Si content in Al4043 alloy was $5.2 \mathrm{wt} \%$. A thick $(\sim 50 \mu \mathrm{m})$ Si-precipitate depleted zone near the IL was observed, and a high-Si content IL such as (U,Mo) $\left(\mathrm{Al}_{0.67} \mathrm{Si}_{0.33}\right)_{3}$ was also observed. The Si, originally in the form of precipitates in this zone, was believed to have diffused to the IL to form the preferred $\mathrm{UAl}_{3}$ type compound. The significance of this result is that $\mathrm{Si}$ preferentially diffuses to the IL and accumulates there. A high-Al content IL was also suppressed. The IL growth rate was also reduced in Si-added tests compared to pure Al tests.

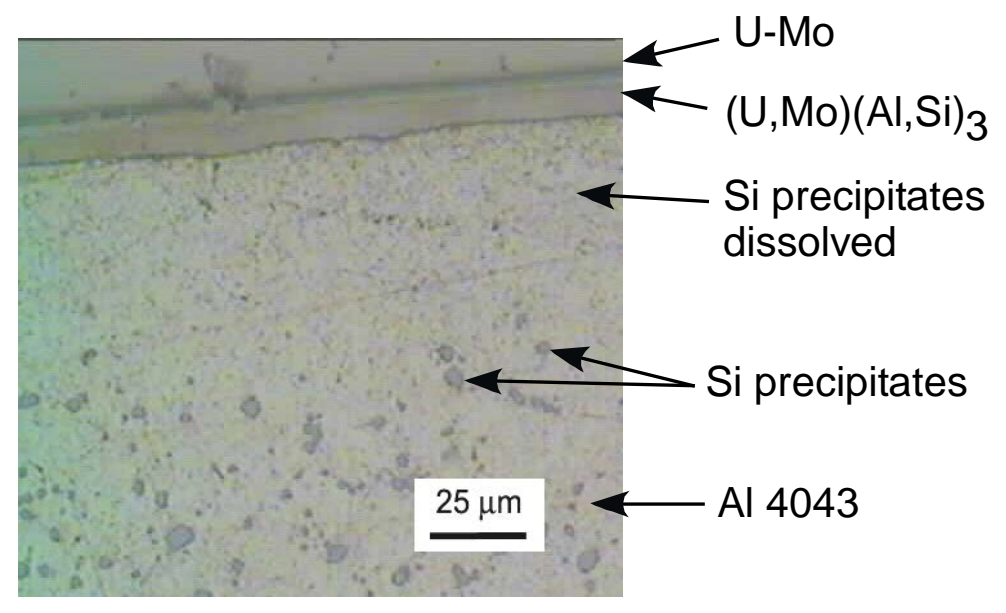

Fig. 28 CNEA diffusion couple test result with U-Mo/Al-Si showing Si-precipitate depletion zone [56].

A more systematic tests exploring the effects of adding $\mathrm{Zr}$ and $\mathrm{Ti}$ in $\mathrm{U}-\mathrm{Mo}$ and adding $\mathrm{Si}$ in $\mathrm{Al}$ were conducted at KAERI [57,58]. Major findings from these studies include: 1) $\mathrm{Zr}$ and $\mathrm{Ti}$ are effective suppressing IL growth, 2) Ti is less harmful than $\mathrm{Zr}$ in terms of deteriorating $\gamma$-stability of U-Mo during annealing tests, 3) $\mathrm{Ti}$ is more effective in reducing $\mathrm{IL}$ growth than $\mathrm{Zr}$ at the addition of the same atomic \%, 4) The $(\mathrm{Al}+\mathrm{Si}) /(\mathrm{U}+\mathrm{Mo}+\mathrm{Ti})$ ratios were less than 4 in the ILs, 5) $\mathrm{Ti}$ and $\mathrm{Zr}$ addition has a synergistic effect when $\mathrm{Si}$ is concomitantly added in the $\mathrm{Al}$.

Figure 29 shows an example of the test results. It is noticeable that the IL thickness decreases as $\mathrm{Si}$ in the $\mathrm{Al}$ and $\mathrm{Zr}$ in the UMo contents increase. Although not shown here, the similar trend has been observed for the tests with Ti addition to U-Mo and Si addition to Al. 


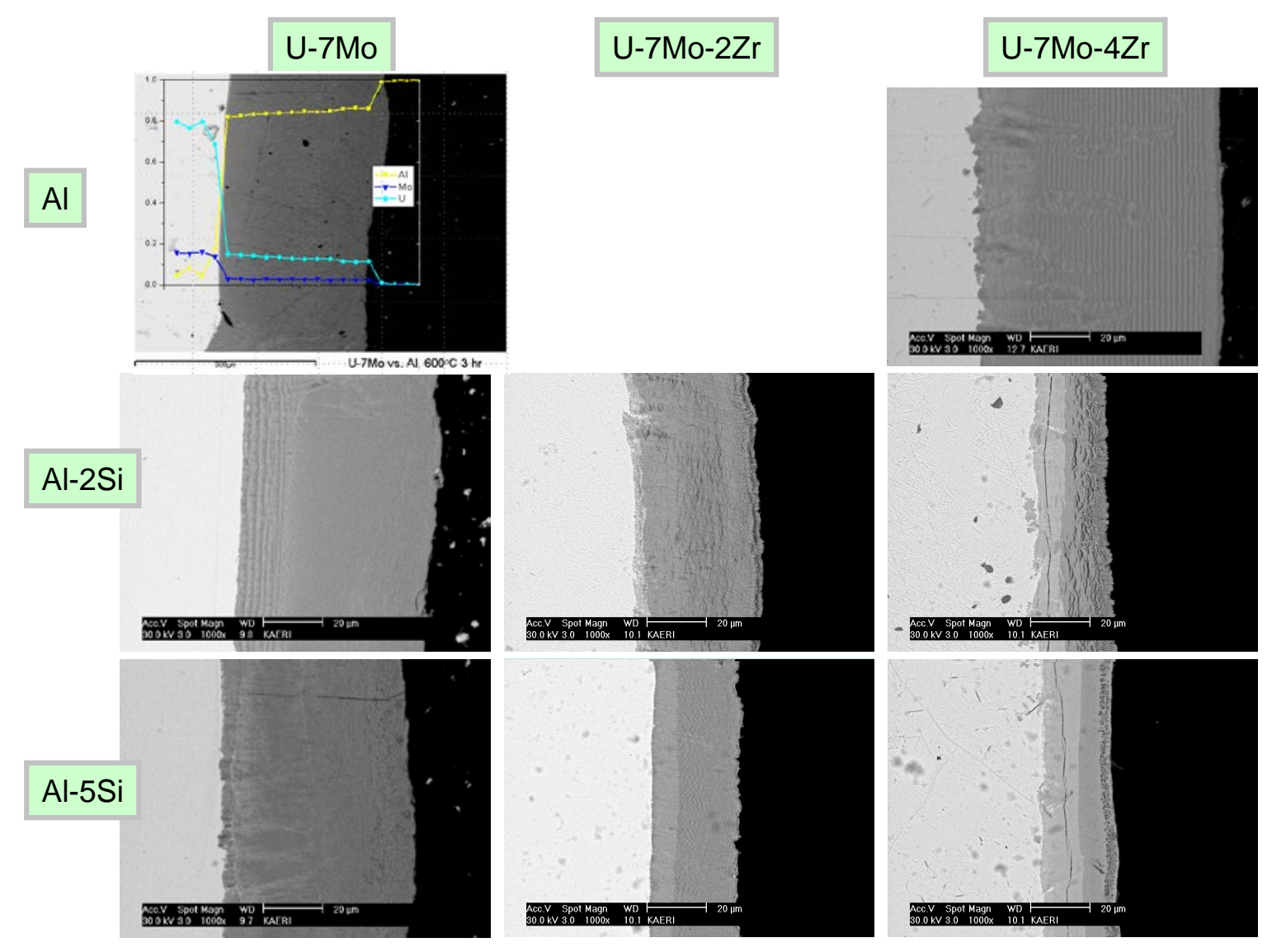

Fig. 29 Diffusion couple tests with U-Mo-xZr versus Al-ySi at $600{ }^{\circ} \mathrm{C}$ for three hours, where $\mathrm{x}$ and $\mathrm{y}$ are concentrations in weight \% [53].

In order to estimate the possible extent of the Si diffusion that is applicable to hot-rolling fabrication, we can make use of a well controlled diffusion couple test between U-7wt\%Mo and Al-7wt\% Si, for example, references such as [54,56]. From these references, Fig. 30 includes information of the rate of formation of both the IL and the adjacent zone depleted of Si precipitates. 

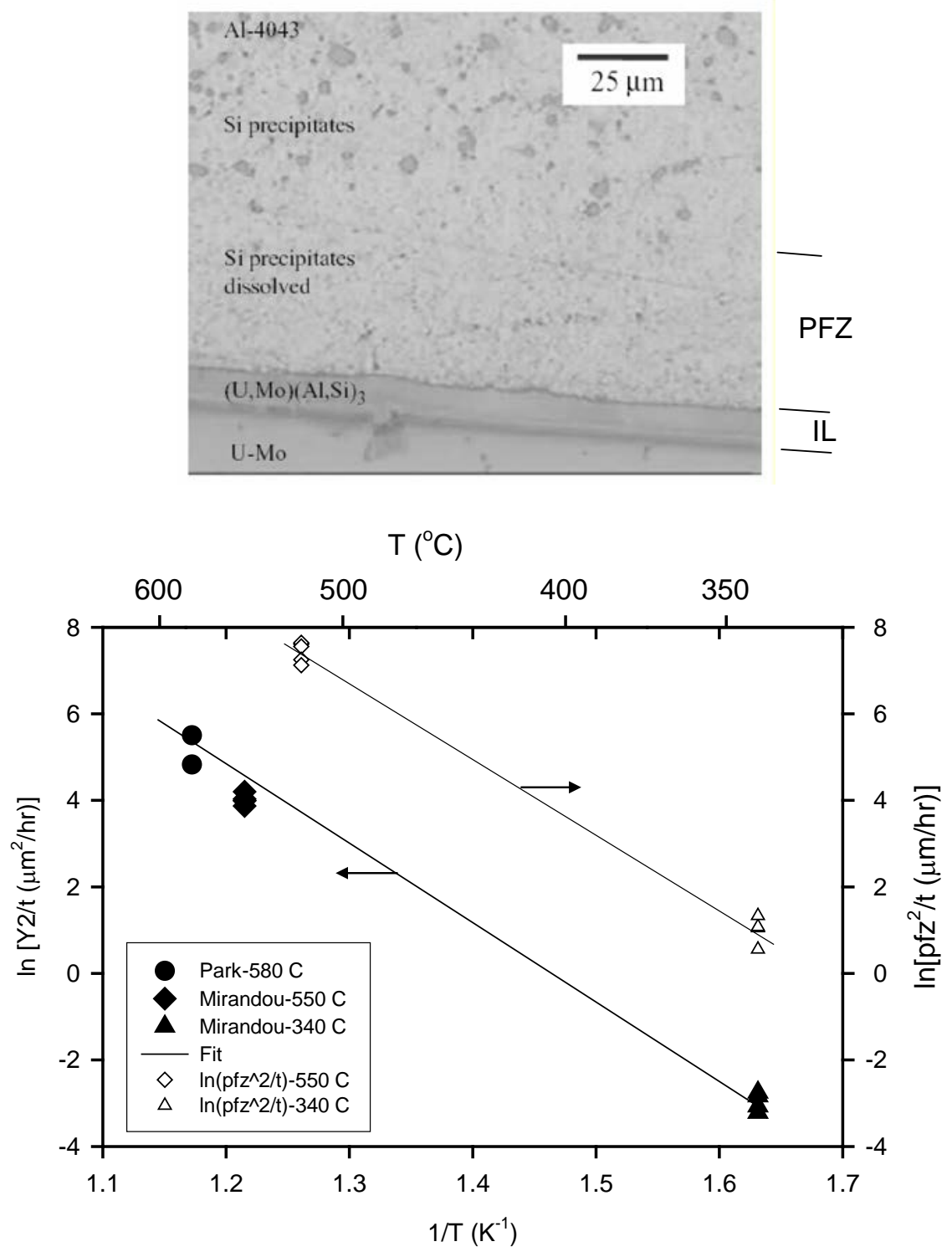

Fig. 30 Interaction layer growth kinetics [56,57] and precipitate-free-zone (PFZ) growth kinetics from Mirandou tests [56].

The out-of-pile tests, because they are typically at high temperatures, a slight difference in test temperature may result in considerable difference in the transformation of the metastable $\gamma$ phase i.e., $\gamma \rightarrow \alpha+\gamma^{\prime}$. Therefore, because of faster Al diffusion in the $\alpha$-U phase, different IL growth for each test is measured.

\subsection{Effect of Zr or Ti addition in U-Mo}

Out-of-pile tests of $\mathrm{Zr}$ addition to U-7Mo were performed [57], and found that it reduced the $\gamma$ phase stability of the U-Mo alloy and the rate of $\gamma \rightarrow \alpha+\gamma^{\prime}$ transformation increased as the $\mathrm{Zr}$ content increased beyond $2 \mathrm{wt} \%$, with progressively finer lamellar 2-phase microstructure. The diffusion couple tests showed that a $\mathrm{Zr}$ addition to U-7wt\%Mo reduced the IL growth rates 
progressively with the $\mathrm{Zr}$ content until a $\mathrm{Zr}$ content of $4 \%$ and increased the temperature dependence. If Si was simultaneously added in the matrix while $\mathrm{Zr}$ was added in the U-Mo, the $\mathrm{Zr}$ addition effect was the strongest in reducing the IL growth. The interaction product formed in a U-Mo-2Zr vs. Al-5Si diffusion couple showed the $\mathrm{Al} /(\mathrm{U}+\mathrm{Mo})$ ratio of $\sim 2$.

Compared to Zr addition in U-Mo, the Ti addition in U-Mo showed a similar $\gamma$-phase stability of the U-Mo alloy as the Ti content increased to $3 \mathrm{wt} \%$. The apparent solubility of Ti in ternary U7Mo-xTi alloy seems to have a limit of $\sim 1 \mathrm{wt} \%$. The U-Mo-Ti vs. Al-Si diffusion couple showed a much thinner IL than the U-Mo-Zr vs. Al-Si diffusion couple [58]. The effectiveness of Ti addition in U-7Mo for suppressing IL growth appears to saturate at $1 \mathrm{wt} \%$. Like Zr when added in U-Mo, Ti demonstrated to be another strong agent to suppress IL growth in combination with Si added to Al. Although Ti addition is $1 \mathrm{wt} \%$, the U-7Mo-1Ti vs. Al-2Si diffusion couple showed that the interaction product formed near the $\mathrm{U}-\mathrm{Mo}-\mathrm{Ti} / \mathrm{IL}$ interface had the $\mathrm{Al} /(\mathrm{U}+\mathrm{Mo})$ ratio less than 2. Moreover, Ti addition to $\mathrm{U}-7 \mathrm{Mo}$ is more effective in reducing the $\mathrm{Al} /(\mathrm{U}+\mathrm{Mo})$ atomic ratio than Zr. 


\section{Section 5 In-pile test}

\subsection{Test plate fabrication for RERTR tests}

Fuel plates are fabricated by hot-rolling. A blister annealing test is performed. The parameters for the process are given in Table 6.

Table 6 Hot rolling parameters used for test plate fabrication

\begin{tabular}{|c|c|c|c|}
\hline Test & Rolling & Blister anneal & Additional heating \\
\hline $\begin{array}{c}\text { RERTR-3, }-4,-5, \\
-6\end{array}$ & $\sim 1.5$ hours at $500^{\circ} \mathrm{C}$ & 1 hour at $485^{\circ} \mathrm{C}$ & None \\
\hline RERTR-7 & $\sim 1.5$ hours at $500^{\circ} \mathrm{C}$ & 1 hour at $485^{\circ} \mathrm{C}$ & None \\
\hline RERTR-8 & $\sim 1.5$ hours at $500^{\circ} \mathrm{C}$ & 1 hour at $485^{\circ} \mathrm{C}$ & None \\
\hline RERTR-9A & $\sim 1.5$ hours at $500^{\circ} \mathrm{C}$ & 0.5 hour at $485^{\circ} \mathrm{C}$ & $\begin{array}{c}\text { Hipped for } 30 \text { min } \\
\text { at } 500^{\circ} \mathrm{C} \\
\text { under } 103 \mathrm{MPa}\end{array}$ \\
\hline RERTR-9B & $\sim 1.5$ hours at $500^{\circ} \mathrm{C}$ & 0.5 hour at $485^{\circ} \mathrm{C}$ & None \\
\hline
\end{tabular}

Pre-heating during the hot rolling is executed for 45 minutes at $500^{\circ} \mathrm{C}$. The first re-heating is performed after the first rolling pass, and the second re-heating is done after the second rolling pass. Each re-heating takes 10 minutes at $500^{\circ} \mathrm{C}$. Supplemental re-heats are performed $\sim 5$ minutes at $500^{\circ} \mathrm{C}$.

Complete bonding is achieved at about the end of the third pass. IL growth during pre-heat and first re-heat (total heating of $\sim 50$ minutes at $500^{\circ} \mathrm{C}$ ) is negligible because of poor contact between the fuel particles and matrix. Most IL thickness grows during the blister annealing and additional heating done as for the RERTR-9A.

For a reasonable time at $500^{\circ} \mathrm{C}$ of $1 \mathrm{hr}$ the IL thickness will be $2.8 \mu \mathrm{m}$ and the precipitated free zone $16 \mu \mathrm{m}$ (see Fig. 30).

As shown in Fig. 31, the metastable $\gamma$ phase begins to transform to the equilibrium $\alpha+\gamma^{\prime}$ phases during the approximately $1.5 \mathrm{hrs}$ at $500^{\circ} \mathrm{C}$. The transformation is rather localized at first and forms areas at the fuel particle surface where Al diffusion into the $\alpha-\mathrm{U}$ phase, which is faster than the $\gamma-\mathrm{U}$ phase, takes place during fabrication. These areas of high $\mathrm{Al}$ and low Si content may explain the irregular interaction layers found after irradiation as discussed below. IL thicknesses and times of $\gamma \rightarrow \alpha+\gamma$ ' transformation for typical working temperatures are given in Table 7. 


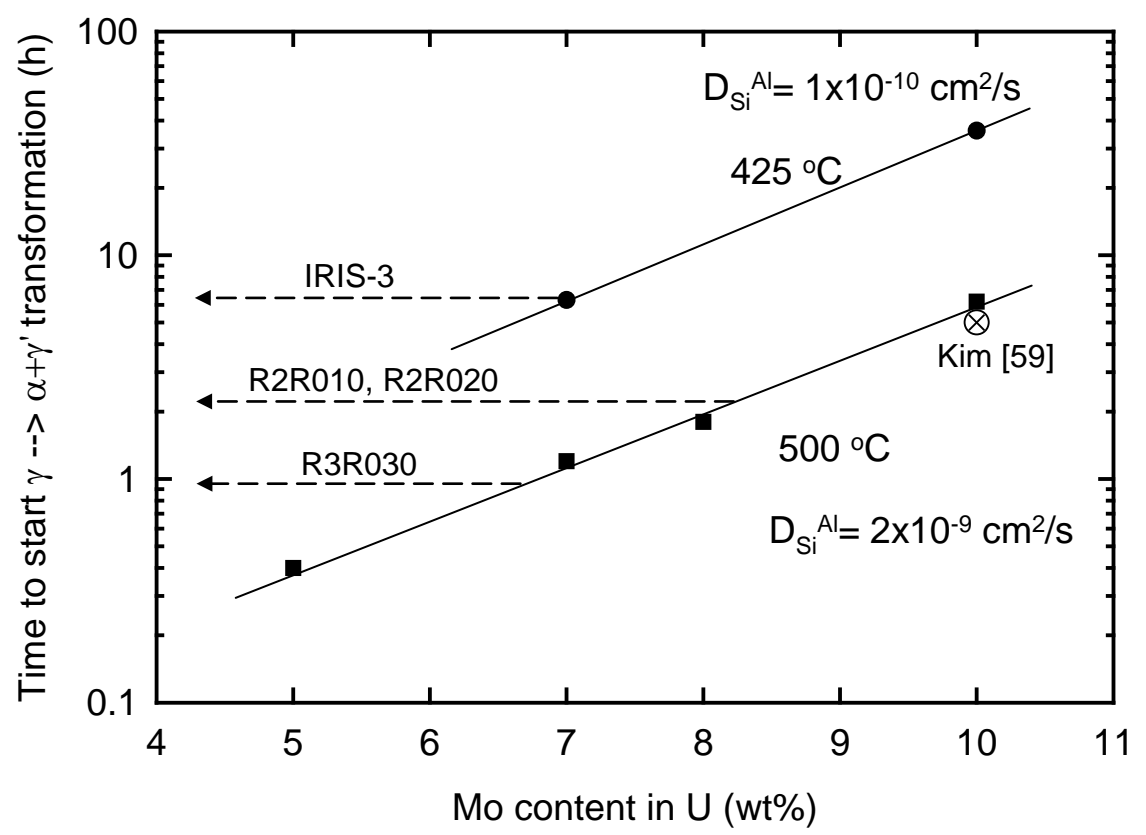

Fig. 31 Time to start $\gamma \rightarrow \alpha+\gamma^{\prime}$ transformation. Although the nominal Mo content is 7wt\%, R2R010 and R2R020 have $8.2 \mathrm{wt} \%$ Mo whereas R3R030 has $6.8 \mathrm{wt} \%$ Mo. An IRIS-3 test plate is shown for comparison that uses a lower hot rolling temperature than RERTR plates.

Table 7 IL thickness and time of $\alpha+\gamma$ ' transformation

\begin{tabular}{|c|c|c|c|}
\hline \multirow{2}{*}{$\mathrm{T}\left({ }^{\circ} \mathrm{C}\right)$} & \multicolumn{2}{|c|}{ IL growth $(\mu \mathrm{m})$} & \multirow{2}{*}{ Time (h) to $\gamma \rightarrow \alpha+\gamma^{\prime}$} \\
\cline { 2 - 3 } & $1 \mathrm{~h}$ & $3 \mathrm{~h}$ & 6 \\
\hline 425 & 1 & 2 & 4 \\
\hline 450 & 2 & 4 & 1 \\
\hline 500 & $5^{*}$ & 8 & 8 \\
\hline
\end{tabular}

* Based on INL data, probably factor of two higher.

\subsection{Irradiation test description}

In this section, the RERTR irradiation test campaigns used in this report are described. The RERTR-1 and -2 were scoping tests to select the most promising fuel alloy that has a combination of high U-density and good irradiation behavior. Based on the results, U-Mo alloy was selected.

The identification of the problem of IL growth and pore formation in the ILs in U-Mo/Al dispersion fuels, and the tests for examining the efficacy of the remedy were related to the RERTR-3, $-4,-5,-6,-7,-8$, and -9 tests.

\subsubsection{RERTR-3 test}


The RERTR-3 irradiation test began on October 7, 1999 in the ATR (Advanced Test Reactor) and ended after 48 effective full power days (EFPD) over two reactor cycles. The main purpose of this test was to investigate the critical issues of U-Mo alloy dispersion fuel at high power and temperature.

Various Mo compositions were tested in the range of 6 - $10 \mathrm{wt} \%$. Atomized U-Mo powder plates, provided from KAERI, were first tested together with ground powder plates. The average fuel particle diameter of the atomized fuel powders was $65 \mu \mathrm{m}$. The ground powders were supplied from AECL. Fuel enrichment was $19.5 \%$. The nominal meat U-density was $8 \mathrm{gU} / \mathrm{cm}^{3}$, with 6 $\mathrm{gU} / \mathrm{cm}^{3}$ for $\mathrm{U}_{3} \mathrm{Si}_{2}$ fuel plates and U-Mo fuel plates with a Mg matrix. Except for the $\mathrm{Mg}$ matrix plates, all other plates have a pure Al matrix.

The test vehicle (called a basket) comprises 6 capsules, and each capsule contains 8 test plates in tow rows. Coolant flows through the test basket from the top and to the bottom.

The plates were $41.1 \mathrm{~mm} \times 10.0 \mathrm{~mm} \times 1.52 \mathrm{~mm}$ in size and contained approximately 0.6 grams of U-Mo in the meat having $22.0 \mathrm{~mm}$ x $4.7 \mathrm{~mm}$ x $0.75 \mathrm{~mm}$ in size. Because of this small size, the RERTR-3 plates are called as 'nanoplates.'

The sizes between nanoplates used for the RERTR-3 and miniplates used for the RERTR-4, -5, 6, -7, -8 and -9 are compared in Fig. 32.
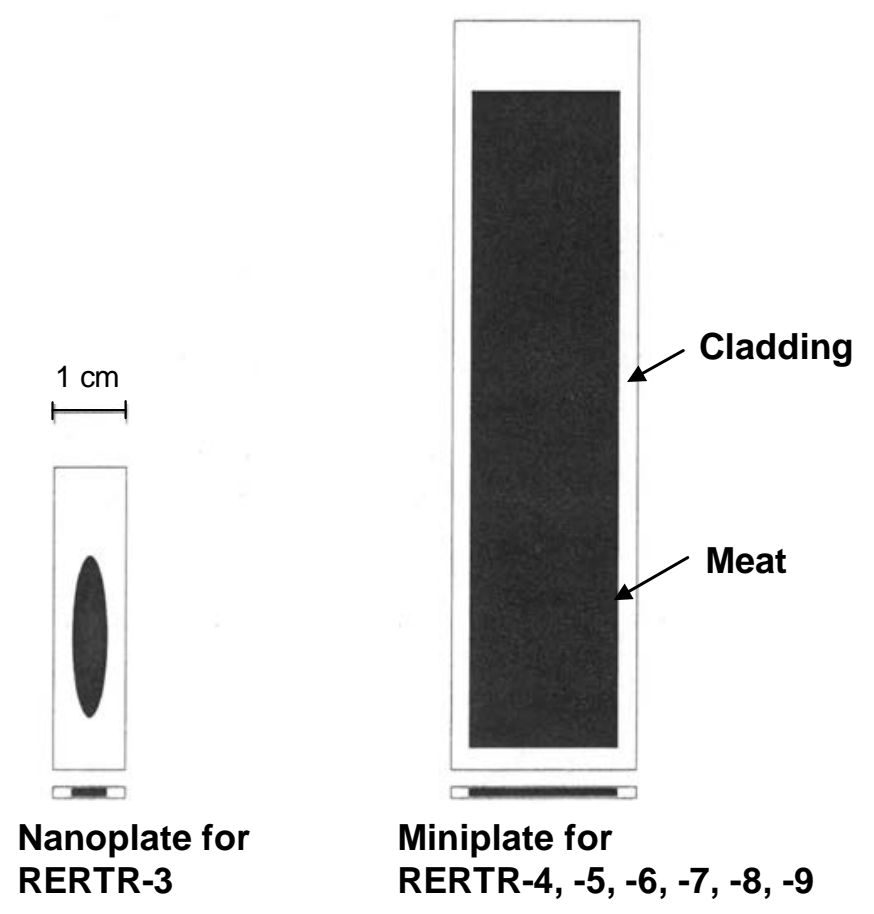

Fig. 32 Comparison of nanoplate and miniplate sizes.

\subsubsection{RERTR-4 and 5}


The RERTR-4 and 5 tests were designed with larger plates than the RERTR-3 test. The plate dimensions are $100 \mathrm{~mm}$ × $25 \mathrm{~mm}$ x $1.40 \mathrm{~mm}$, which are more prototypic of full-size test reactor fuel plates and allow for more accurate postirradiation measurements. Specifically, irradiation tests were designed to obtain intermediate temperature irradiation performance information on a variety of high density dispersion fuels, most of which were previously irradiated at lower temperature in experiments the RERTR- 1 and 2 tests and higher temperature in the RERTR-3 test. The meat size of the RERTR is $81.3 \mathrm{~mm} \times 18.5 \mathrm{~mm} \times 0.64 \mathrm{~mm}$.

The RERTR-4 and 5 plates are called as 'miniplates.' The nominal uranium loading was 6 or 8 $\mathrm{gU} / \mathrm{cm}^{3}$ in the meat, depending upon the fuel volume. The miniplates contained either atomized fuel particles from the same powder used for the RERTR-3 supplied by KAERI, or machined fuel particles supplied by AECL. Like the RERTR-3 test, the matrix was made of pure Al. Four capsules, each with 8 plates in two rows, were loaded in the test basket as shown in Fig. 33.

A schematic illustrating the miniplate test loadings is given in Fig. 32. The burnup and coolant temperature profiles over the test vehicle are also schematically shown. The bottom row B plates and the top row $\mathrm{C}$ plates achieve the highest burnups. Coolant flows downward in the ATR, so coolant temperature reaches maximum at the bottom D plates.

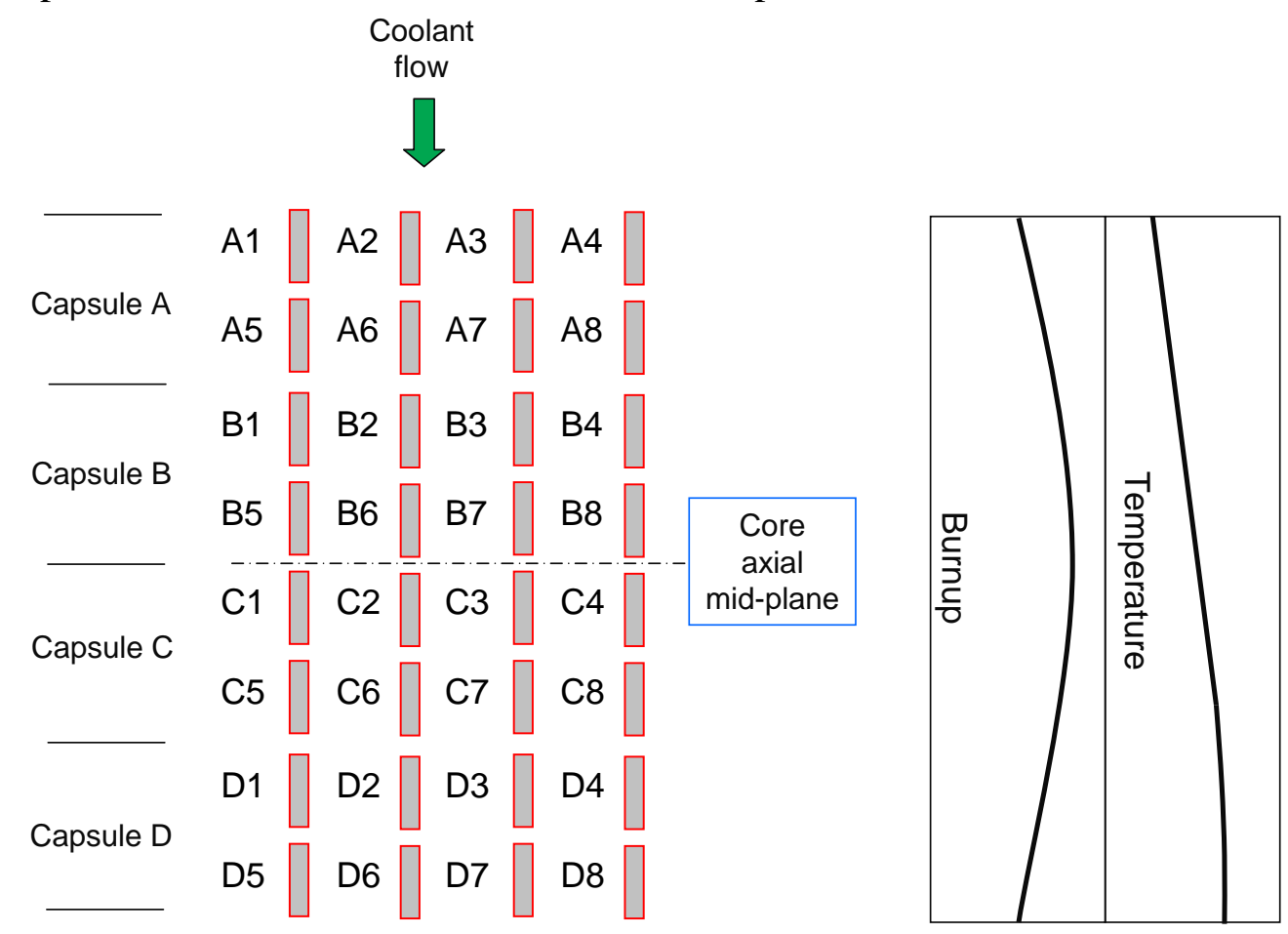

Fig. 33 Schematic of test plate loading scheme used for RERTR-4, -5, -6, -7, -8 and -9 tests.

The RERTR-4 and 5 are sibling tests; they have the same fabrication processes and similar power histories. The irradiation of these tests started in August 2000 in the ATR. The RERTR-5 test was irradiated for 116 EFPD to a peak burnup of 52\% U-235 LEU Equivalent and the RERTR-4 test 
was continued for 257 EFPD with $~ 80 \%$ U-235 LEU Equivalent burnup. The test locations in the ATR are shown in Fig. 34.

The test vehicle was loaded in the way that one of the thin sides faces the ATR core center. This loading scheme imposes non-uniform neutron flux across the plate width; the neutron flux and, therefore, the higher fission density at the end closer to the ATR core center is higher than the other end (see Fig. 35). The ratio of the fission density at the end closer to the ATR core center to that at the other end is about 2. Because of self-shielding, the ratio is higher for the internal plates than the external plates, where for example, A2 and A3 are called internal plates while A1 and A4 are external plates. The higher the enrichment, the higher the ratio the plates experience also.

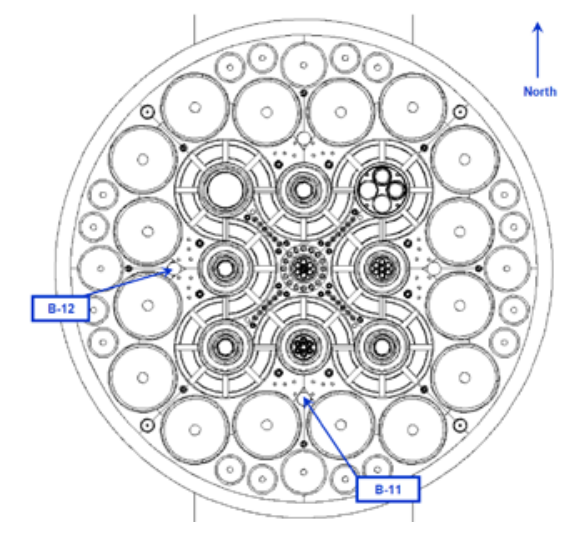

(a) ATR core cross section diagram
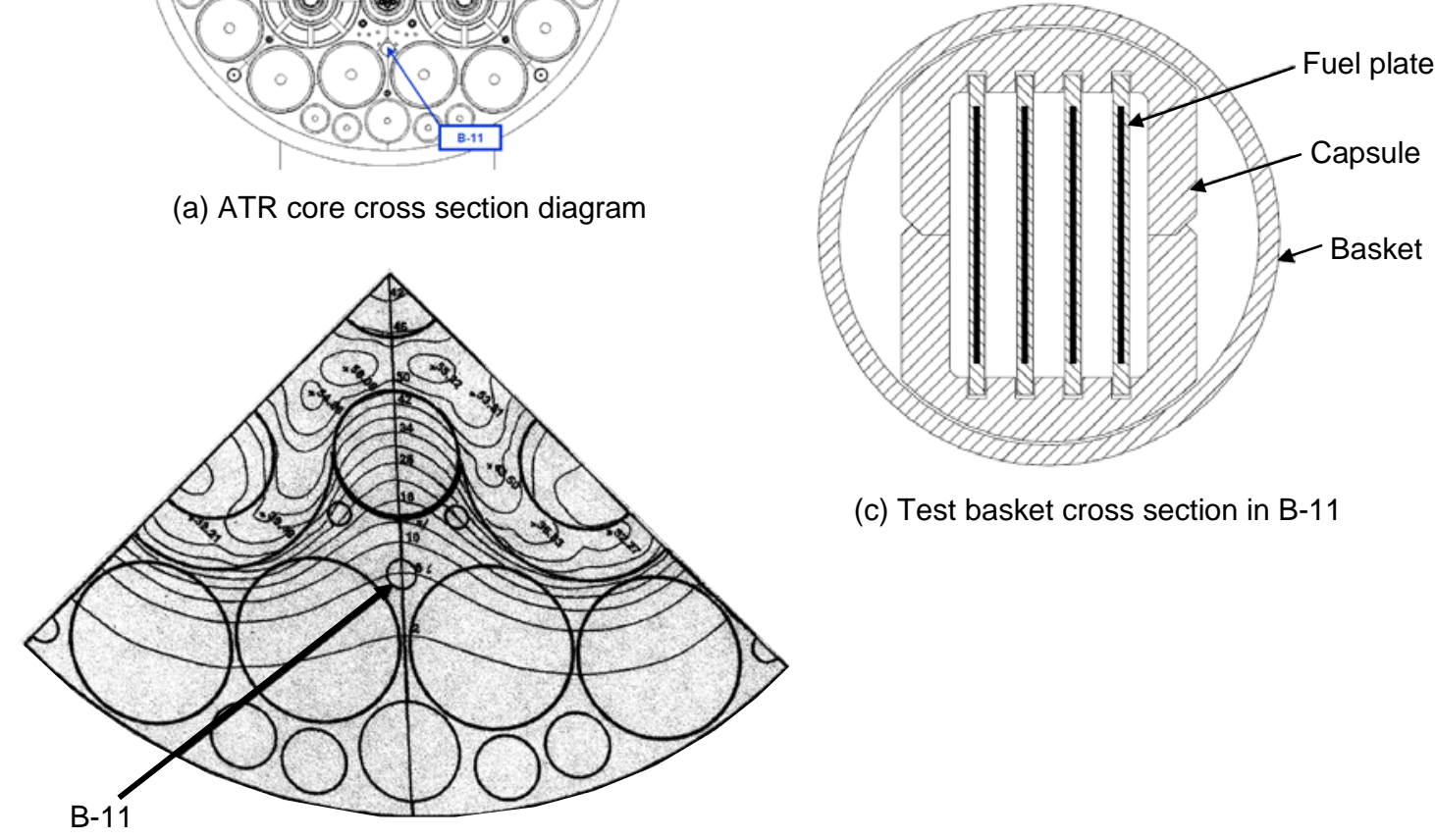

(c) Test basket cross section in B-11

(b) Quarter core including B-11 hole

Fig. 34 ATR core diagram showing the locations of RERTR-4 (B-11) and -5 (B-12) irradiation and plate loading direction in the test vehicle. (a) ATR core diagram, (b) Detailed description of the quarter core and neutron flux contours. (c) Test basket B-11 showing plate loading direction. In B-12 hole for RERTR-5, the basket is turned $90^{\circ}$. 
In order to have more uniform fission across the plate width, the test basket was flipped horizontally to switch sides for every irradiation cycle. Fig. 35 is a schematic to illustrate the change of plate loading direction and the neutron flux distribution across the meat width.

$\leftarrow$ Center of ATR core
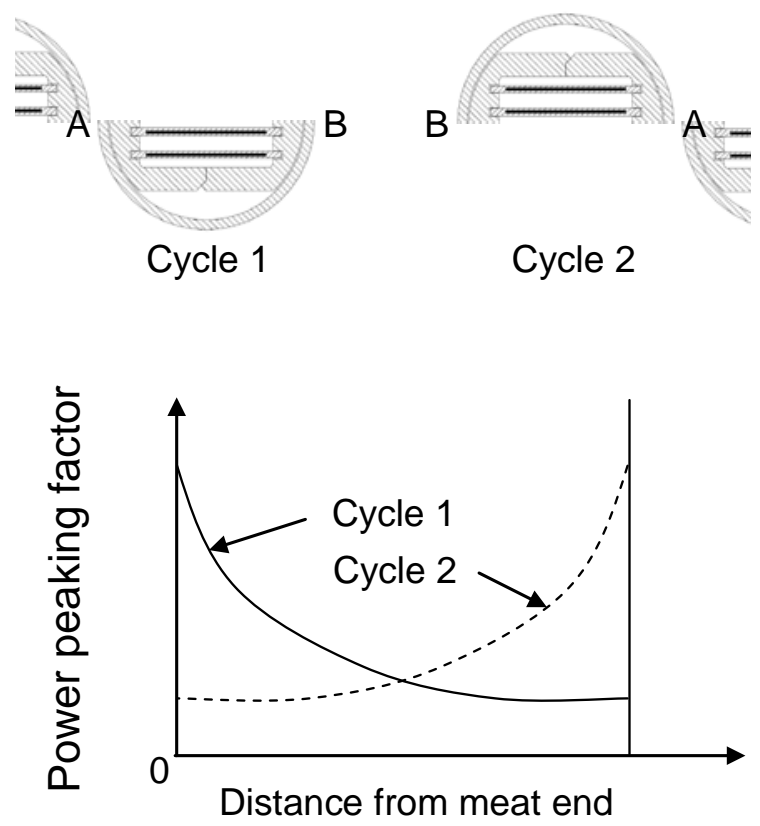

Fig. 35 Changes in plate direction and power peaking factors across the plate width by flipping of basket between cycles (RERTR-4 and -5).

\subsubsection{RERTR-6, -7, -8, -9}

The RERTR-6, -7, -8, and -9 tests are tests using miniplates with the same design used for the RERTR-4 and -5 . The fabrication process is basically the same for all these tests. The differences in irradiation and basic fabrication parameters are summarized in Table 8. 
Table 8 Summary of irradiation test data for plates of RERTR-3, -4, -5, -6, -7, -8, $-9 A$, and $-9 B$ tests

\begin{tabular}{|c|c|c|c|c|c|c|c|c|c|c|c|c|}
\hline Test & Plate ID & Pos. & $\begin{array}{l}\text { Fuel/matrix } \\
\text { composition }\end{array}$ & $\begin{array}{l}\text { Nominal } \\
\text { Meat U } \\
\text { density } \\
\mathrm{gU} / \mathrm{cm}^{3}\end{array}$ & $\begin{array}{c}\text { Enrich. } \\
\text { U-235 } \\
\%\end{array}$ & $\begin{array}{l}\text { Time } \\
\text { EFPD }\end{array}$ & $\begin{array}{c}\text { Average } \\
\text { particle } \\
\text { size } \\
\mu \mathrm{m}\end{array}$ & $\begin{array}{c}\text { FD * } \\
\mathrm{f} / \mathrm{cm}^{3} \\
\left(\mathrm{x} 10^{21}\right) \\
\text { at meat } \\
\text { hot } \\
\text { side }\end{array}$ & $\begin{array}{c}\text { FR \# } \\
f / \mathrm{cm}^{3}-5 \\
\left(x 10^{14}\right) \\
\text { at } \\
\text { Meat } \\
\text { hot } \\
\text { side }\end{array}$ & $\begin{array}{l}\mathrm{FD} * \\
\text { at } \\
\text { meat } \\
\text { cold } \\
\text { side }\end{array}$ & $\begin{array}{c}\text { FR \# } \\
\text { at } \\
\text { meat } \\
\text { cold } \\
\text { side }\end{array}$ & $\begin{array}{c}\text { BOL } \\
\text { Temp } \\
{ }^{\circ} \mathrm{C} \\
\S\end{array}$ \\
\hline RERTR-3 & V07 & A7 & $\mathrm{U}-10 \mathrm{Mo} / \mathrm{Al}$ & 8.5 & 19.5 & 48 & 65 & 2.2 & 5.2 & 2.2 & 5.2 & 122 \\
\hline \multirow{2}{*}{ Nanoplate } & R04 & $\mathrm{C} 2$ & U-7Mo/Al & 8.5 & 19.5 & 48 & 65 & 2.9 & 6.9 & 2.9 & 6.9 & 155 \\
\hline & S03 & C8 & $\mathrm{U}-6 \mathrm{Mo} / \mathrm{Al}$ & 8.5 & 19.5 & 48 & 65 & 3.0 & 7.2 & 3.0 & 7.2 & 158 \\
\hline RERTR-4 & V6001M & A1 & $\mathrm{U}-10 \mathrm{Mo} / \mathrm{Al}$ & 6 & 19.5 & 257 & 65 & 4.9 & 2.2 & 4.9 & 2.2 & 100 \\
\hline \multirow[t]{6}{*}{ Miniplate } & R6003F & B5 & U-7Mo/Al & 6 & 19.5 & 257 & 65 & 6.2 & 2.8 & 6.2 & 2.8 & 135 \\
\hline & V8006B & C2 & $\mathrm{U}-10 \mathrm{Mo} / \mathrm{Al}$ & 8 & 19.5 & 257 & 65 & 5.7 & 2.6 & 5.7 & 2.6 & 157 \\
\hline & S6004C & C6 & U-6Mo/Al & 6 & 19.5 & 257 & 65 & 6.3 & 2.8 & 6.3 & 2.8 & 137 \\
\hline & V6015G & C8 & $\mathrm{U}-10 \mathrm{Mo} / \mathrm{Al}$ & 6 & 19.5 & 257 & 65 & 5.8 & 2.6 & 5.8 & 2.6 & 143 \\
\hline & S6006C & D2 & U-6Mo/Al & 6 & 19.5 & 257 & 65 & 6.0 & 2.7 & 6.0 & 2.7 & 132 \\
\hline & V6022M & D4 & $\mathrm{U}-10 \mathrm{Mo} / \mathrm{Al}$ & 6 & 19.5 & 257 & 65 & 5.5 & 2.5 & 5.5 & 2.5 & 137 \\
\hline RERTR-5 & V6018G & A4 & $\mathrm{U}-10 \mathrm{Mo} / \mathrm{Al}$ & 6 & 19.5 & 116 & 65 & 2.4 & 2.4 & 2.4 & 2.4 & 90 \\
\hline \multirow[t]{5}{*}{ Miniplate } & V6019G & B4 & $\mathrm{U}-10 \mathrm{Mo} / \mathrm{Al}$ & 6 & 19.5 & 116 & 65 & 3.1 & 3.1 & 3.1 & 3.1 & 111 \\
\hline & S8007L & B6 & U-6Mo/Al & 8 & 19.5 & 116 & 65 & 3.2 & 3.2 & 3.2 & 3.2 & 120 \\
\hline & R8002E & B7 & $\mathrm{U}-7 \mathrm{Mo} / \mathrm{Al}$ & 8 & 19.5 & 116 & 65 & 3.0 & 3.0 & 3.0 & 3.0 & 126 \\
\hline & S6010D & C6 & U-6Mo/Al & 6 & 19.5 & 116 & 65 & 3.5 & 3.5 & 3.5 & 3.5 & 119 \\
\hline & V8005B & D8 & $\mathrm{U}-10 \mathrm{Mo} / \mathrm{Al}$ & 8 & 19.5 & 116 & 65 & 2.5 & 2.5 & 2.5 & 2.5 & 120 \\
\hline RERTR-6 & R1R010 & A2 & $\mathrm{U}-7 \mathrm{Mo} / \mathrm{Al}-0.9 \mathrm{Si}$ & 6 & 19.5 & 135 & 65 & 3.4 & 2.9 & 2.4 & 2.0 & 101 \\
\hline \multirow[t]{5}{*}{ Miniplate } & R2R020 & B2 & U-7Mo/Al-2Si & 6 & 19.4 & 135 & 65 & 3.9 & 3.3 & 2.6 & 2.2 & 110 \\
\hline & R3R030 & B5 & $\mathrm{U}-7 \mathrm{Mo} / \mathrm{Al}-5 \mathrm{Si}$ & 6 & 19.1 & 135 & 65 & 3.8 & 3.3 & 2.6 & 2.3 & 118 \\
\hline & R2R010 & C3 & $\mathrm{U}-7 \mathrm{Mo} / \mathrm{Al}-2 \mathrm{Si}$ & 6 & 19.4 & 135 & 65 & 4.0 & 3.4 & 2.7 & 2.3 & 116 \\
\hline & R5R020 & C5 & $\mathrm{U}-7 \mathrm{Mo} / \mathrm{Al}-0.2 \mathrm{Si}$ & 6 & 19.1 & 135 & 65 & 3.9 & 3.3 & 2.7 & 2.3 & 124 \\
\hline & V1R010 & D3 & $\mathrm{U}-10 \mathrm{Mo} / \mathrm{Al}-0.9 \mathrm{Si}$ & 6 & 19.2 & 135 & 65 & 3.7 & 3.2 & 2.5 & 2.2 & 124 \\
\hline RERTR-7 & R3R040 & A5 & U-7Mo/Al-5Si & 6 & 58.3 & 90 & 80 & 5.7 & 7.3 & 3.8 & 4.9 & 145 \\
\hline \multirow[t]{6}{*}{ Miniplate } & R2R040 & B2 & $\mathrm{U}-7 \mathrm{Mo} / \mathrm{Al}-2 \mathrm{Si}$ & 6 & 58.2 & 90 & 75 & 5.8 & 7.5 & 3.4 & 4.4 & 140 \\
\hline & R0R010 & B3 & U-7Mo/Al & 6 & 58.1 & 90 & 140 & 5.7 & 7.3 & 3.3 & 4.2 & 141 \\
\hline & V5R050 & B6 & $\mathrm{U}-10 \mathrm{Mo} / \mathrm{Al}-0.2 \mathrm{Si}$ & 6 & 58.0 & 90 & 90 & 5.7 & 7.3 & 3.4 & 4.3 & 150 \\
\hline & R3R050 & C7 & U-7Mo/Al-5Si & 6 & 58.2 & 90 & 135 & 5.9 & 7.6 & 3.4 & 4.4 & 149 \\
\hline & R0R020 & D3 & U-7Mo/Al & 6 & 58.1 & 90 & 135 & 7.2 & 9.3 & 4.7 & 6.1 & 176 \\
\hline & R2R050 & D8 & U-7Mo/Al-2Si & 6 & 58.2 & 90 & 90 & 5.3 & 6.8 & 3.4 & 4.4 & 149 \\
\hline RERTR-8 & D3R030 & $\mathrm{C} 5$ & U-7Mo-1Ti/Al-5Si & 6 & 58.1 & 105 & 80 & 6.9 & 7.6 & 4.5 & 5.0 & 164 \\
\hline Miniplate & F3R040 & C8 & U-7Mo-2Zr/Al-5Si & 6 & 58.1 & 105 & 80 & 6.7 & 7.4 & 4.3 & 4.7 & 163 \\
\hline RERTR-9 & R2R088 & B6 & U-7Mo/Al-2Si & 8.5 & 58.1 & 115 & 50 & 8.2 & 8.3 & 4.8 & 4.9 & 155 \\
\hline \multirow[t]{4}{*}{ Miniplate } & R6R018 & B7 & U-7Mo/Al-3.5Si & 8.5 & 58.1 & 115 & 50 & 8.3 & 8.4 & 4.9 & 5.0 & 157 \\
\hline & R3R108 & $\mathrm{C} 2$ & U-7Mo/Al-5Si & 8 & 44.4 & 98 & 50 & 5.5 & 5.5 & 3.1 & 3.1 & 130 \\
\hline & R2R078 & C3 & $\mathrm{U}-7 \mathrm{Mo} / \mathrm{Al}-2 \mathrm{Si}$ & 8 & 44.4 & 98 & 50 & 5.4 & 5.4 & 3.2 & 3.2 & 131 \\
\hline & R4R018 & C7 & $\mathrm{U}-7 \mathrm{Mo} / \mathrm{Al}-2 \mathrm{Si}$ & 8 & 44.4 & 98 & 50 & 5.2 & 5.3 & 3.1 & 3.2 & 132 \\
\hline
\end{tabular}

* In fuel particles

\# In fuel particles averaged over life, including fission by Pu.

$\S$ At plate center

$\ddagger$ In hot-side region 
The test basket was not flipped between cycles for the RERTR-6, -7, -8 and -9, so the meat end closer to the ATR core center achieved considerably higher burnup than the other end. The EOL burnup distributions across the plate width are compared between the tests in Fig. 36. The RERTR-3 has the most uniform burnup because of its smallest size although the plates were not flipped. The RERTR-4 and -5, with flipped sides, have relatively uniform burnup distributions. Among the tests with no flipping, the RERTR-6 (LEU fuel) has less non-uniformity than the RERTR-7, -8, and -9 (HEU fuel), because of less self-shielding.

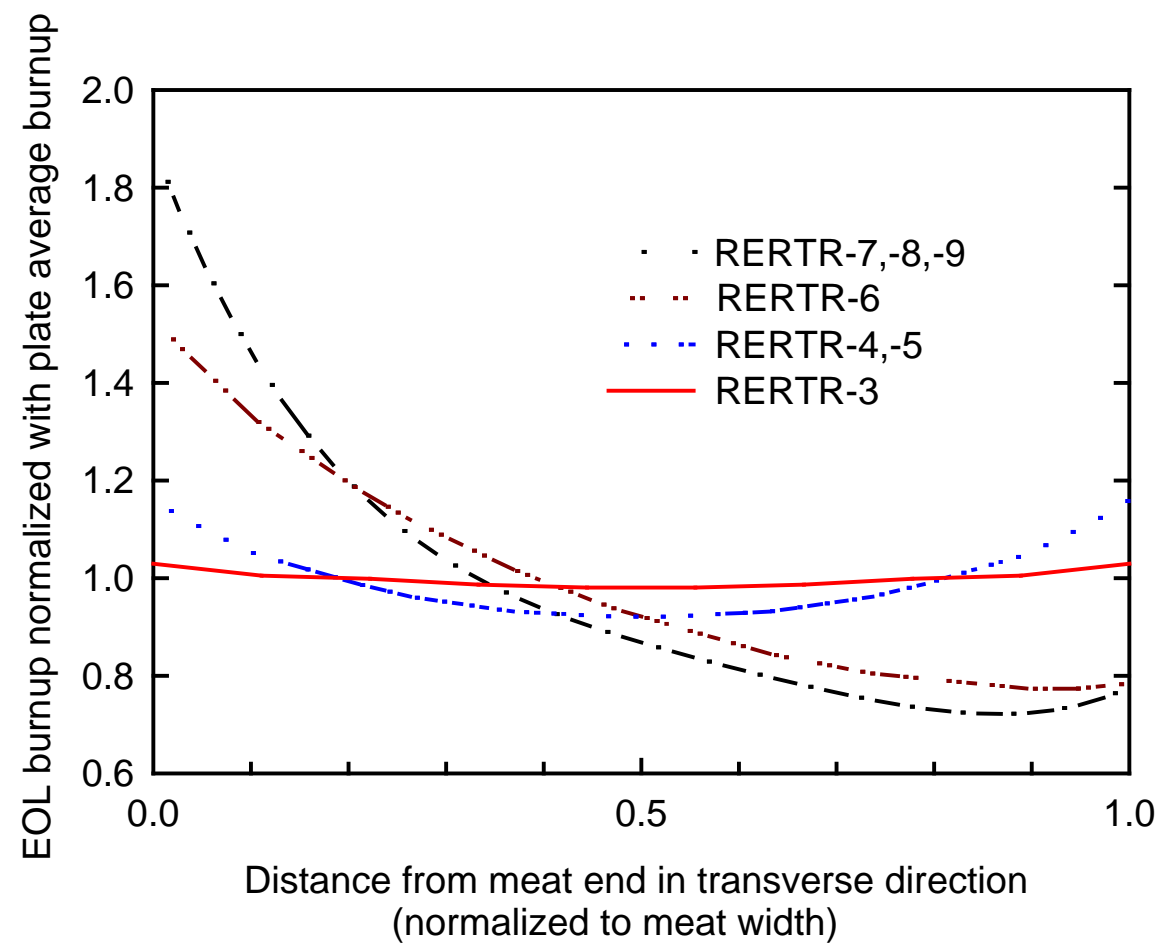

Fig. 36 EOL burnup distributions across the meat width for RERTR-3, -4, -5, -6, -7, -8 , and -9 .

The RERTR-6 test is the first in-pile test of plates with silicon additions. The fabrication process, plate (meat) size, powder were the same as those for the RERTR-4 and 5. The matrixes with various Si concentrations were tried.

The RERTR-7 test is a designed to obtain higher burnup than the RERTR-6 in a short irradiation time; hence, higher enrichment and fission rates were adopted.

Powders used for the test were fabricated in INL using a rotating electrode method. The U-Mo is instantaneously heated to melting and the particles are cooled while flying. The fuel melt does not reach a super heat state. In contrast, the KAERI method uses a super heated melt poured on a rotating disk, which probably provides more homogeneous alloy particles. The INL equipment is smaller than the KAERI facility, so a shorter cooling time during particle flying. This results in slightly a different microstructure in fuel particles from the KAERI powder. For example, 
columnar grain structures, typical in KAERI powders, are not observed in the INL powders. The INL powders were used for the RERTR-8 and -9 also.

The RERTR-8 is the test included plates with $\mathrm{Ti}$ or $\mathrm{Zr}$ addition in the fuel particles and simultaneously with Si-added matrixes.

The RERTR-9 is the highest burnup test of all the RERTR tests. The high power locations in some plates achieved burnups beyond 100\% U-235 LEU equivalent. The effect of silicon addition was systematically tested with side-by-side plates with different Si contents.

The fission rate histories of plates of the RERTR tests are compared in Fig. 37.

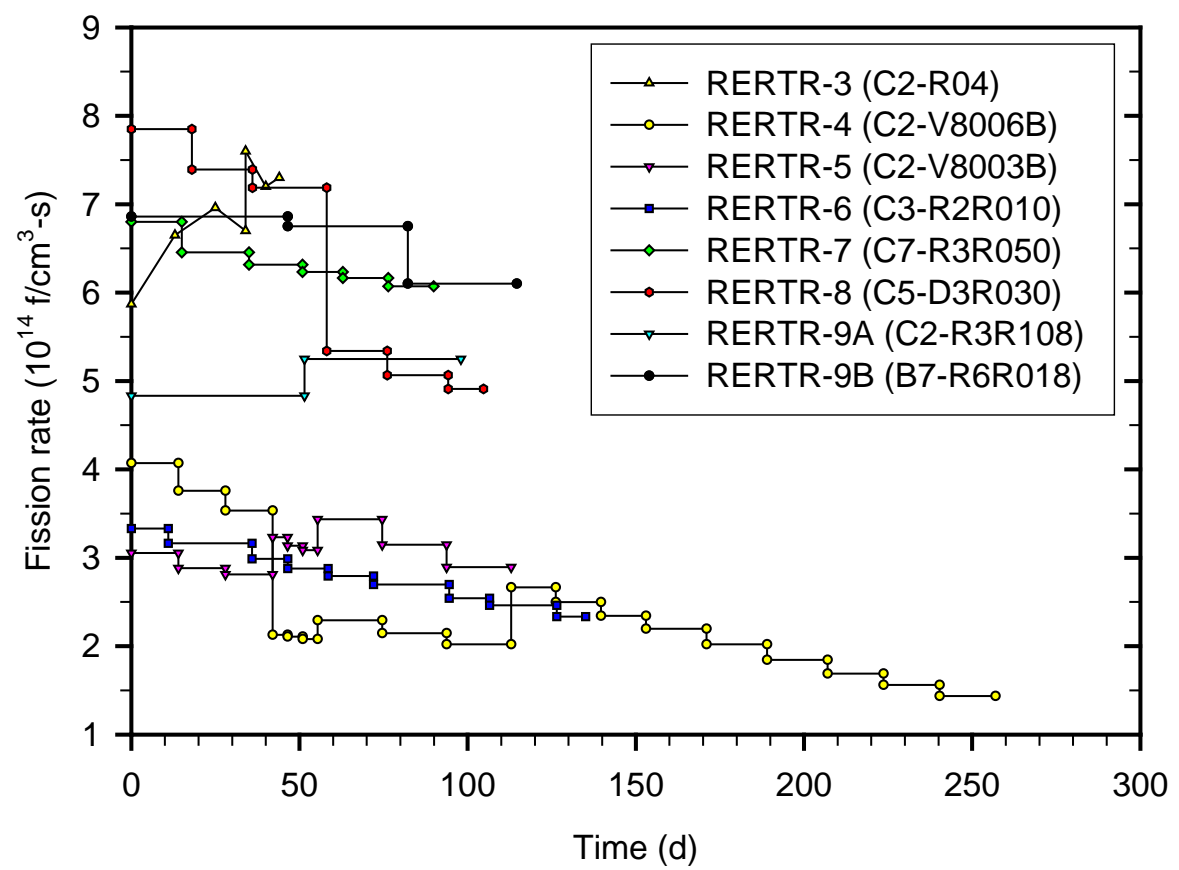

Fig. 37 Fission rate histories (meat average in the fuel particles) of RERTR-3, -4, -5, 6, $-7,-8$ and -9 tests. Fission by Pu not included.

\subsection{Test plate PIE method}

Some plates from each irradiation test were metallographically examined. From the view point of IL growth and pore formation in the IL, optical micrography served as a major method. The test plate is cut on the axial mid-plane. One of the exposed cross section, i.e., a transverse cross section, was metallographed. Three locations, hot side, cold side and middle, on the transverse cross section were examined. On the higher power side that was closer to the ATR core center, for RERTR-6, -7, -8, and -9, the location is designated as 'hot side,' for the other side it is called 'cold side.' These locations are equidistance, $5.1 \mathrm{~mm}$, from the plate transverse center as shown in Fig. 38. For the plates irradiated in the RERTR-3, -4 , and -5 , only two locations, plate middle and location $5.1 \mathrm{~mm}$ apart from the center, are examined. 
For the RERTR-3 having nanoplates, optical micrography was performed at the transverse center.
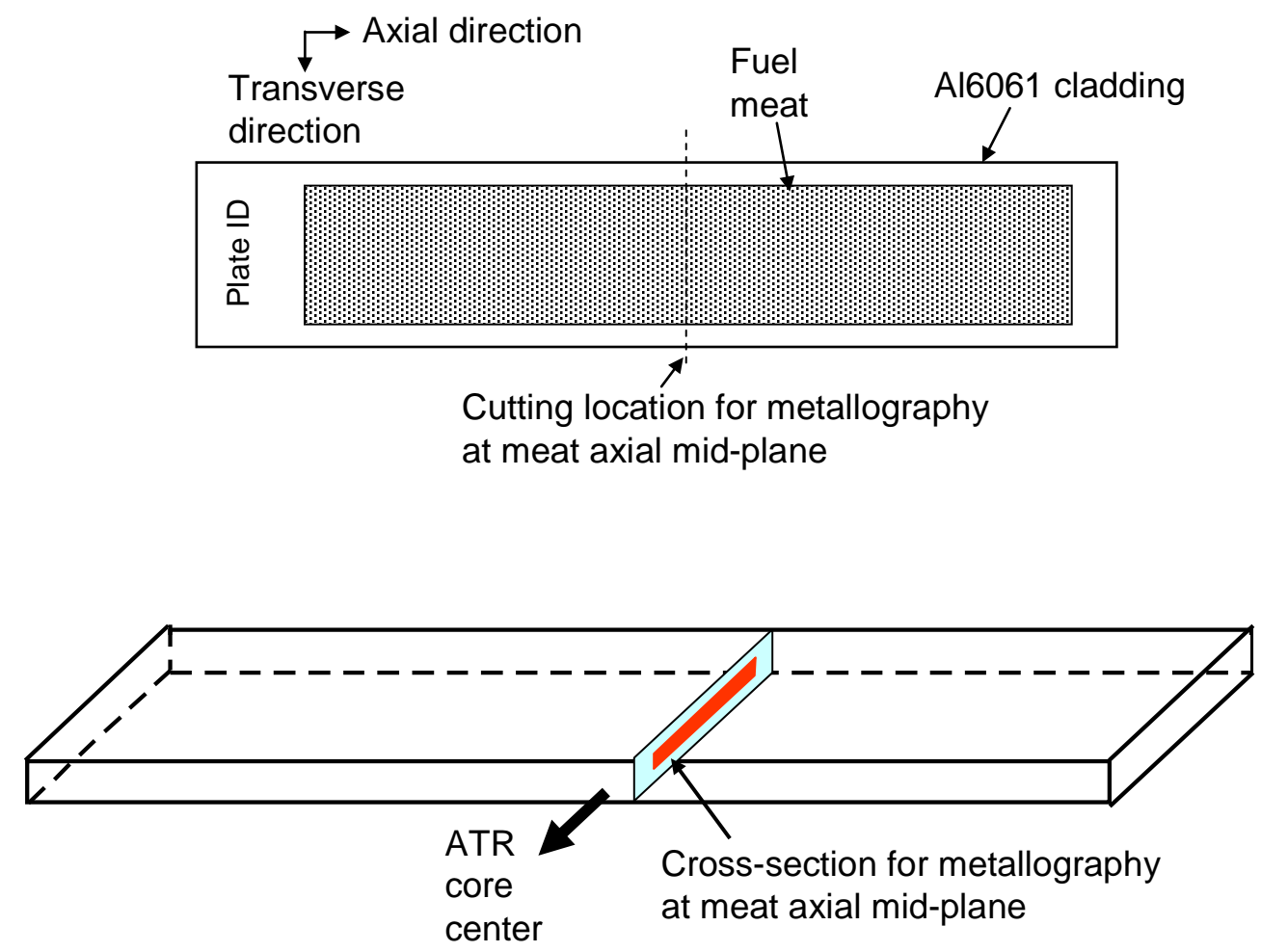

(a) Miniplate transverse cross section diagram

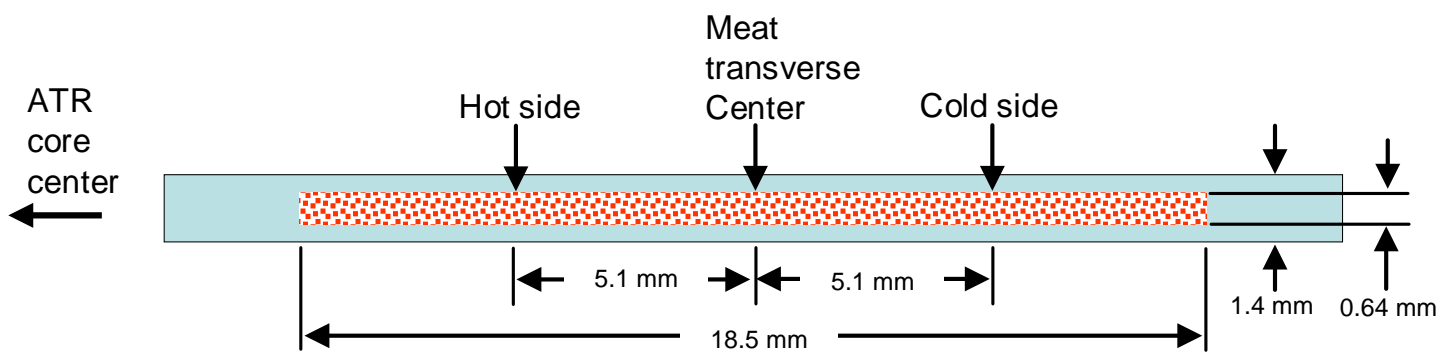

(b) Typical metallography locations on transverse cross section of miniplates.

Fig. 38 Schematic diagrams showing PIE locations for miniplates.

\subsubsection{Optical Microscopy}

The samples are mounted in electrically conductive mounts and then prepared by grinding and polished using procedures for aluminum clad dispersion fuels. Micrographs are made at magnification 50x, 100x, 200x, and 500x. Micrographs taken at $2500 \mathrm{x}$ is to show the relative areal fraction of the fuel, interaction zones and matrix. 


\subsubsection{Interaction layer thickness measurement}

From an optical microscopy photo, several interaction layer thicknesses are measured and the average value is used as the nominal value. The method to obtain the true interaction layer thickness is illustrated in Fig. 39.

For the cut surface A, L1 is not the true interaction layer thickness. If B is the cut surface, L2 is the correct interaction layer thickness. Generally, on a metallographic picture, the thinnest interaction layer in a spot is more likely to give the true interaction layer thickness because it is more likely to be on the equator of the fuel particle.

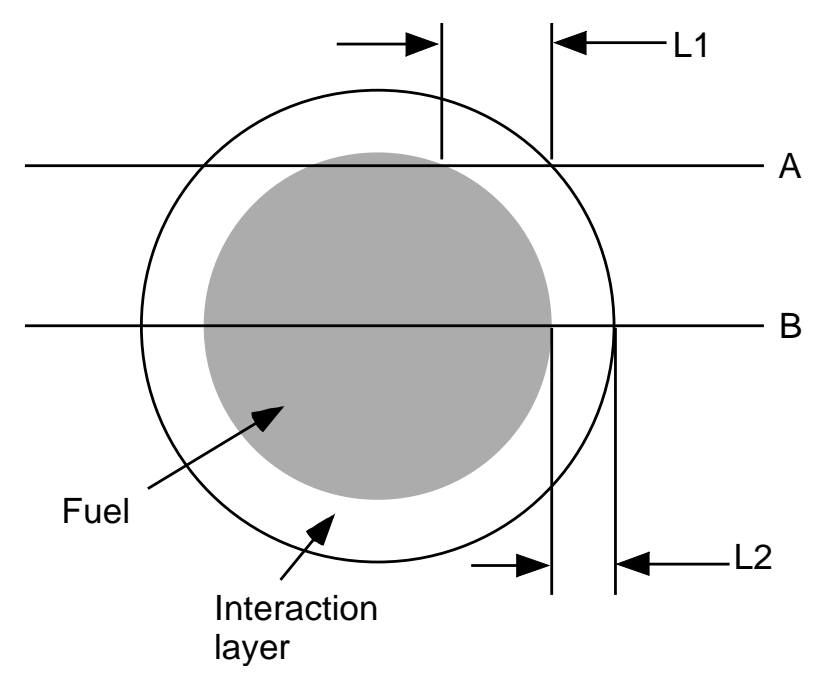

Fig. 39 Schematic of metallographic surface to obtain interaction layer thickness. A and $\mathrm{B}$ are cutting planes.

\subsubsection{Interaction layer volume measurement}

The IL volume fraction is obtained manually by using the point counting method [60]. The IL volume fraction is obtained by counting the number of grid points lying on the ILs from transparent square grids superimposed on the micrograph and dividing the number by the total number of grids. A simple example of the point counting method is shown in Fig. 40. The number of grids enclosed by the ILs is 6 and the total number of meshes of the grid is 49. Therefore, the volume fraction of the ILs is $6 / 49=0.12$. The accuracy of the method increases if the grid gets finer. 


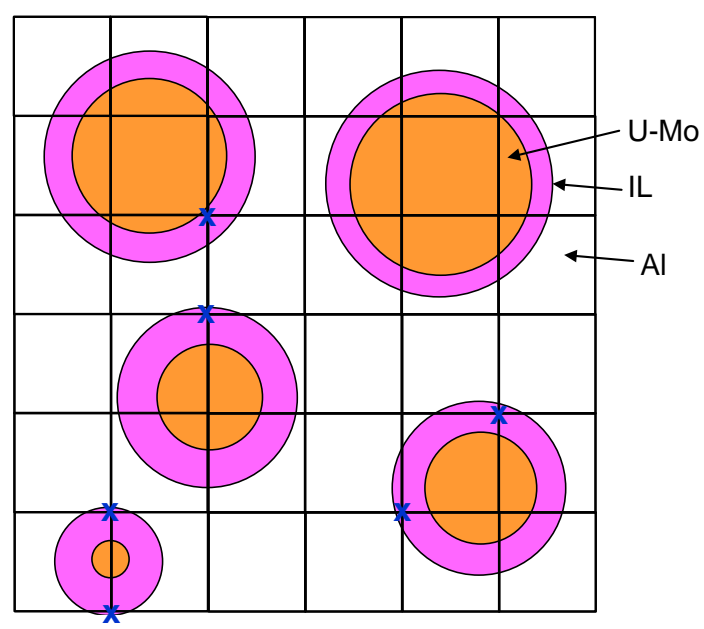

Fig. 40 Schematic of an optical micrograph with superimposed grids.

A commercially available computer software Image Pro Plus ${ }^{\mathrm{TM}}$ is sometimes used to obtain more accurate results. However, the point counting method serves as a reliable base with reasonable accuracy.

\subsubsection{SEM and TEM}

Post-irradiation examination also includes scanning electron microscopy. The sample for SEM is punched out of the plate for a $1.6 \mathrm{~mm}$ diameter disk, sandwiched by Al cladding, and then split in half to expose the fuel zone.

The SEM work performed at the ANL AGHCF for RERTR-3, -4 and -5 . MFC INL started to SEM on the RERTR-6, and TEM work also.

\subsection{In-pile Test Results}

\subsubsection{IL thickness reduction}

The first PIE results examining the effect of Si addition on IL thickness reduction and pore formation during irradiation was reported for the RERTR-6 test in the 2006 RERTR meeting [61,62]. The confirmation of the positive effect of Si addition was reported when the PIE of the higher burnup test REERTR-7 was available than the RERTR-6 [63]. A side-by-side test plate comparison was shown later in RRFM 2009 based on populated data including a variety of Si content from the RERTR-6, -7, and -9 [64].

The effect of the Si addition to the matrix for suppressing IL growth is clearly distinguishable when the pairs of side-by-side test plates are juxtaposed. Figures $41-44$ are optical micrographs comparing the IL thicknesses of the plates irradiated side-by-side (see the schematic diagram shown in Fig. 38 for the cold and hot side locations). The plate pairs from each test have similar irradiation conditions, so comparable. 
In the figures, the right-hand side plate is higher in Si concentration than the left-hand side plate. The IL thickness in the right-hand side plate is always thinner than the left-hand side plate.

The ILs of Si-added plates are commonly uneven and the thicknesses are different among neighboring particles. This is due to the local difference of the IL growth rate caused by the nonuniform Si diffusion and consequently non-uniform Si concentration in the IL. Furthermore, for the fuel particles in densely populated regions, the available amount of Si is effectively restricted by the region enclosed by the fuel particles. This is also a cause for local heterogeneity in IL thickness.

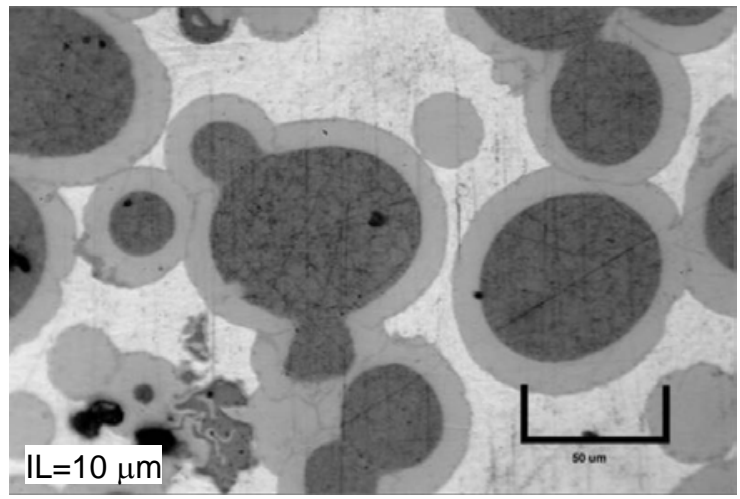

$\mathrm{U}-7 \mathrm{Mo} / \mathrm{Al}-0.2 \mathrm{Si}$

R5R020 (C5)

$\mathrm{BU}=40 \%$

Cold side

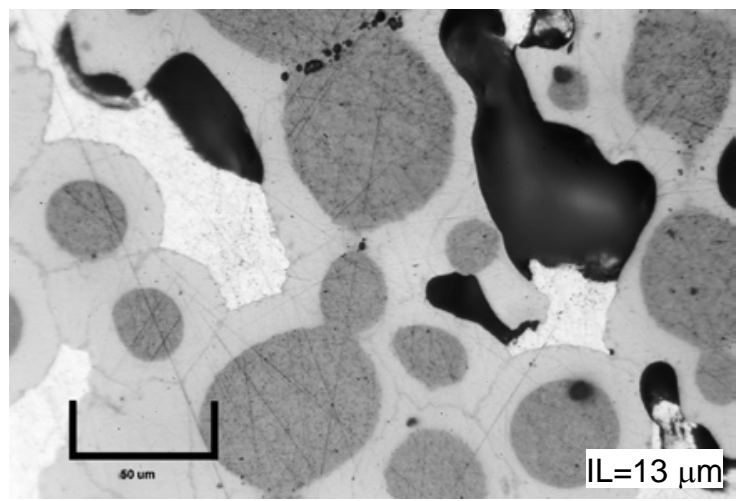

$\mathrm{U}-7 \mathrm{Mo} / \mathrm{Al}-0.2 \mathrm{Si}$

R5R020 (C5)

$\mathrm{BU}=60 \%$

Hot side

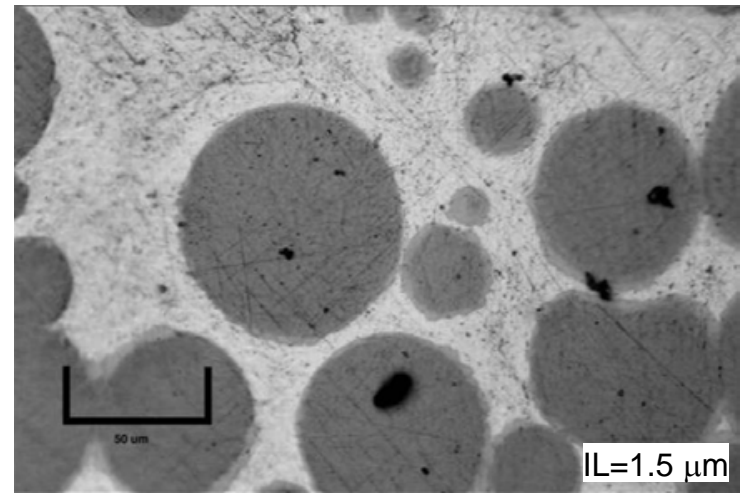

U-7Mo/Al-2Si

R2R010 (C3)

$\mathrm{BU}=38 \%$

Cold side

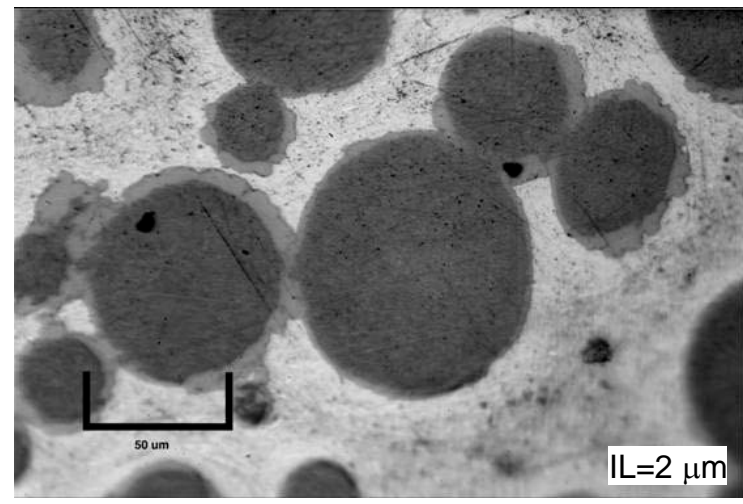

$\mathrm{U}-7 \mathrm{Mo} / \mathrm{Al}-2 \mathrm{Si}$

R2R010 (C3)

$\mathrm{BU}=57 \%$

Hot side

Fig. 41 Optical micrographs of test plates from RERTR-6. IL is IL thickness. The number in front of Si represents Si concentration in weight \%. BU is given LEU Equiv. 


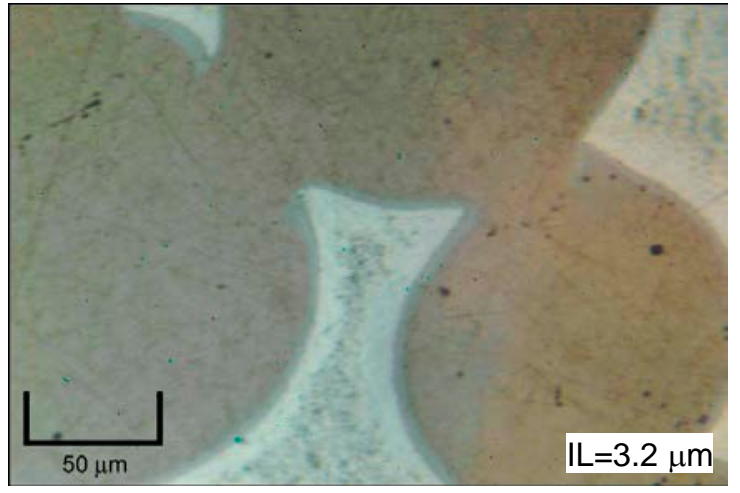

$\mathrm{U}-7 \mathrm{Mo} / \mathrm{Al}-0.1 \mathrm{Si}$

R0R010 (B3)

$\mathrm{BU}=52 \%$

Cold side

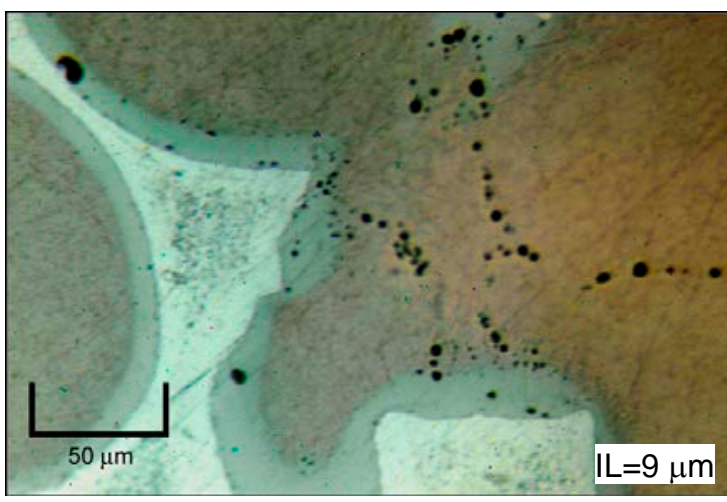

U-7Mo/Al-0.1Si

R0R010 (B3)

$\mathrm{BU}=86 \%$

Hot side

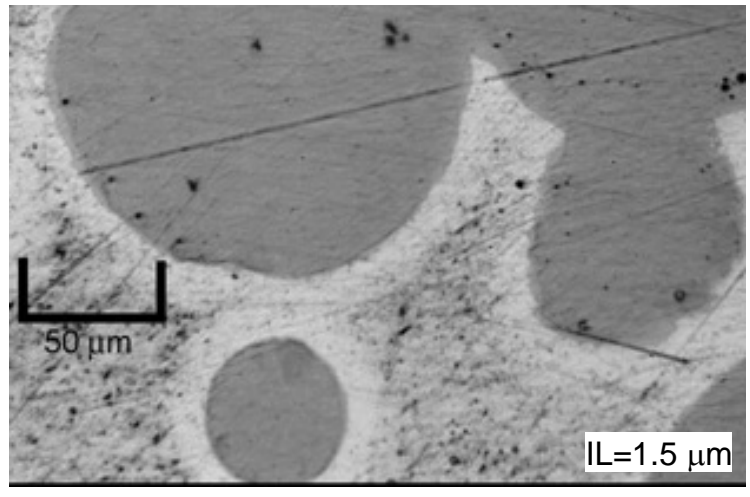

U-7Mo/Al-2Si

R2R040 (B2)

$\mathrm{BU}=52 \%$

Cold side

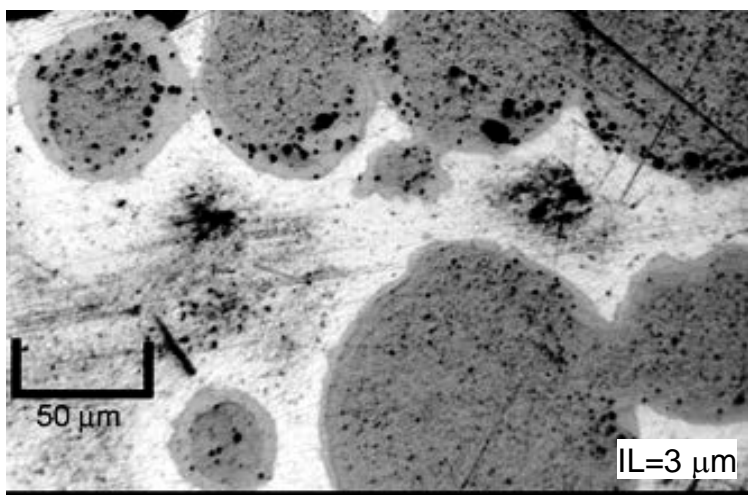

U-7Mo/Al-2Si

R2R040 (B2)

$\mathrm{BU}=86 \%$

Hot side

Fig. 42 Optical micrographs of test plates from RERTR-7. BU is U-235 LEU equivalent burnup. IL is IL thickness. The number in front of Si represents Si concentration in weight \%. BU is given LEU Equiv. 


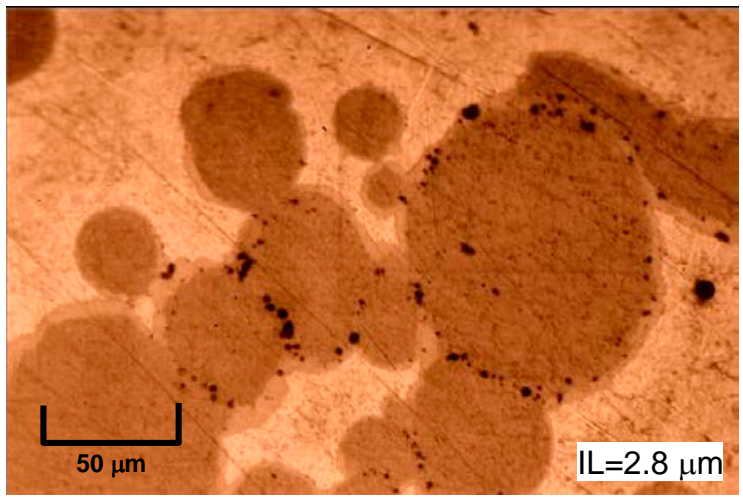

$\mathrm{U}-7 \mathrm{Mo} / \mathrm{Al}-2 \mathrm{Si}$

R2R078 (C3)

$\mathrm{BU}=45 \%$

Cold side

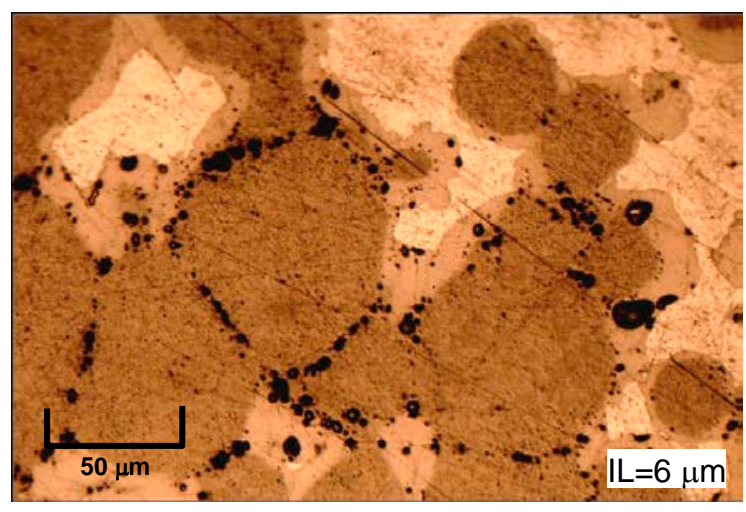

U-7Mo/Al-2Si

R2R078 (C3)

$\mathrm{BU}=78 \%$

Hot side

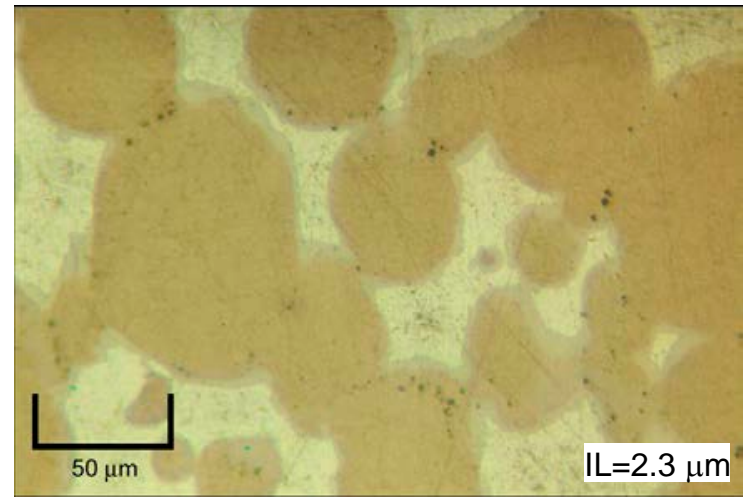

U-7Mo/Al-5Si

R3R108 (C2)

$\mathrm{BU}=45 \%$

Cold side

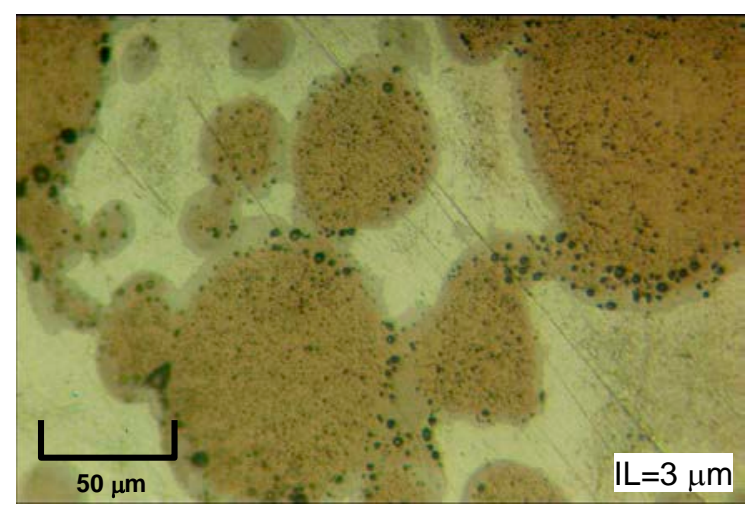

U-7Mo/Al-5Si

R3R108 (C2)

$\mathrm{BU}=78 \%$

Hot side

Fig. 43 Optical micrographs of test plates from RERTR-9A. BU is U-235 LEU equivalent burnup. IL is IL thickness. The number in front of Si represents Si concentration in weight \%. BU is given LEU Equiv. 


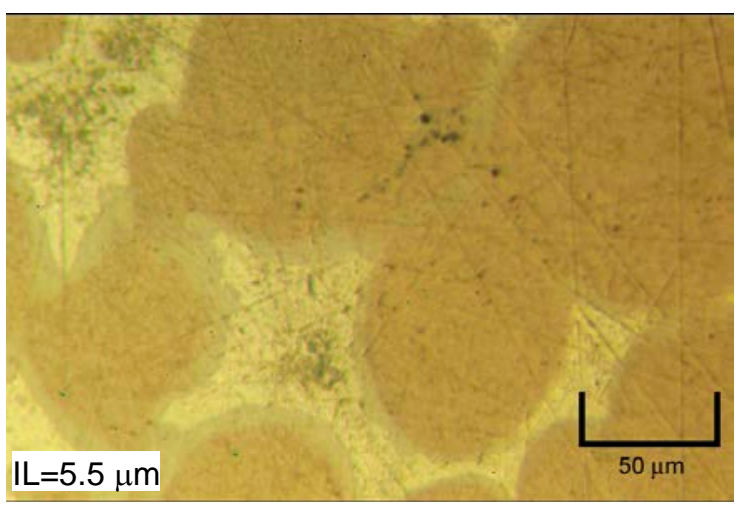

$\mathrm{U}-7 \mathrm{Mo} / \mathrm{Al}-2 \mathrm{Si}$

R2R088 (B6)

$\mathrm{BU}=69 \%$

Cold side

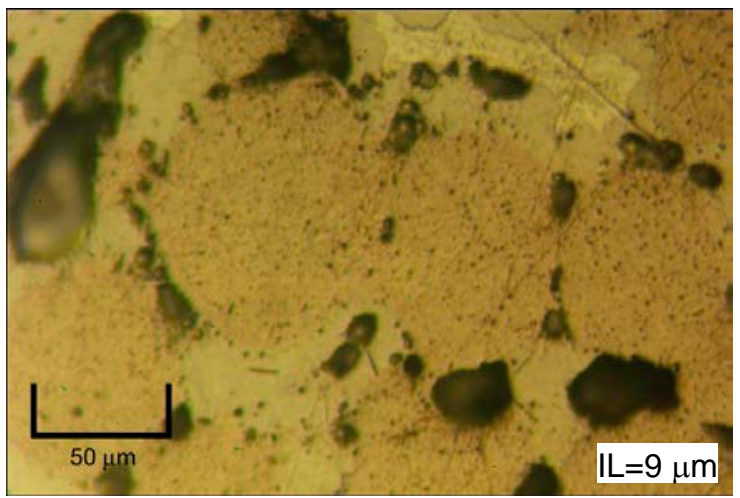

$\mathrm{U}-7 \mathrm{Mo} / \mathrm{Al}-2 \mathrm{Si}$

R2R088 (B6)

$\mathrm{BU}=119 \%$

Hot side

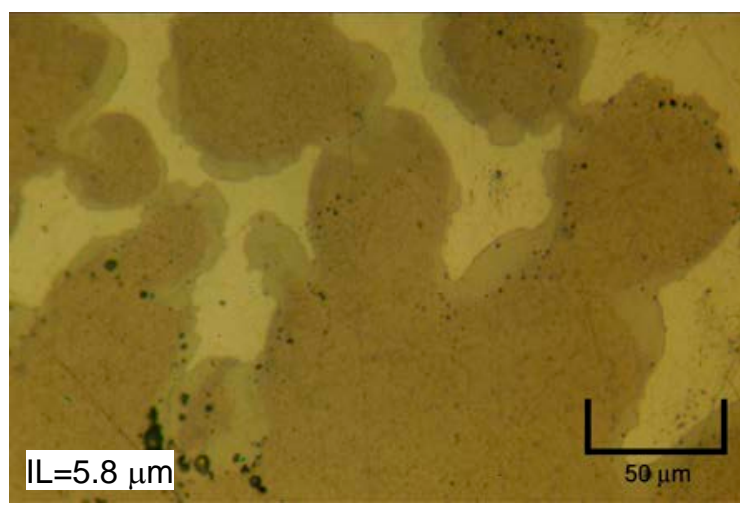

$\mathrm{U}-7 \mathrm{Mo} / \mathrm{Al}-3.5 \mathrm{Si}$

R6R018 (B7)

$\mathrm{BU}=69 \%$

Cold side

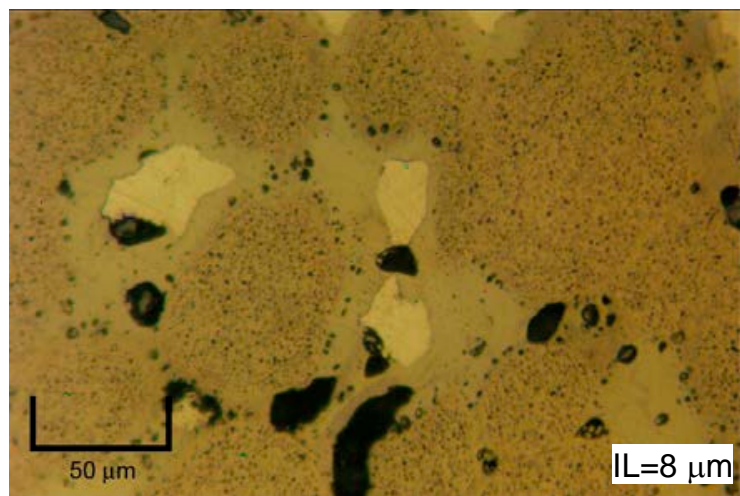

$\mathrm{U}-7 \mathrm{Mo} / \mathrm{Al}-3.5 \mathrm{Si}$

R6R018 (B7)

$\mathrm{BU}=119 \%$

Hot side

Fig. 44 OM taken from the cold side of test plates from RERTR-9B. BU is U-235 LEU equivalent burnup. IL is IL thickness. The number in front of Si represents Si concentration in weight \%. BU is given LEU Equiv. 
The Si effect on the IL thickness reduction was quantized using the RERTR-6 test plates with the Si concentration range of 0.1 to $4.8 \mathrm{wt} \%$ [62]. Figure 45 shows the fission rate histories, temperature histories, and the corresponding reduction factors of IL thickness by Si addition. The 'reduction factors' is defined as the ratio of measured IL thickness for a Si-added plate to IL thickness calculated for the pure-Al plate at the same irradiation condition. For calculation of the IL thickness for the pure Al plates, the ANL IL growth correlation [62,65] is used. In the calculation, we do not remove the temperature effect; however, the Si effect in Fig. 45(c) is clearly shown.

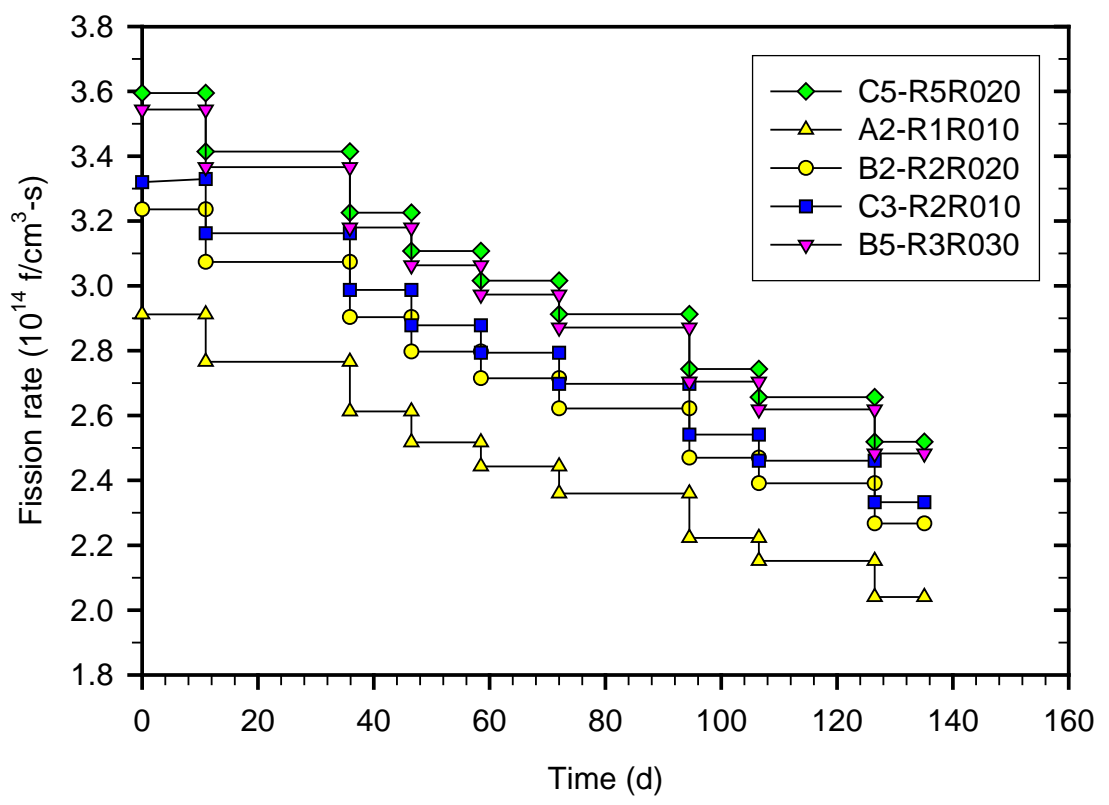

(a) Meat-average fission rate histories in fuel particles

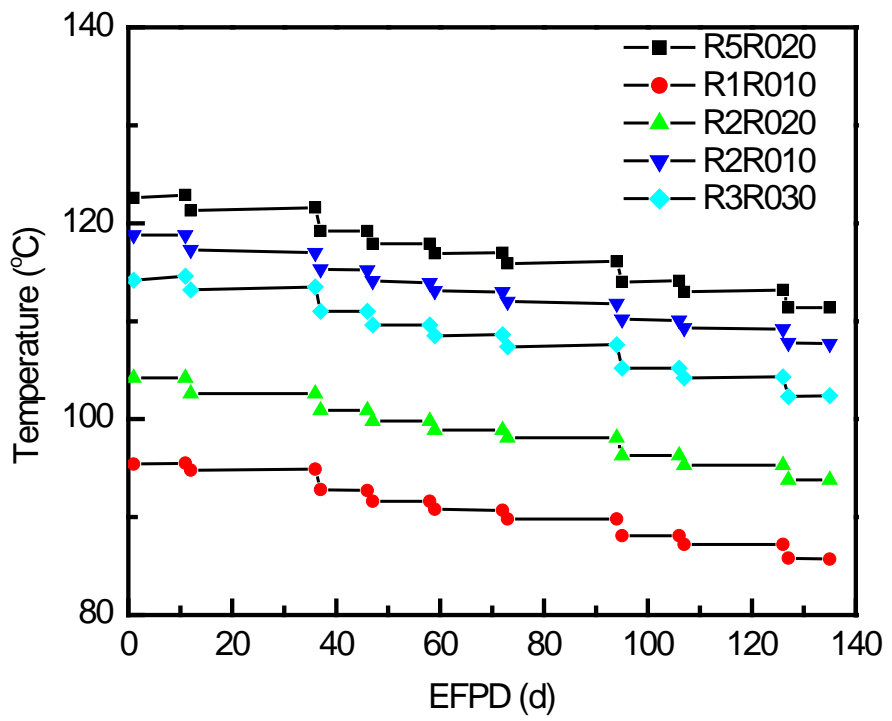

(b) Temperature at plate center

Fig. 45 Effect of Si addition on IL thickness for RERTR-6 plates. 


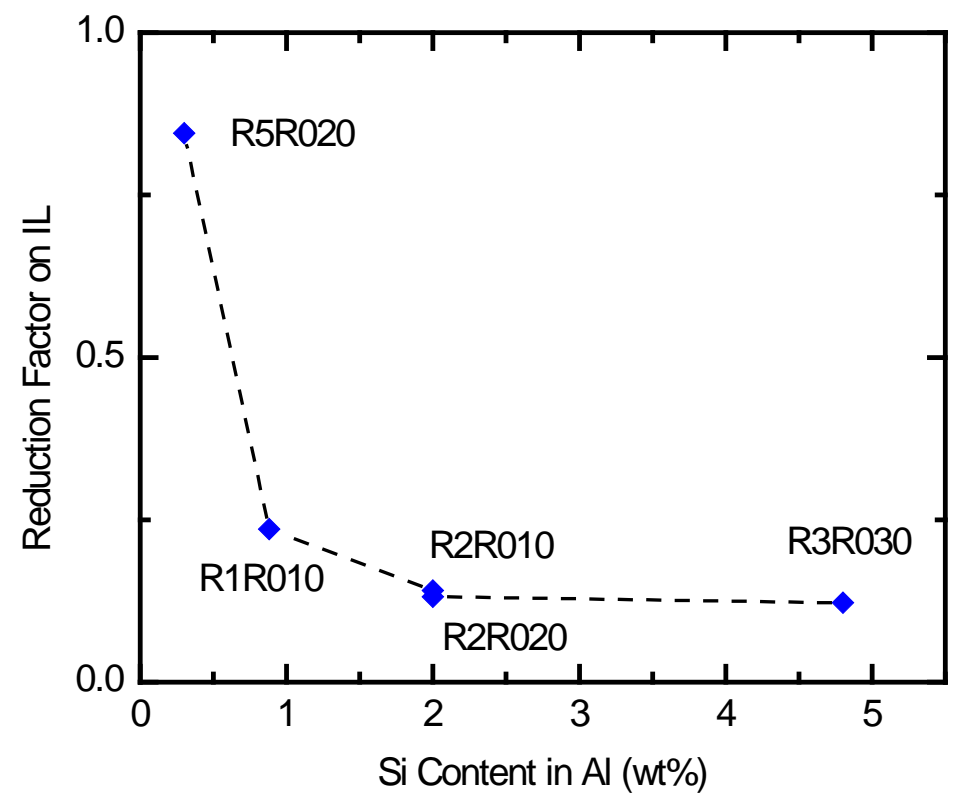

(c) IL thickness reduction factor by Si addition. The 'reduction factors' is defined as the ratio of measured IL thickness for a Si-added plate to IL thickness calculated for the pure-Al plate at the same irradiation condition.

Fig. 45 Effect of Si addition on IL thickness for RERTR-6 plates (continued).

The Si-added plates have generally thinner ILs than the pure-Al plates. However, it is also noticeable that the Si-added plates have irregular ILs. In particular, some ILs are locally extremely thin. The IL thickness in this case is virtually invariant from that formed during fabrication (see section 4 and subsection 5.1). Van den Berghe et al. observed that the thin ILs, compared to other thick ILs around, were frequently observed near a Si precipitate [66]. This evidently tells that the $\mathrm{Si}$ added $\mathrm{IL}$ is an effective barrier against $\mathrm{Al}$ diffusion, and that $\mathrm{Si}$ diffusion is localized. According to Jue and Keiser [67], the IL formed during fabrication also showed identical behavior. The ILs formed during fabrication of the French test that Van den Berghe reported are thinner because of lower fabrication temperature than the RERTR test.

\subsubsection{Delayed pore formation in IL in U-Mo/Al-Si}

The benefit of Si addition is also observed in pore formation. Pore formation in ILs was delayed considerable duration in burnup in Si added plates. As shown in Fig. 46, pore formation in ILs is delayed substantially when $2 \mathrm{wt} \% \mathrm{Si}$ is added. Compared to the image of R5R020 on the hot side from the RERTR-6 shown in Fig. 41 and V6022M from the RERTR-4 shown in Fig. 4, the delay of pore formation in R2R040 on the hot side is remarkable up to such a high burnup ( 90 LEU Equiv. BU). The reduced IL thickness and increase in IL stability are believed to be the contributors for the improvement. 
The in-pile test of Si-added plates showed that the break-away fission gas pore formation (Type A) in ILs (see Fig. 4) solved. Instead, it appears that another kind fission gas bubble formation has surfaced. Large bubbles formed (Type B) in the U-Mo fuel itself at the periphery of the fuel particles (Fig. 47(b)), contrarily to the interaction layer (Fig. 47(a)). Accelerated growth and interlinking of these pores appear to yield large pores at the fuel periphery, still different from the pores in the ILs. At burnup values of $100 \%$ LEU equivalent BU, both type pores formed (Fig. 47(c)). Type B pores are confined locally and therefore they provide less potential for fuel failure than Type A pores. Furthermore, they do not form until full LEU burnup. Type B pores appear, therefore, not to present an obvious performance issue as LEU fuel is not driven to such high fission densities. However, at very high burnup, Type A pores also form as the Si concentration generally decreases below the Si deficient state in the ILs.

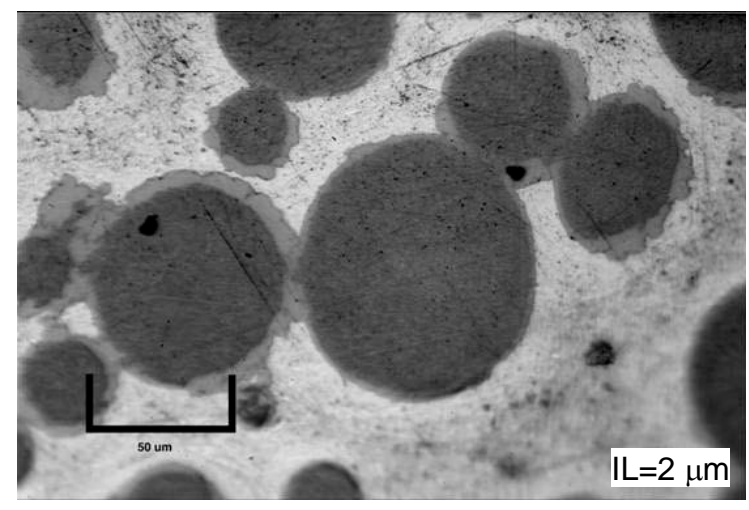

U-7Mo/Al-2Si

R2R010 (C3)

RERTR-6

$\mathrm{BU}=57 \%$

Hot side

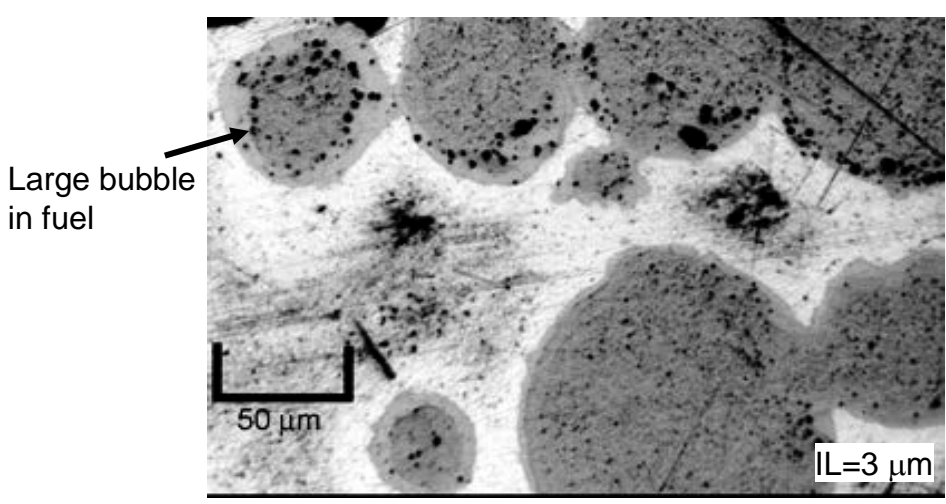

U-7Mo/Al-2Si

R2R040 (B2)

RERTR-7

$\mathrm{BU}=86 \%$

Hot side

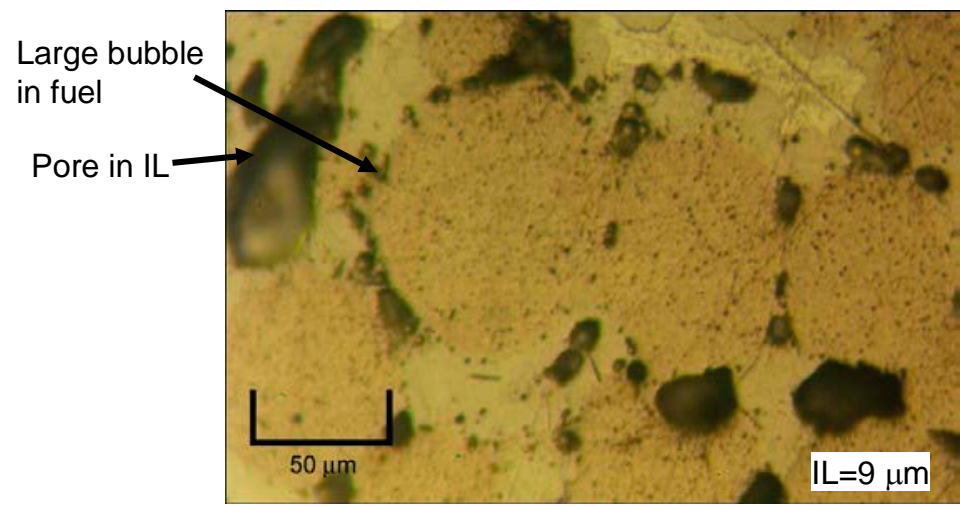

$\mathrm{U}-7 \mathrm{Mo} / \mathrm{Al}-2 \mathrm{Si}$

R2R088 (B6)

RERTR-9B

BU $=119 \%$

Hot side

Fig. 46 Optical micrographs showing fuel microstructures. 

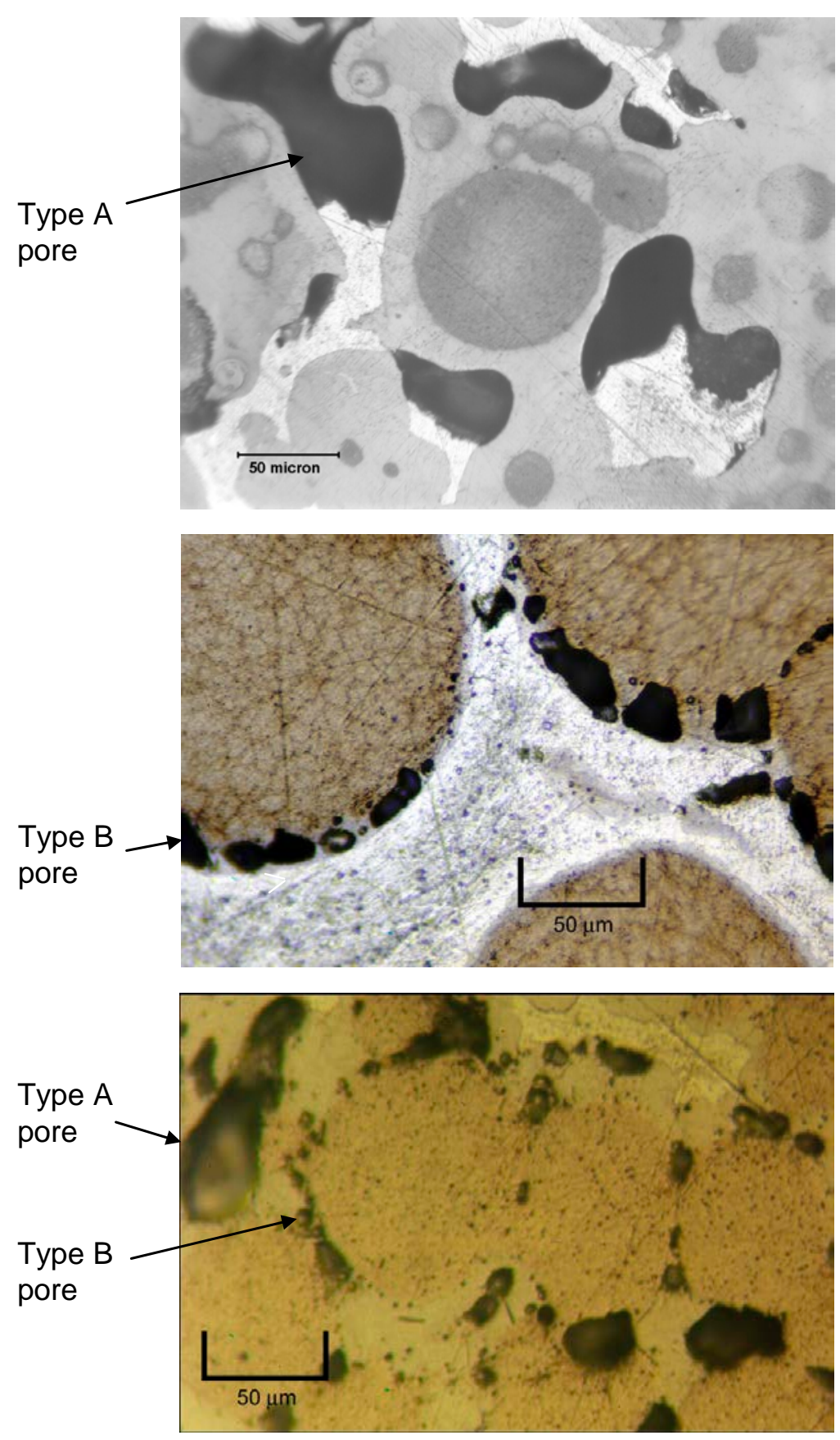

(a) V6022M-D4 78\% LEU Equiv BU $5.5 \times 10^{21} \mathrm{f} / \mathrm{cm}^{3}$ $\mathrm{U}-10 \mathrm{Mo} / \mathrm{Al}$ RERTR-4

(b) R3R050-C7 Hot side 88\% LEU Equiv BU $5.9 \times 10^{21} \mathrm{f} / \mathrm{cm}^{3}$ U-7Mo/Al-5Si RERTR-7

Fig. 47 Comparison of pore morphology in dispersion plates at different burnups.

The fission yield of transition metals is substantial that could change the chemistry of the fuel alloy at high burnup. The most likely one, in terms of yield ( 0.32 per U-235 fission) and its known destabilizing effect on the U-Mo $\gamma$ phase stability, is $\mathrm{Zr}$. Zr is known to reduce the $\gamma$ stabilizing power of Mo by forming $\mathrm{ZrMo}_{2}$ [56]. This effect is shown in the TTT diagrams in Fig. 26 and can be expressed in terms of the $\mathrm{Zr}$ /Mo ratio in the alloy. Because of the higher fission yield of $\mathrm{Zr}$ compared to Mo, this ratio increases with burnup. This is shown in Fig. 47 for U-Mo 
and U-Mo-2Zr together with the $\gamma \rightarrow \alpha+\gamma^{\prime}$ transformation time derived from the TTT diagram shown in Fig. 27. The TTT curves do not extend to the lower temperatures prevailing in the irradiation, and do not include the stabilizing effects of the high fission rate in the fuel. However, they illustrate the dramatic effect of the $\mathrm{Zr} / \mathrm{Mo}$ ratio on the metastability of the U-Mo alloy.

As far as the appearance of gas bubbles at the fuel particle periphery is concerned, it has been shown by electron microprobe examination that the fission product $\mathrm{Zr}$ migrates to the fuel particle surface during irradiation [68-70]. Therefore, a high $\mathrm{Zr}$ /Mo ratio may occur initially at the fuel particle periphery.

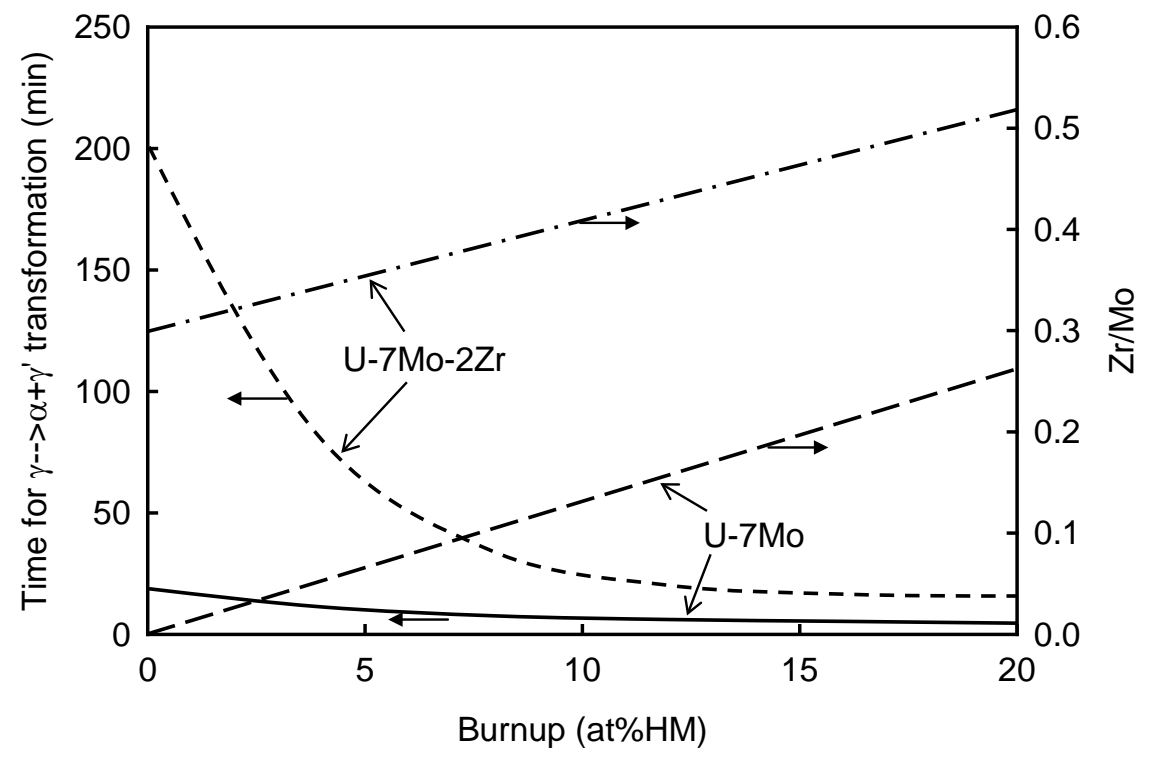

Fig. 48 Change in $\mathrm{Zr} / \mathrm{Mo}$ ratio as a function of burnup and time of $\gamma \rightarrow \alpha+\gamma^{\prime}$ transformation for U-7Mo and U-7Mo-2Zr alloys at $450^{\circ} \mathrm{C}$. (No irradiation effects considered.)

\subsubsection{Effect of Ti and Zr addition in U-Mo}

The effect of $\mathrm{Ti}$ or Zr addition in U-Mo dispersion in an Al-5Si matrix was in-pile tested in the RERTR-8, of which the PIE analysis results were reported previously [71]. Micrographs taken at two locations, one on the higher-power side and the other on the lower-power side, indicated in Fig. 38 are shown in Fig. 49. For comparison, micrographs of R3R050 from the RERTR-7 test, which was irradiated at similar condition, is also shown.

The additions of $\mathrm{Ti}$ and $\mathrm{Zr}$ in combination with $\mathrm{Si}$ added to the matrix $\mathrm{Al}$ had been shown, in exreactor diffusion couple tests [53,58,59], to reduce the extent of fuel-matrix interdiffusion more than with Si alone. As indicated in Fig. 49, there appears to be a beneficial effect of adding Ti and $\mathrm{Zr}$ also from the irradiation, albeit small in absolute terms, because of the overwhelming 
reduction in interaction due to $\mathrm{Si}$ alone. It remains to be seen if the effect of $\mathrm{Ti}$ or $\mathrm{Zr}$ is more pronounced at lower Si additions.

Of the three miniplates shown in Fig. 49, F3R040 containing U-7Mo-2Zr is the only plate showing large fission gas bubbles in the interior regions of the fuel particles, presumably because of its initial high $\mathrm{Zr} / \mathrm{Mo}$ ratio (see the discussion in the previous subsection for the disadvantageous effect of Zr contained in U-Mo). Plate D3R030 containing Ti has a similar peripheral porosity as the U-7Mo plate without Ti. This appears consistent with the negligible fission yield of Ti and its lack of effect on the $\gamma$ stability of U-Mo [72].

As the above discussion is merely a hypothesis, only detailed micro-chemical analysis can improve our understanding of the metallurgy underlying this fission gas bubble phenomenon. In addition, future tests with monolithic miniplates containing various barrier layers between U-Mo foils and $\mathrm{Al}$ cladding, viz., $\mathrm{Zr}, \mathrm{Nb}$ and Mo, should provide important clues. In the interim, based on the above discussion, starting with as high a Mo content as practicable, i.e., 10 or $12 \mathrm{wt} \%$ as a means of maintaining a low $\mathrm{Zr} / \mathrm{Mo}$ ratio is recommended.
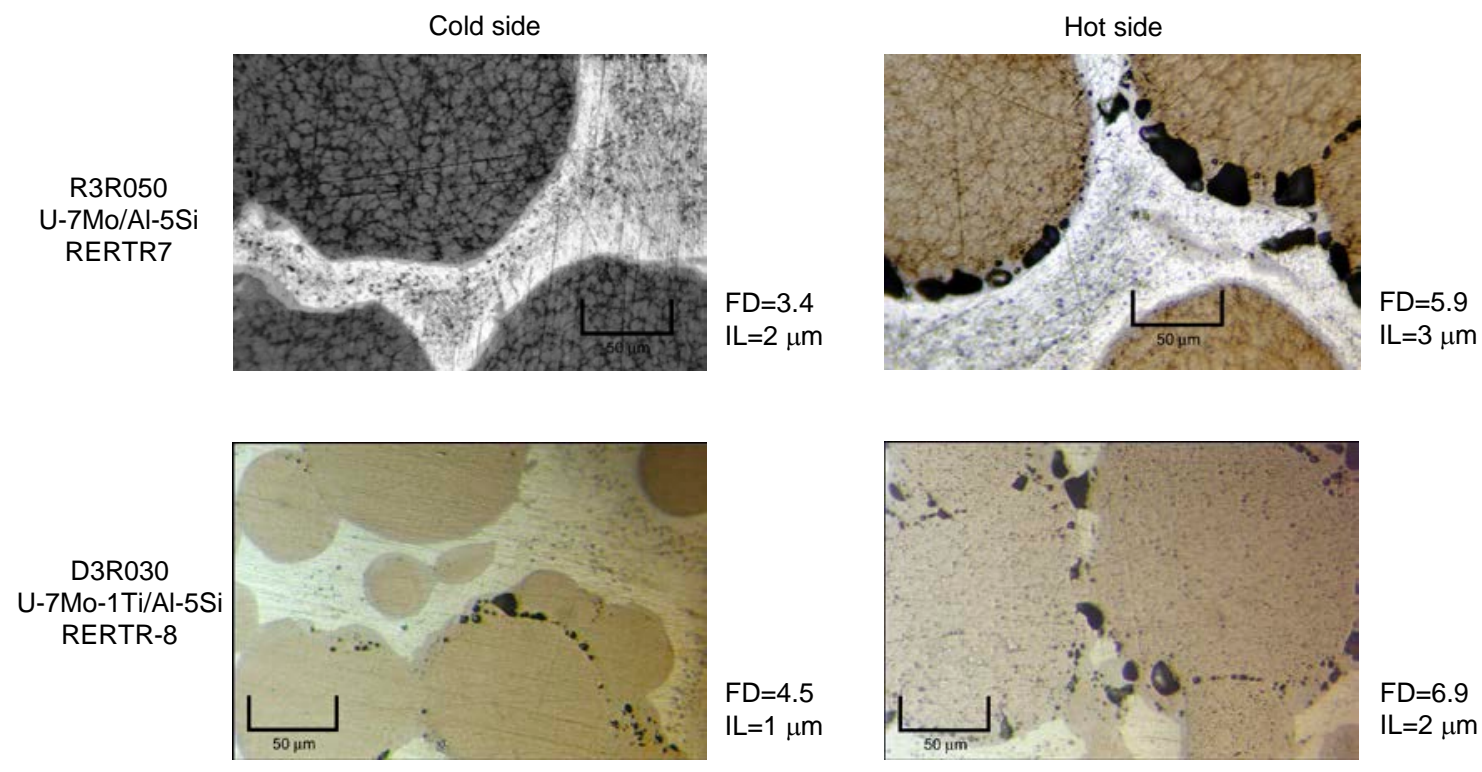

$\mathrm{FD}=6.9$ $\mathrm{IL}=2 \mu \mathrm{m}$
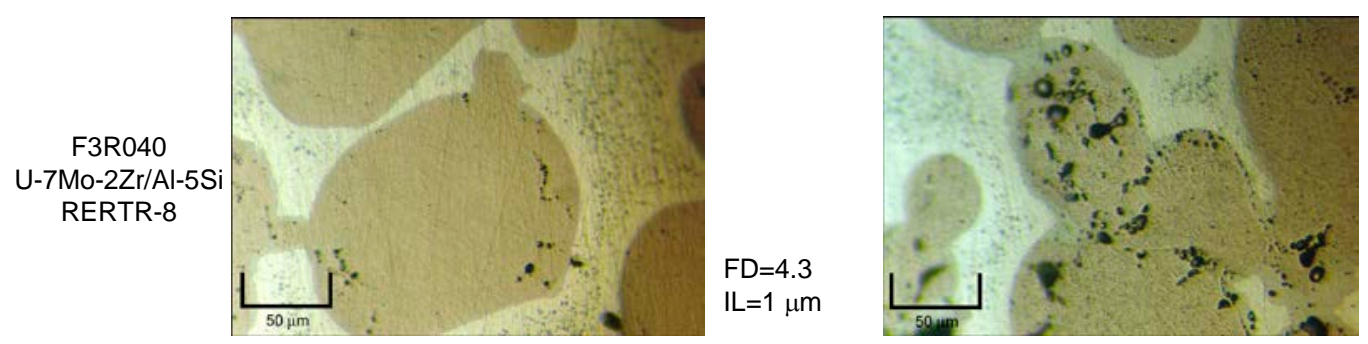

$\mathrm{FD}=6.7$ $\mathrm{IL}=2 \mu \mathrm{m}$

Fig. 49 Comparison of post-irradiation microstructures in U-7Mo/Al-5Si, U-7Mo1Ti/Al-5Si and U-7Mo-2Zr/Al-5Si. FD is the fission density in $10^{21} \mathrm{f} / \mathrm{cm}^{3}$ fuel particle. 


\subsubsection{Si diffusion to IL during irradiation}

Si diffusion to IL under thermal annealing is clearly shown in section 4; the result is the Siprecipitate denuded zone formed near the IL. At the irradiation temperature of $\sim 100{ }^{\circ} \mathrm{C}$, however, thermally driven Si diffusion is negligible. Only possible source of energy that can be provided to activate Si diffusion is by fission product recoil from the fuel particles.

Figure 50 is an image showing fuel cross section of R3R030 irradiated from the RERTR-6 test, in which Si-precipitates are scarcely populated near fuel particles. However, since all RERTR test plates undergo heat processes during fabrication (see subsection 5.1), it is not clear whether this occurs during fabrication or during irradiation.

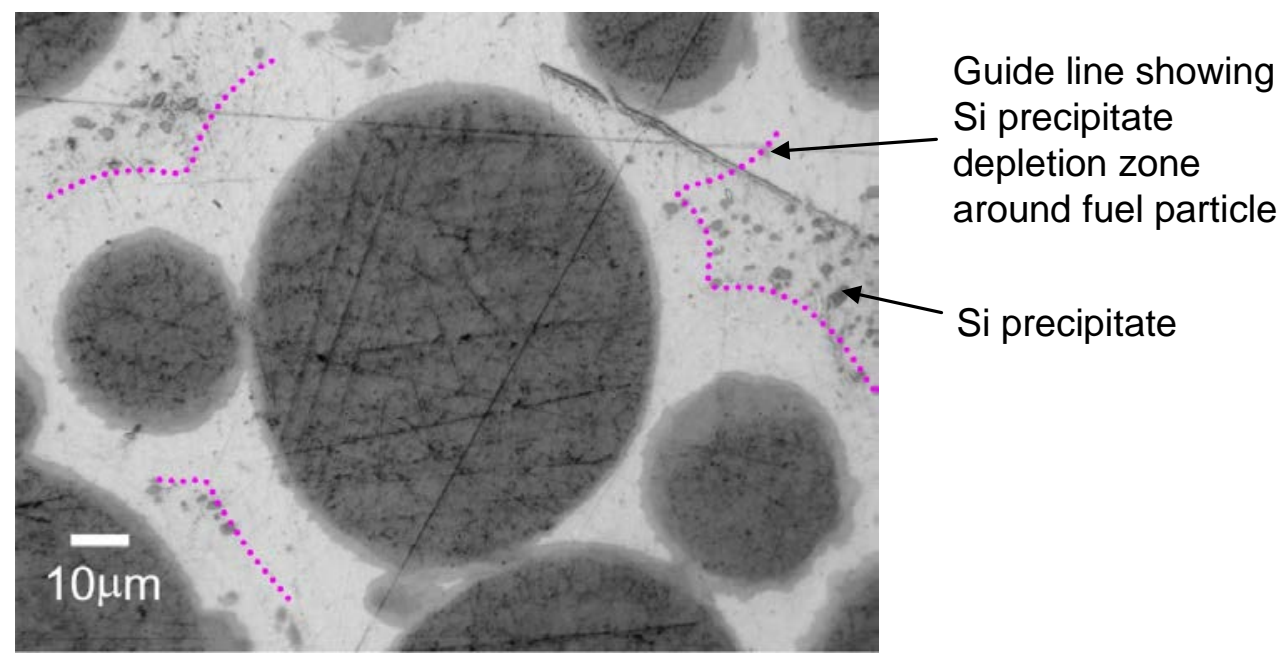

Fig. 50 Precipitate free zones observed in R3R030 from RERTR-6.

X-ray mapping of a typical as-fabricated plate, shown in Fig. 51, also indicates that substantial Si diffusion occurred during fabrication; a Si-enriched band is formed around the fuel particles in Simapping. Some Si precipitates still remain around the fuel particles, different observation from the out-of-pile annealing tests reported by Mirandou [57], suggesting that Si-precipitate dissolution and Si diffusion during fabrication were not complete.

Comparing Figs. 50 and 51, although it is not comparable to that in the heat processes during fabrication, Si diffusion during irradiation also occurs. The Si precipitates should be dissolved in Al to diffuse. Precipitate dissolution during irradiation was well documented by Russell [73]. 


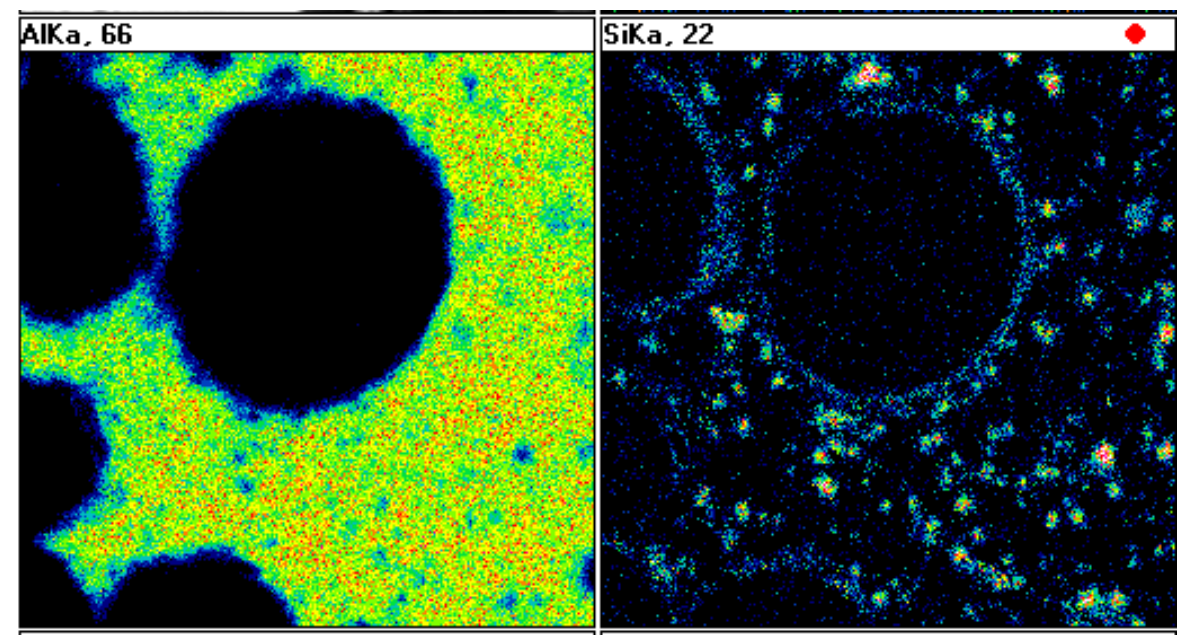

Fig. 51 Si X-ray map of as-fabricated U-7Mo/Al-3.5Si used for RERTR-9B [67]. The right side image is for $\mathrm{Si}$.

\subsubsection{KOMO test results from KAERI}

The KOMO-4 test samples from KAERI showed removal of the Si precipitates from the recoil zone. The Si X-ray mappings are shown in Figs. 52 - 55 for U-7Mo/U-2Si, U-7Mo/Al-5Si, U7Mo/Al-8Si and U-7Mo/Al-5Si with heating before irradiation, respectively. The sample with 8wt\% Si, shown in Fig. 54, however, does not show a clear Si depleted zone maybe because of the overwhelm amount of Si available around. The sample shown in Fig. 55 underwent preheating before irradiation (at $580{ }^{\circ} \mathrm{C}$ for 1 hour), which provided a Si-rich interaction layer of $\sim 5$ $\mu \mathrm{m}$. This sample was subsequently irradiated like other samples. The depletion of the $\mathrm{Si}$ precipitates of this sample is believed to have happened during the pre-heating. The as-heated concentration profiles are given in Fig. 56.

The other samples were fabricated at low temperatures so that the thickness of as-fabrication ILs is virtually negligible. Therefore, this result confirmed that the removal of the Si precipitates occurred during irradiation. A more detailed description is given in Table 9 for irradiation condition. 


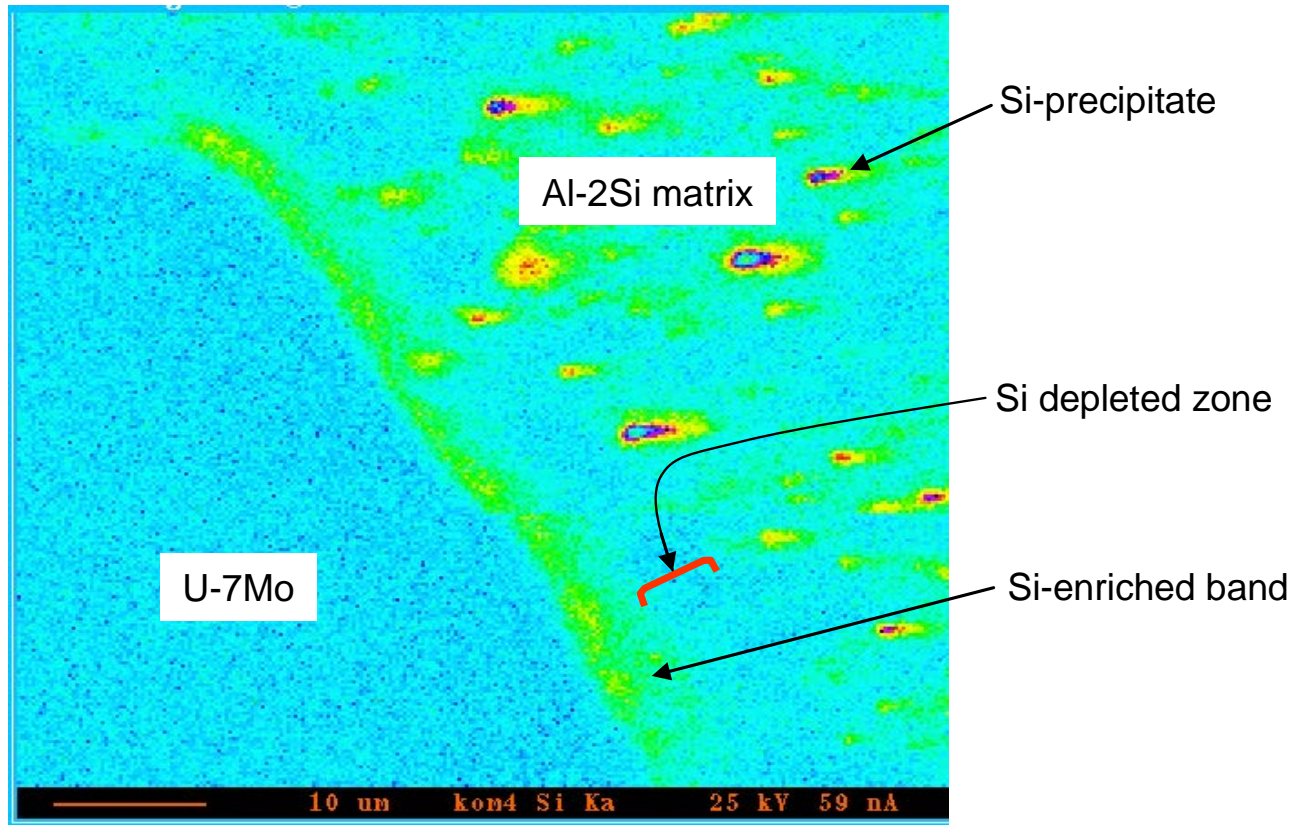

Fig. 52 U-7Mo/Al-2Si irradiated to $3.7 \times 10^{21} \mathrm{f} / \mathrm{cm}^{3}$ (51\% LEU equiv burnup) at $195{ }^{\circ} \mathrm{C}$ for 132 EFPD in the HANARO [74].

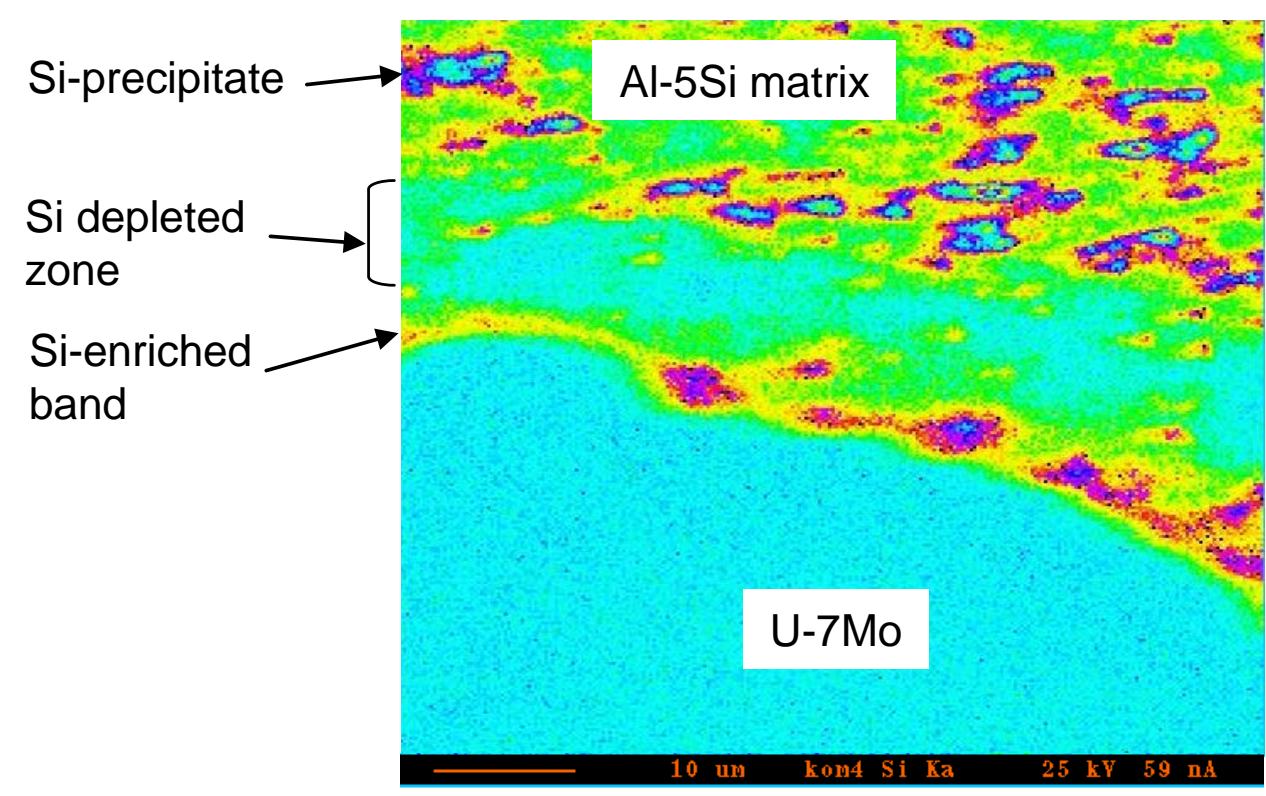

Fig. $53 \mathrm{U}-7 \mathrm{Mo} / \mathrm{Al}-5 \mathrm{Si}$ irradiated to $3.6 \times 10^{21} \mathrm{f} / \mathrm{cm}^{3}$ (49\% LEU equiv burnup) at $190{ }^{\circ} \mathrm{C}$ for 132 EFPD in the HANARO [74]. 


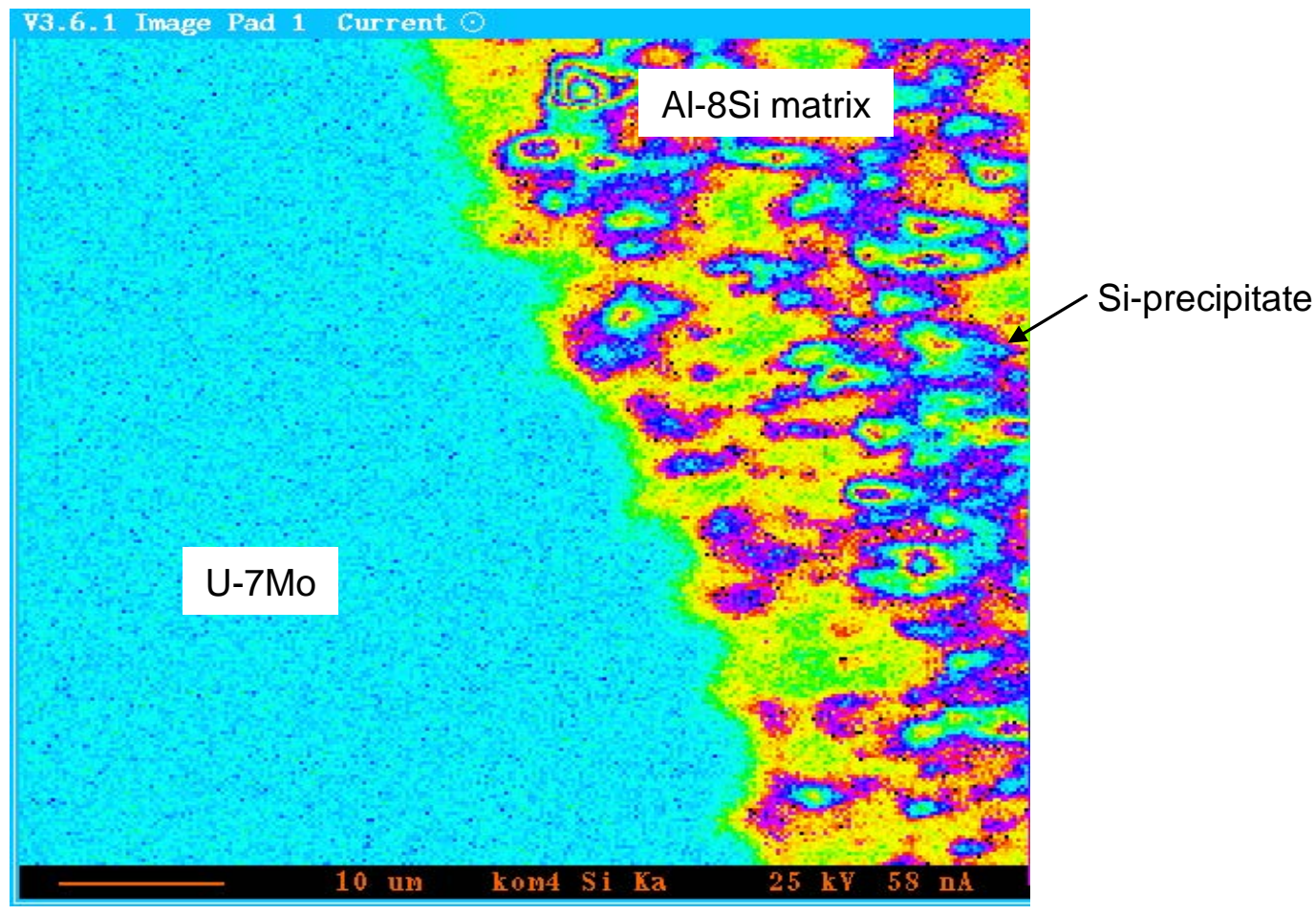

Fig. $54 \mathrm{U}-7 \mathrm{Mo} / \mathrm{Al}-8 \mathrm{Si}$ irradiated to $3.5 \times 10^{21} \mathrm{f} / \mathrm{cm}^{3}$ (48\% LEU equiv burnup) at $190{ }^{\circ} \mathrm{C}$ for $132 \mathrm{EFPD}$ in the HANARO [74].

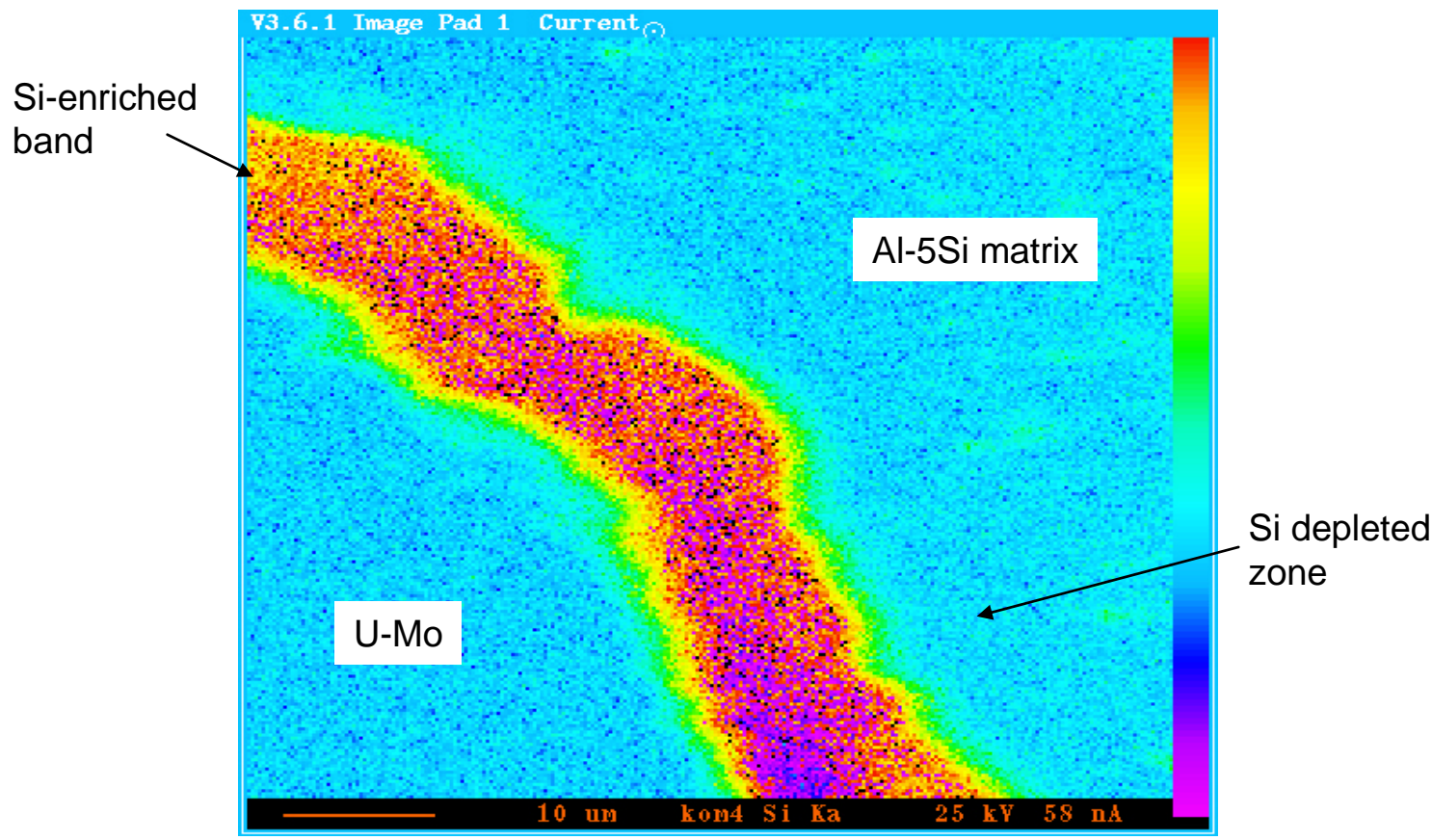

Fig. 55 U-7Mo/Al-5Si with heating before irradiation (for 1 hour at $580{ }^{\circ} \mathrm{C}$ ) and subsequently irradiated to $4.0 \times 10^{21} \mathrm{f} / \mathrm{cm}^{3}$ (54\% LEU equiv burnup) at $190{ }^{\circ} \mathrm{C}$ for 132 EFPD in the HANARO [74]. 


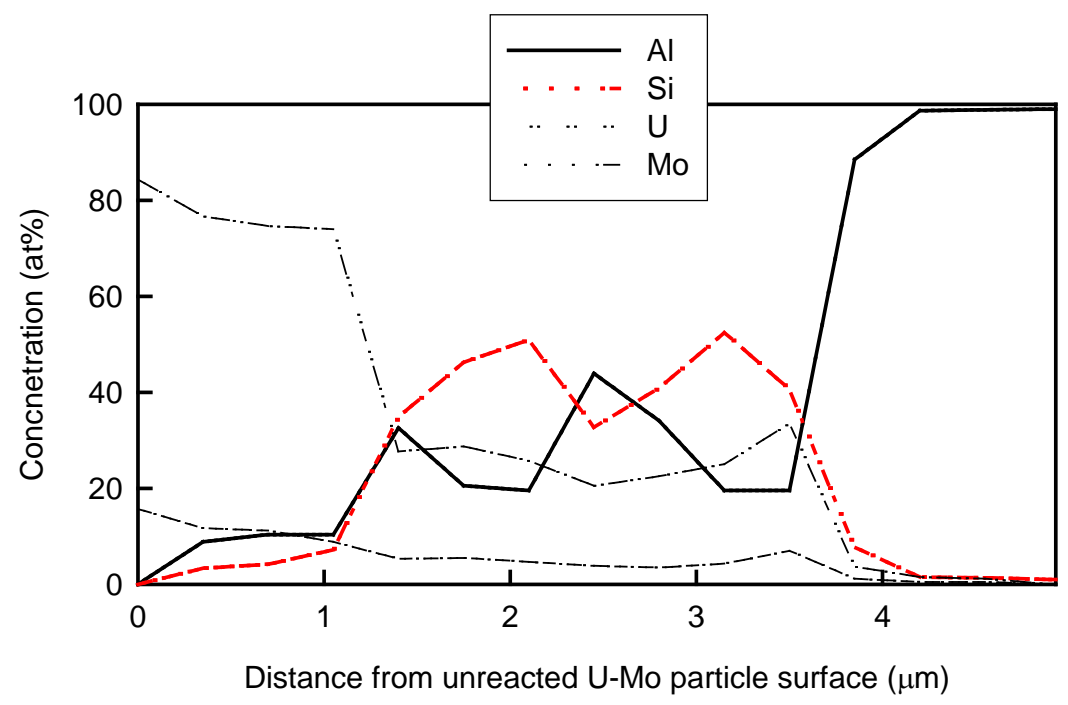

Fig. 56 Concentration profiles of pre-heated U-7Mo/Al-5Si sample before irradiation.

EPMA also revealed that Si diffusion occurs during irradiation as shown in Fig. 57 [75]. However, unlike the out-of pile tests results shown in Fig. 51, Si accumulation in the ILs is weak in regions at a low fission rate and non-uniform throughout the ILs occurring only near the ILmatrix interface (see Fig. 57(b)). Ryu et al. [75] also reported that Si diffusion during irradiation is small when the low fission rate and, hence, typically the temperature is low. These observations suggest that the energy for Si diffusion to the ILs is primarily supplied by thermal activation, and that irradiation enhanced diffusion is small. The low temperature behavior observed in the KOMO test is assumed applicable for the RERTR test plates.

Another important finding from Fig. 57 (b) is that the low Si content in the IL ( 4\%) played as an effective barrier against Al diffusion. The Si concentration is not homogeneous throughout the IL.

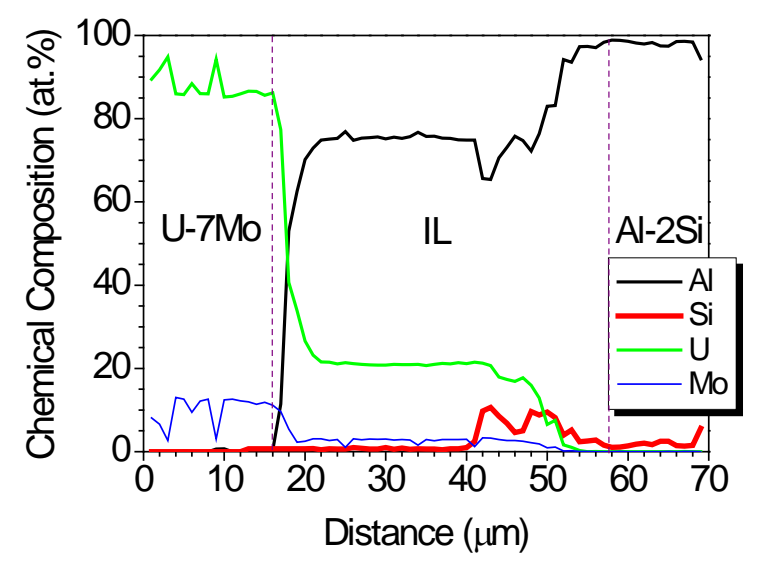

(a) Fuel meat center $\left(-200^{\circ} \mathrm{C}\right)$ 64.8 at $\%$ BU

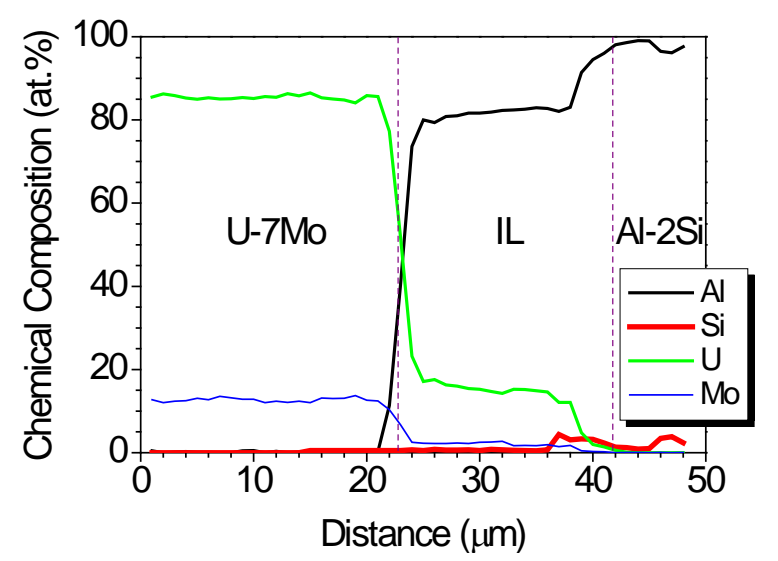

(b) Fuel meat periphery $\left(-120^{\circ} \mathrm{C}\right)$ 47.3 at $\%$ BU

Fig. 57 EPMA data showing composition in IL from KOMO-3 irradiation test of U$7 \mathrm{Mo} / \mathrm{Al}-2 \mathrm{Si}$ in a fuel rod [75]. 
The concentration profiles of $\mathrm{Al}, \mathrm{Si}, \mathrm{U}$, and $\mathrm{Mo}$ in the ILs measured for the KOMO-4 test samples are given in Figs. 58 - 61. The Al concentration data for the Al-2Si, Al-5Si, Al-8Si, and Al-5Si with pre-formed IL before irradiation were used to calculate the interdiffusion fluxes and effective diffusivities of $\mathrm{Al}$ in the ILs. The modified Boltzmann-Matano method was used for the calculations [76]. Derivation of the necessary equations is given in Appendix A. The calculated Al fluxes are also shown in Figs. 58 - 61.
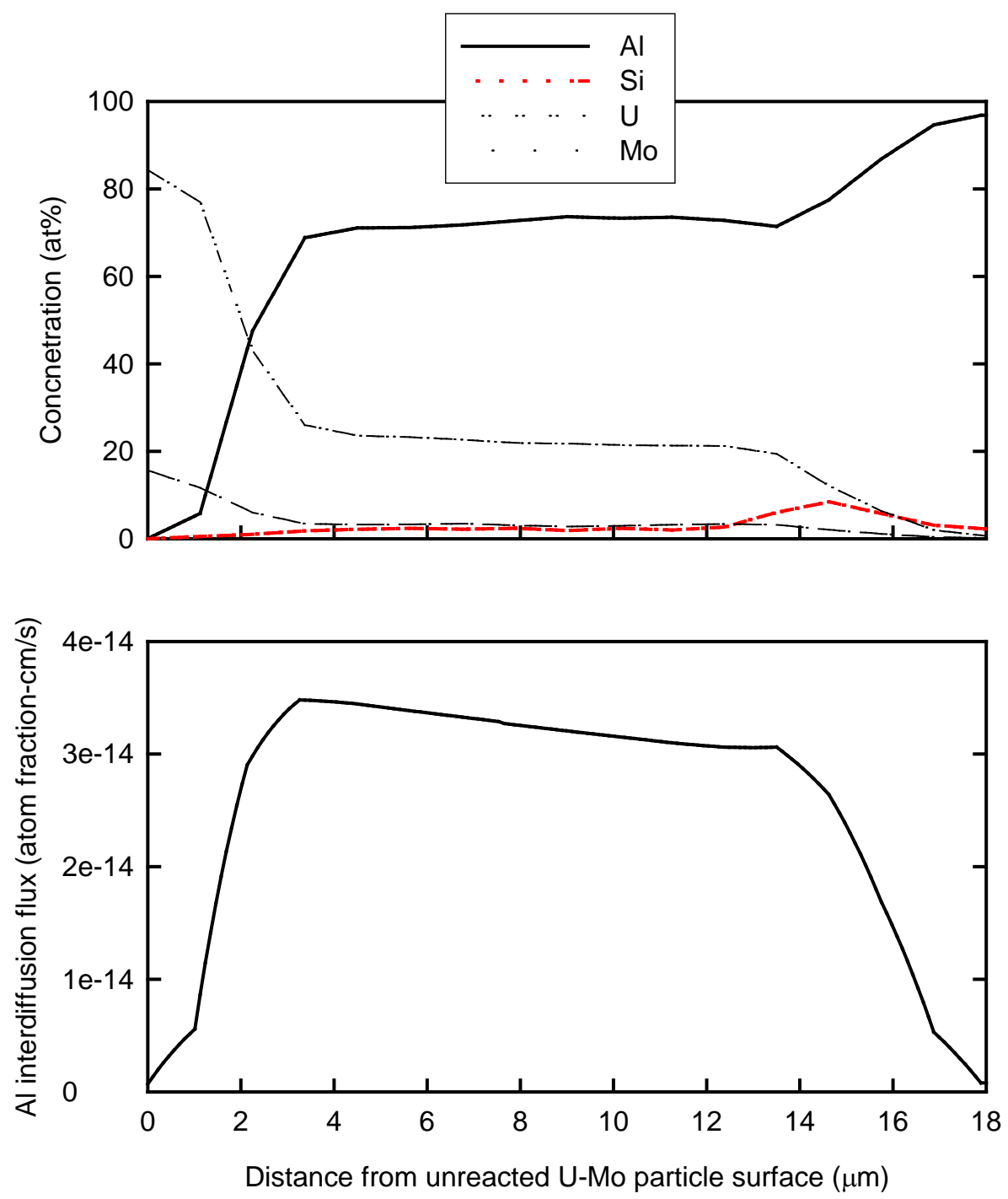

Fig. 58 Concentration profiles and Al flux in the IL calculated for the U-7Mo/Al-2Si sample described in Fig. 52, irradiated to $3.7 \times 10^{21} \mathrm{f} / \mathrm{cm}^{3}$ (51\% LEU equiv burnup) at $195{ }^{\circ} \mathrm{C}$ for $132 \mathrm{EFPD}$ in the HANARO. 

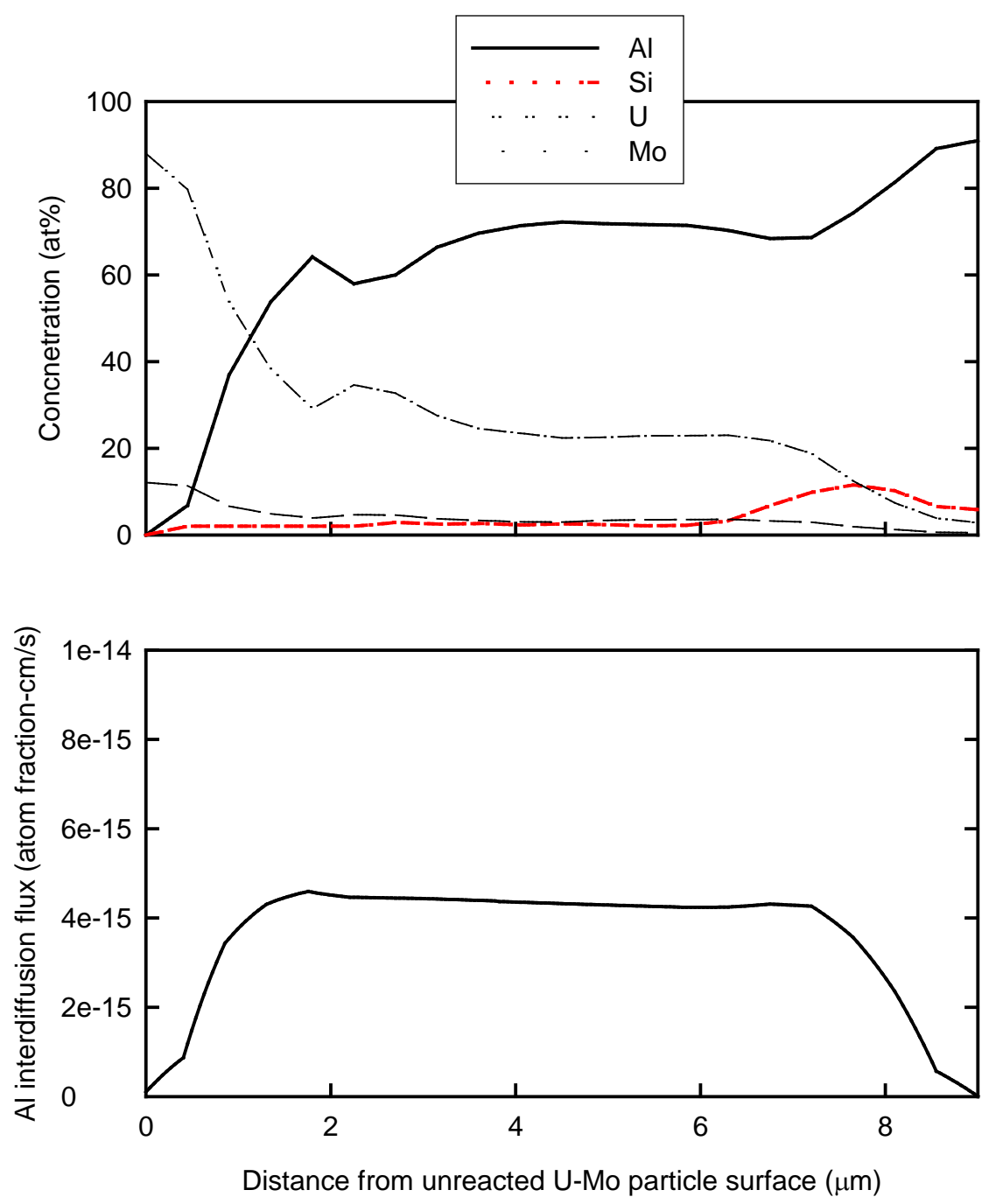

Fig. 59 Concentration profiles and Al flux in the IL calculated for the U-7Mo/Al-5Si sample described in Fig. 53, irradiated to $3.6 \times 10^{21} \mathrm{f} / \mathrm{cm}^{3}$ (49\% LEU equiv burnup) at $195{ }^{\circ} \mathrm{C}$ for $132 \mathrm{EFPD}$ in the HANARO. 

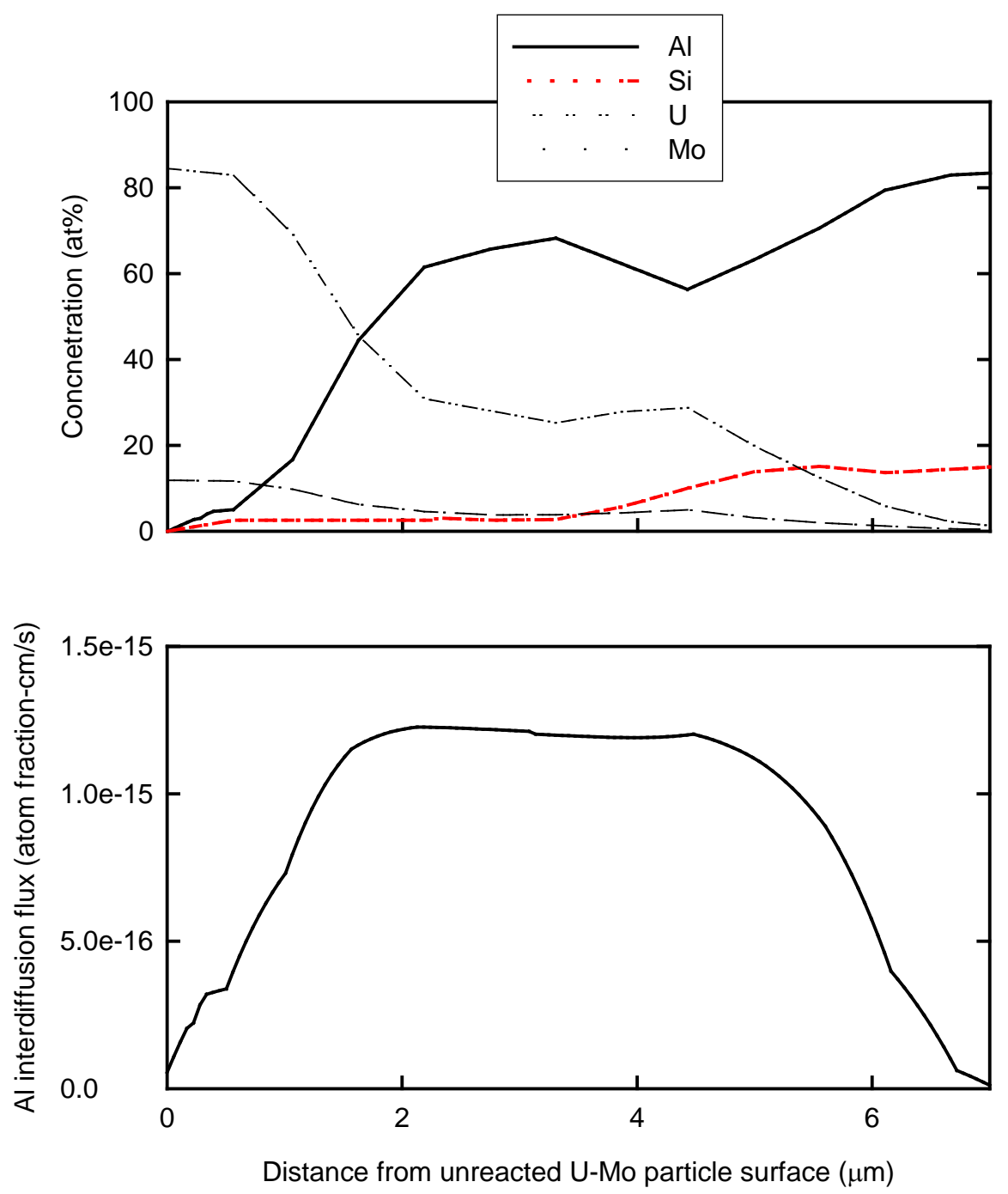

Fig. 60 Concentration profiles and Al flux in the IL calculated for the U-7Mo/Al-8Si sample described in Fig. 54, irradiated to $3.5 \times 10^{21} \mathrm{f} / \mathrm{cm}^{3}$ (48\% LEU equiv burnup) at $190{ }^{\circ} \mathrm{C}$ for $132 \mathrm{EFPD}$ in the HANARO. 

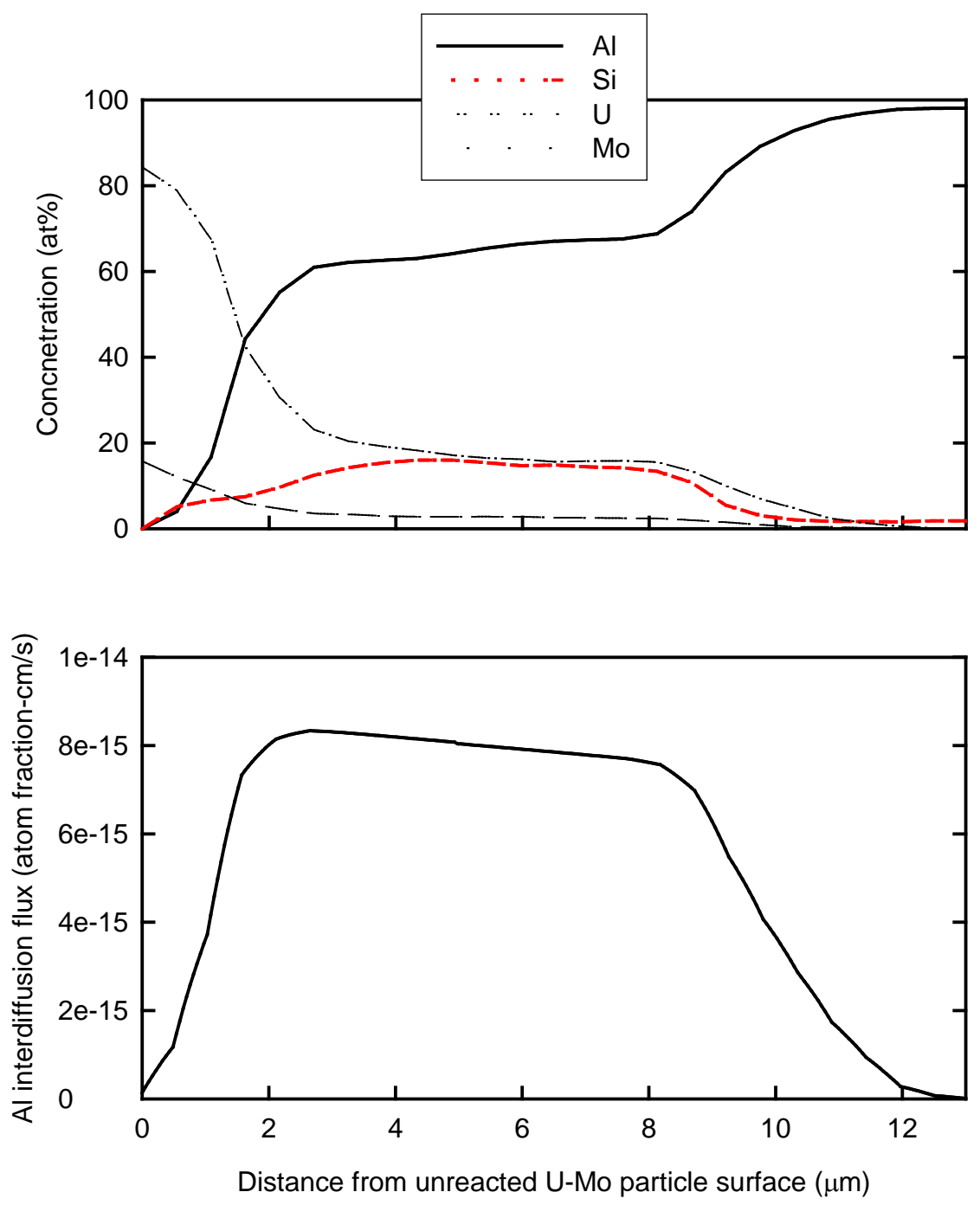

Fig. 61 Concentration profiles and Al flux in the IL calculated for the U-7Mo/Al-5Si sample with pre-heating before irradiation described in Fig. 55, irradiated to $4.0 \times 10^{21} \mathrm{f} / \mathrm{cm}^{3}$ (54\% LEU equiv burnup) at $190{ }^{\circ} \mathrm{C}$ for $132 \mathrm{EFPD}$ in the HANARO.

The total Al atoms included in the IL are calculated and given in Table 9. The effective interdiffusion coefficients are also calculated and given in Table 9.

The ratio of the total atoms of $\mathrm{Si}$ to $\mathrm{Al}$ in the IL is calculated and also given in Table 9. The ratio is a linear function of the as-fabricated Si concentration in the matrix, but higher than the asfabricated Si content in the IL as shown in Fig. 62.

The effective diffusion coefficient of $\mathrm{Al}$ decreases with the as-fabricated Si concentration in the matrix, showing that the more the Si amount addition in the matrix, the larger the effect of the Si addition reducing IL growth. 
Table 9 Total amount of $\mathrm{Al}$ and $\mathrm{Si}$ in the IL and average effective interdiffusion coefficient of $\mathrm{Al}$ in the IL after 132 days of irradiation in HANARO

\begin{tabular}{|c|c|c|c|c|c|c|}
\hline \multirow{3}{*}{$\begin{array}{l}\text { Matrix } \\
\text { type }\end{array}$} & $\begin{array}{c}\text { Irradiation } \\
\text { data }\end{array}$ & \multirow{3}{*}{$\begin{array}{l}\text { Average } \\
\text { IL } \\
\text { thickness } \\
(\mu \mathrm{m})\end{array}$} & \multirow{3}{*}{$\begin{array}{c}\mathrm{Al} \\
\text { concentration } \\
\text { in the IL } \\
\left(10^{-2}\right. \\
\left.\mathrm{mol} / \mathrm{cm}^{3}\right)\end{array}$} & \multirow{3}{*}{$\begin{array}{c}\mathrm{Si} \\
\text { concentration } \\
\text { in the IL } \\
\left(10^{-2}\right. \\
\left.\mathrm{mol} / \mathrm{cm}^{3}\right)\end{array}$} & \multirow{3}{*}{$\begin{array}{l}\mathrm{Si} / \mathrm{Al} \\
\text { ratio in } \\
\text { the IL } \\
(\%)\end{array}$} & \multirow[t]{3}{*}{$\begin{array}{c}\widetilde{\mathrm{D}}_{\mathrm{Al}}^{\mathrm{eff}} \\
\left(10^{-14}\right. \\
\left.\mathrm{cm}^{2} / \mathrm{s}\right) *\end{array}$} \\
\hline & $\begin{array}{c}\text { BU (\%U- } \\
235 \text { LEU } \\
\text { equiv) }\end{array}$ & & & & & \\
\hline & Temp $\left({ }^{\circ} \mathrm{C}\right)$ & & & & & \\
\hline \multirow[t]{2}{*}{ Al-0Si } & 55 & \multirow[t]{2}{*}{25} & \multirow[t]{2}{*}{6.2} & \multirow[t]{2}{*}{0} & \multirow[t]{2}{*}{0} & \multirow[t]{2}{*}{2} \\
\hline & 180 & & & & & \\
\hline \multirow[t]{2}{*}{$\mathrm{Al}-2 \mathrm{Si}$} & 51 & \multirow[t]{2}{*}{18} & \multirow[t]{2}{*}{5.6} & \multirow[t]{2}{*}{0.23} & \multirow[t]{2}{*}{4} & \multirow[t]{2}{*}{0.47} \\
\hline & 195 & & & & & \\
\hline \multirow[t]{2}{*}{ Al-5Si } & 49 & \multirow[t]{2}{*}{9} & \multirow[t]{2}{*}{5.1} & \multirow[t]{2}{*}{0.31} & \multirow[t]{2}{*}{6} & \multirow[t]{2}{*}{0.036} \\
\hline & 190 & & & & & \\
\hline \multirow[t]{2}{*}{ Al-8Si } & 48 & \multirow[t]{2}{*}{7} & \multirow[t]{2}{*}{4.3} & \multirow[t]{2}{*}{0.56} & \multirow[t]{2}{*}{13} & \multirow[t]{2}{*}{0.0074} \\
\hline & 190 & & & & & \\
\hline \multirow{2}{*}{$\begin{array}{c}\text { Al-5Si } \\
\text { with pre- } \\
\text { heating } \\
\text { ** }\end{array}$} & 55 & \multirow[t]{2}{*}{13} & \multirow[t]{2}{*}{5.6} & \multirow[t]{2}{*}{0.71} & \multirow[t]{2}{*}{13} & \multirow[t]{2}{*}{0.73} \\
\hline & 190 & & & & & \\
\hline $\begin{array}{c}\text { Al-5Si } \\
\text { pre- } \\
\text { heated } \\
\text { archive \# }\end{array}$ & NA & 5 & 3.4 & 1.9 & 54 & 4.9 \\
\hline
\end{tabular}

* Defined as $\widetilde{D}_{\mathrm{Al}}^{\text {eff }}=\int_{\mathrm{r}_{1}}^{\mathrm{r}_{2}} \widetilde{\mathrm{J}}_{\mathrm{Al}}(\mathrm{r}) \mathrm{dr} /\left[\mathrm{C}\left(\mathrm{r}_{2}\right)-\mathrm{C}\left(\mathrm{r}_{1}\right)\right]$, where $\widetilde{\mathrm{J}}_{\mathrm{Al}}(\mathrm{r})$ is the Al interdiffusion flux at $r$ in the IL, and $r_{1}$ and $r_{2}$ are the radii at IL boundaries (see Appendix A for the derivation of $\tilde{J}_{\mathrm{Al}}(\mathrm{r})$ ). Details of this definition can be found in Ref. 76.

** Pre-heated at $580{ }^{\circ} \mathrm{C}$ for an hour before irradiation to give an IL thickness of $\sim 5 \mu \mathrm{m}$.

\# An archive sample after pre-heated at $580{ }^{\circ} \mathrm{C}$ for an hour. NA: Not applicable 


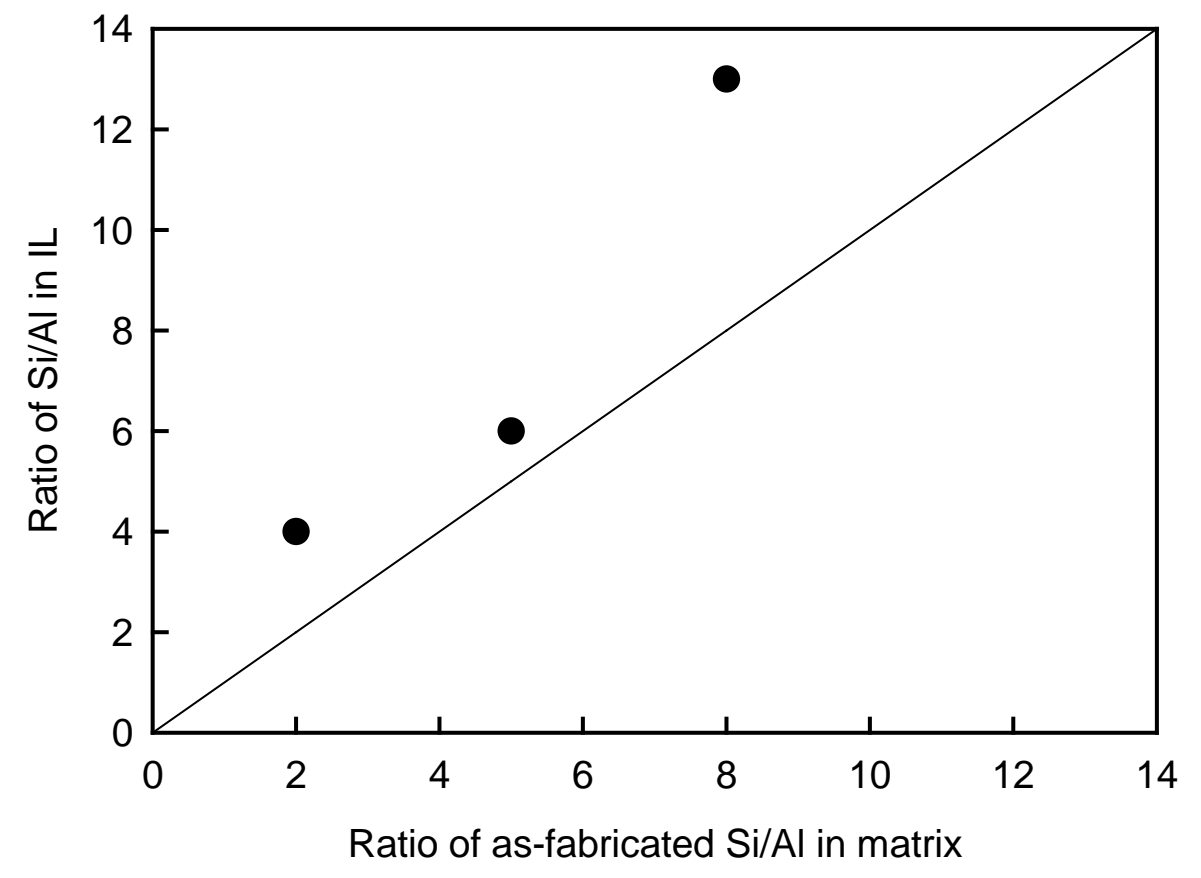

Fig. $62 \mathrm{Si} / \mathrm{Al}$ ratio in the IL versus as-fabricated $\mathrm{Si} / \mathrm{Al}$ ratio in the matrix. 


\section{Section 6 Si effect on performance of U-Mo/Al}

\subsection{Mechanism of Si effect on IL reduction}

The KOMO-4 test result showed that as the Si content in the matrix increases, the IL thickness decreases as given in Table 9, consistent with the observation from the RERTR test results shown in Fig. 45. As the Si content in the matrix increases, the Al interdiffusion flux decreases in the IL. This is also consistent with the theoretical prediction and out-of-pile test results. As given in Table 9, the Al diffusivity decreases as the Si concentration in the matrix increases.

It is also noticeable that the accumulation of Si at the IL-matrix interface, although not uniformly distributed in the IL and lower than out-of-pile test results, is effective in reduction of IL growth. KOMO-4 test results also revealed that $\mathrm{Si}$ accumulation occurs only at the IL close to the matrix and $\mathrm{Al}$ diffusion in the IL is higher than that of Si. The accumulation of Si at the IL occurs only near the IL-matrix interface, implying that the Si migrates in the IL at a slower rate than Al. This observation is the opposite of the out-of-pile test data, suggesting that extrapolation of the out-ofpile data to the low temperature regime is inappropriate. To have this result, $\mathrm{Al}$ is more readily activated than $\mathrm{Si}$ in radiation enhanced diffusion (RED) at low temperatures of interest. Referring to the data reported by Rossi et al. [77], this phenomenon can be explained. Rossi claimed that above the critical temperature ( $100{ }^{\circ} \mathrm{C}$ for $\mathrm{Ar}$ ion mixing), the mixing rate depends on temperature with an Arrhenius form. At $150{ }^{\circ} \mathrm{C}$ by Ar irradiation, the ion mixing rate (in the unit of $\mathrm{cm}^{4}$ ) of $\mathrm{U} / \mathrm{Al}$ is $\sim 6$ times larger than that of U/Si.

However, the atom ratio of $\mathrm{Si}$ to $\mathrm{Al}$ in the $\mathrm{IL}$ is slightly higher than that in the matrix (see Fig. 62). This implies that the Si diffusion in the $\mathrm{Al}$ matrix was still higher than $\mathrm{Al}$. The slower diffusion in the IL and higher diffusion in the matrix of $\mathrm{Si}$ than $\mathrm{Al}$ results in the accumulation of $\mathrm{Si}$ at the IL-matrix interface.

Akdeniz et al. [78] explained that the influence of Si addition in $\mathrm{Al}$ on the reduction in IL growth between $\mathrm{Fe}$ and $\mathrm{Al}$ is the result of the reduction in the activity coefficient of Al. The physical interpretation of their explanation is that since the term activity is defined as the measure of 'effective concentration' of the element of interest, the added Si reduces the effective population of $\mathrm{Al}$ atoms and therefore reduces interdiffusion layer formation. While Si reduces the activity coefficient of $\mathrm{Al}$, for example, $\mathrm{Zn}$ does the opposite. Although this result is applicable for the reaction between $\mathrm{Fe}$ and $\mathrm{Al}$, the product of which is crystalline, an analogous effect of Si addition in $\mathrm{Al}$ should be applicable for the interdiffusion between $\mathrm{U}(\mathrm{Mo})$ and $\mathrm{Al}$ during irradiation, the product of which is amorphous. Specifically, the presence of $\mathrm{Si}$ in $\mathrm{Al}$ at the interface between $\mathrm{U}$ and $\mathrm{Al}$ is more effective in reducing the activity coefficient of $\mathrm{Al}$ since the interdiffusion of $\mathrm{Al}$ and $\mathrm{U}$ is the main mechanism for IL growth. The effect of Si concentration can be explained by the same token; as the Si content increases, the activity of Al decreases further.

$\mathrm{Al}$ diffusion in the sample with pre-heating shows a larger $\mathrm{Al}$ flux profile than the sample without pre-heating, and the IL thickness of the pre-heated sample is larger than that of the sample without pre-heating (see Table 9). They are similar if the IL thickness formed during pre-heating is subtracted (see Table 9). The Si accumulation in the IL occurred during pre-heating does not 
appear to be more effective than the small accumulation at the IL-matrix interface and Si precipitates in the matrix. This suggests that the presence of high Si content in the IL is not the pre-requisite for Si addition to be effective in reducing IL growth. The high as-heated Si accumulation approximately 50 at\% in the IL (see Fig. 56) does not effectively stop Al diffusion through the IL. Instead the Si concentration is reduced to about 15 at\% redistributed evenly in the IL. Since Si was depleted from the zone around the U-Mo particle during the pre-heating, neither additional Si migration to the IL could occur nor Si accumulation at the IL-matrix interface. A comparison between the Si amounts in the ILs of the last two rows shows that the Si amount did not increase from the as-heated during irradiation. The Si concentration was diluted as the IL grew.

The minimum Si content model applicable for crystalline out-of-pile ILs (see section 3) should be modified in order to be applicable for amorphous in-pile ILs because the amorphous ILs behave differently. Since the ILs are amorphous, there is no stoichiometry constraint in the ILs. The U, $\mathrm{Mo}, \mathrm{Al}$ and $\mathrm{Si}$ atoms then mix together without any phase constraint [11]. Hence, the minimum Si amount to form a certain phase, such as $\mathrm{UAl}_{3}$, is not required. Therefore, the presence of $\mathrm{Si}$ in the IL, regardless of the amount, has an effect on reducing IL growth.

In addition, as discussed above, the existence of Si at the IL-matrix interface is more effective, where the reaction between $\mathrm{U}$ and Al occurs. IL growth is probably composed of two reactions; diffusion through the IL and reaction at interface. The observation from KOMO-4 indicates that the latter is significant to determine the overall rate. As discussed in subsection 5.4.2, some ILs in the Si added plates are locally extremely thin; in some cases they are so thin that the thickness is virtually negligible in an OM image. Van den Berghe et al. [66] observed that the thin ILs, contrarily to thick ILs, were frequently observed near a Si precipitate. Because the IL thickness is so small, it is impossible to discern whether the location of the Si precipitate is in the IL or in the matrix that contacts the IL surface. It is reasonable that the effectiveness of $\mathrm{Si}$, as a diffusion barrier to Al diffusion, is the strongest when it is present at interface between $\mathrm{U}$ and $\mathrm{Al}$. This also implies that the reaction at the IL-matrix interface, and probably diffusion near the matrix that contacts the IL, is important in the IL growth.

\subsection{Mechanism of Si effect on pore formation in IL}

From the composition of the dominant region of ILs observed from the KOMO-4 test, for all three samples with a Si addition (Al-2Si, Al-5Si and Al-8Si samples given in Table 9), the ratio $(\mathrm{U}+\mathrm{Mo}) /(\mathrm{Al}+\mathrm{Si})$ is about 3 . This low ratio is a sign of formation of a stable IL in terms of pore formation in the IL.

The tenuous Si content near the U-Mo particle surface, particularly for the Al-2Si case with a low Si addition, can establish a Si deficient condition there. As a result, the IL stability decreases below such a level that the pores form.

The stability of the amorphous ILs is a function of the Si content (see subsection 3.2). Therefore, a higher Si content in the IL is beneficial although a low Si content is still effective for low IL growth. 
From the U-Si intermetallic fuel data $[48,49]$, the higher the Si content in the amorphous material, the material has less free volume and as a result more resistant to plastic flow. This is consistent with the observation in Fig. 63, where pores form at the IL-matrix interface in the lower Si plate whereas they form at the U-Mo particle surface in the higher Si plate. In the latter (R3R050), the pores form at the fuel particle surfaces where the Si concentration is probably the lowest in the IL although the ILs are negligibly thin. As discussed in subsection 5.4.3, the concentration of fission products is higher in the ILs because of fission product migration. The high fission product concentration may be deleterious for the IL strength.

In Table 10, a summary of fuel pore locations and fuel particle microstructures is given. Fuel pore formation, in general fuel swelling, depends on external stress. In order for a complete interpretation of pore formation data, mechanical analysis is required.

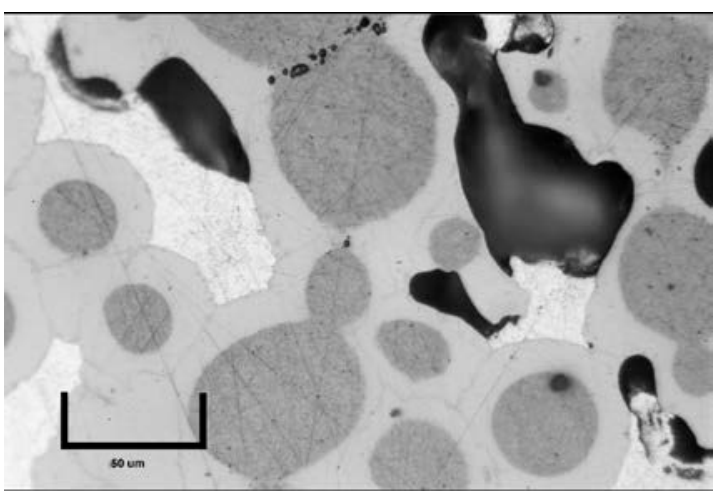

(a) R5R020 from RERTR-6

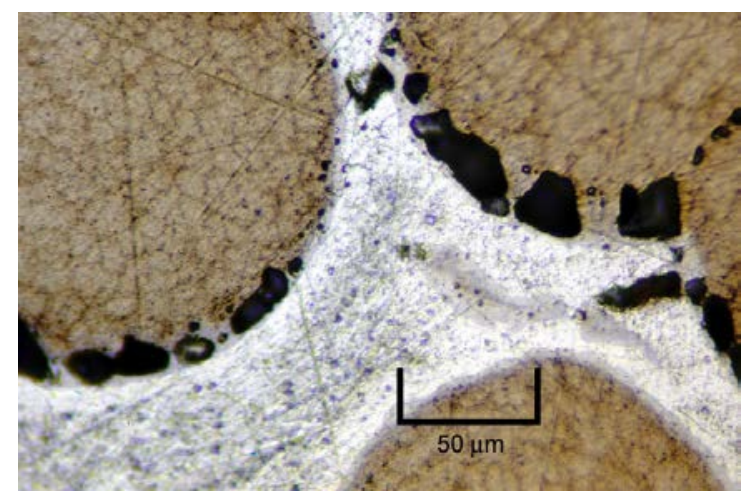

(b) R3R050 from RERTR-7

Fig. 63 Microstructures of R5R020 (Al-0.2Si) irradiated in the RERTR-6 test and R3R050 (Al-4.8Si) irradiated in RERTR-7. See table 9 for irradiation conditions. 
Table 10 Post-irradiation fuel microstructure data for RERTR tests

\begin{tabular}{|c|c|c|c|c|c|c|c|c|c|c|}
\hline Test & Plate ID & $\begin{array}{l}\text { Fuel/matrix } \\
\text { composition }\end{array}$ & $\begin{array}{c}\text { Calculated } \\
\text { fuel } \\
\text { swelling } \\
\left(\Delta \mathrm{V} / \mathrm{V}_{\mathrm{o}}\right)_{\mathrm{f}} \\
\%\end{array}$ & \begin{tabular}{|c}
$\mathrm{v}_{\mathrm{F}} / \mathrm{V}_{\mathrm{IL}}$ \\
$(\%)$ \\
at high- \\
power \\
meat end \\
region
\end{tabular} & $\begin{array}{c}\mathrm{x} / \mathrm{t}(\mathrm{mm}) \\
\text { at max } \\
\text { plate } \\
\text { thickness } \\
\text { location }\end{array}$ & $\begin{array}{c}\text { Particle } \\
\text { transverse } \\
\text { elongation } \\
\text { at meat } \\
\text { end \# }\end{array}$ & $\begin{array}{c}\text { Particle } \\
\text { sintering } \\
\wedge\end{array}$ & \begin{tabular}{|c} 
Pore \\
formation \\
in fuel \\
periphery
\end{tabular} & $\begin{array}{l}\text { Pores } \\
\text { in IL } \\
\text { on hot } \\
\text { side } \ddagger\end{array}$ & $\begin{array}{c}\text { Pores } \\
\text { in IL } \\
\text { on cold side }\end{array}$ \\
\hline \multirow{3}{*}{$\begin{array}{l}\text { RERTR-3 } \\
\text { Nanoplate }\end{array}$} & V07 & $\mathrm{U}-10 \mathrm{Mo} / \mathrm{Al}$ & 12 & $45 / 23$ & - & No & No & No & \multirow{3}{*}{$\begin{array}{c}\text { Initial state } \\
\text { Yes } \\
\text { No }\end{array}$} & \\
\hline & R04 & $\mathrm{U}-7 \mathrm{Mo} / \mathrm{Al}$ & 15 & 49 / 45 & - & No & No & No & & \\
\hline & S03 & U-6Mo/Al & 16 & 49 / 43 & - & No & No & No & & \\
\hline \multirow{7}{*}{$\begin{array}{l}\text { RERTR-4 } \\
\text { Miniplate }\end{array}$} & V6001M & $\mathrm{U}-10 \mathrm{Mo} / \mathrm{Al}$ & 28 & $38 / 42$ & - & No & No & No & \multirow{7}{*}{$\begin{array}{c}\text { Initial state } \\
\text { Yes } \\
\text { Yes } \\
\text { Yes } \\
\text { Yes } \\
\text { Yes } \\
\text { Yes } \\
\end{array}$} & \multirow{7}{*}{\begin{tabular}{|c} 
Initial State \\
Yes \\
Yes \\
Yes \\
Yes \\
Yes \\
Yes \\
\end{tabular}} \\
\hline & R6003F & $\mathrm{U}-7 \mathrm{Mo} / \mathrm{Al}$ & 38 & 27 / 60 & 2.6/1.55 & No & No & Yes & & \\
\hline & V8006B & $\mathrm{U}-10 \mathrm{Mo} / \mathrm{Al}$ & 34 & $40 / 59$ & $3.8 / 1.54$ & No & Rare & Yes & & \\
\hline & S6004C & U-6Mo/Al & 39 & $40 / 54$ & 2.9/1.56 & No & Rare & Yes & & \\
\hline & V6015G & $\mathrm{U}-10 \mathrm{Mo} / \mathrm{Al}$ & 35 & 32 / 60 & $2.9 / 1.54$ & No & No & Yes & & \\
\hline & S6006C & $\mathrm{U}-6 \mathrm{Mo} / \mathrm{Al}$ & 37 & $31 / 57$ & $2.8 / 1.51$ & No & No & Yes & & \\
\hline & V6022M & $\mathrm{U}-10 \mathrm{Mo} / \mathrm{Al}$ & 33 & $32 / 57$ & $2.7 / 1.56$ & No & Rare & No & & \\
\hline \multirow{6}{*}{$\begin{array}{l}\text { RERTR-5 } \\
\text { Miniplate }\end{array}$} & V6018G & $\mathrm{U}-10 \mathrm{Mo} / \mathrm{Al}$ & 13 & $44 / 22$ & - & No & No & No & \multirow{6}{*}{$\begin{array}{c}\text { No } \\
\text { Yes } \\
\text { Yes } \\
\text { Yes } \\
\text { Yes } \\
\text { Yes } \\
\end{array}$} & No \\
\hline & V6019G & $\mathrm{U}-10 \mathrm{Mo} / \mathrm{Al}$ & 16 & 33 / 34 & $3.7 / 1.53$ & No & No & No & & Yes \\
\hline & S8007L & U-6Mo/Al & 17 & $45 / 44$ & $3.4 / 1.55$ & No & No & No & & Yes \\
\hline & R8002E & $\mathrm{U}-7 \mathrm{Mo} / \mathrm{Al}$ & 16 & $40 / 48$ & 2.9/1.61 & No & No & No & & Yes \\
\hline & S6010D & $\mathrm{U}-6 \mathrm{Mo} / \mathrm{Al}$ & 19 & $28 / 57$ & $2.9 / 1.54$ & No & No & No & & Yes \\
\hline & V8005B & $\mathrm{U}-10 \mathrm{Mo} / \mathrm{Al}$ & 13 & 38 / 60 & $3.5 / 1.51$ & No & No & No & & Yes \\
\hline \multirow{6}{*}{$\begin{array}{l}\text { RERTR-6 } \\
\text { Miniplate }\end{array}$} & R1R010 & U-7Mo/Al-0.9Si & 18 & $50 / 14$ & - & No & No & No & \multirow{6}{*}{$\begin{array}{c}\text { No } \\
\text { No } \\
\text { No } \\
\text { No } \\
\text { Yes } \\
\text { Initial state } \\
\end{array}$} & No \\
\hline & R2R020 & $\mathrm{U}-7 \mathrm{Mo} / \mathrm{Al}-2 \mathrm{Si}$ & 21 & $52 / 13$ & $1.7 / 1.51$ & No & No & No & & No \\
\hline & R3R030 & U-7Mo/Al-5Si & 21 & $41 / 10$ & $1.8 / 1.48$ & No & No & No & & No \\
\hline & R2R010 & U-7Mo/Al-2Si & 22 & $55 / 10$ & - & No & No & No & & No \\
\hline & R5R020 & U-7Mo/Al-0.2Si & 21 & 32 / 45 & $3.1 / 1.57$ & No & Rare & No & & No \\
\hline & V1R010 & U-10Mo/Al-0.9Si & 20 & 33 / 28 & $1.7 / 1.51$ & No & No & No & & No \\
\hline \multirow{7}{*}{$\begin{array}{l}\text { RERTR-7 } \\
\text { Miniplate }\end{array}$} & R3R040 & U-7Mo/Al-5Si & 34 & $55 / 7$ & - & No & No & Yes & \multirow{7}{*}{$\begin{array}{c}\text { Yes* } \\
\text { Yes* } \\
\text { Yes* } \\
\text { Yes* } \\
\text { Yes* } \\
\text { Yes } \\
\text { Yes }\end{array}$} & No \\
\hline & R2R040 & $\mathrm{U}-7 \mathrm{Mo} / \mathrm{Al}-2 \mathrm{Si}$ & 35 & $55 / 7$ & $1.6 / 1.65$ & No & Rare & Yes & & No \\
\hline & R0R010 & $\mathrm{U}-7 \mathrm{Mo} / \mathrm{Al}$ & 34 & $66 / 14$ & - & No & Yes & No & & No \\
\hline & V5R050 & $\mathrm{U}-10 \mathrm{Mo} / \mathrm{Al}-0.2 \mathrm{Si}$ & 34 & $53 / 14$ & $2.2 / 1.54$ & Yes & Yes & No & & No \\
\hline & R3R050 & U-7Mo/Al-5Si & 36 & $60 / 13$ & $1.5 / 1.66$ & Yes & Yes & Yes & & Yes * \\
\hline & R0R020 & $\mathrm{U}-7 \mathrm{Mo} / \mathrm{Al}$ & 47 & $70 / 30$ & 2.8/1.69 & Yes & Yes & No & & Yes * \\
\hline & R2R050 & $\mathrm{U}-7 \mathrm{Mo} / \mathrm{Al}-2 \mathrm{Si}$ & 31 & $42 / 29$ & $1.6 / 1.68$ & No & Yes & No & & No \\
\hline \multirow{7}{*}{$\begin{array}{l}\text { RERTR-8 } \\
\text { Miniplate } \\
\text { RERTR-9 } \\
\text { Miniplate }\end{array}$} & D3R030 & U-7Mo-1Ti/Al-5Si & 47 & $61 / 20$ & - & Yes & Yes & Yes & \multirow{2}{*}{$\begin{array}{l}\text { Yes } \\
\text { Yes }\end{array}$} & \multirow{2}{*}{$\begin{array}{l}\text { Initial state } \\
\text { Initial state }\end{array}$} \\
\hline & F3R040 & U-7Mo-2Zr/Al-5Si & 48 & $61 / 20$ & - & Yes & Yes & Yes & & \\
\hline & R2R088 & $\mathrm{U}-7 \mathrm{Mo} / \mathrm{Al}-2 \mathrm{Si}$ & 57 & $54 / 17$ & - & Yes & Yes & Yes & Yes & Yes \\
\hline & R6R018 & U-7Mo/Al-3.5Si & 58 & $56 / 16$ & - & Yes & Yes & Yes & Yes & Yes \\
\hline & R3R108 & U-7Mo/Al-5Si & 33 & $55 / 15$ & $1.5 / 1.66$ & No & Rare & Yes & Yes & Yes \\
\hline & R2R078 & $\mathrm{U}-7 \mathrm{Mo} / \mathrm{Al}-2 \mathrm{Si}$ & 32 & $54 / 40$ & 2.9/1.65 & Yes & Yes & Yes & Yes & Yes * \\
\hline & R4R018 & U-7Mo/Al-2Si & 30 & $53 / 38$ & - & Yes & Yes & Yes & Yes & No \\
\hline
\end{tabular}

$\checkmark: v_{F}$ is the fuel volume fraction, and $v_{\text {IL }}$ is the IL volume fraction.

\#: Particle extrusion in the width direction from the plate transverse end region to the center region.

$\wedge$ : Particle sinters in the plate transverse end region.

¥: at plate center for RERTR-3 test plates

$\mathrm{x}$ : distance from the meat transverse end.

t: plate thickness

*: pores mostly observed at fuel-IL interface 


\subsection{Interaction layer growth correlation for U-Mo/Al-Si plates}

The IL growth correlation applicable during irradiation is a modified Arrhenius equation, and an additional term with fission rate is multiplied to account for fission-enhanced-diffusion:

$$
\mathrm{Y}^{2}=\operatorname{Af}^{\mathrm{p}} \exp \left(-\frac{\mathrm{q}}{\mathrm{T}}\right) \mathrm{t}
$$

where $\dot{f}$ is the fission rate, $A$ and $q$ are empirical constants. The power, $p$, for the fission rate was empirically determined as $p=0.5$ [62]. Eq. (62) is applicable for plates with a pure Al matrix. There have been several papers that take a similar equation to Eq. (13) with slightly different fitting constants [62,64,65,79,80]. In order to fit both the RERTR and KOMO data, the fitting constants were slightly changed from those of Refs. 79 and 80 . The best fit was obtained with $\mathrm{A}=2.6 \times 10^{-8}$ and $\mathrm{q}=3.85 \times 10^{3} \mathrm{~K}$. Therefore, the correlation for the samples with a pure Al matrix is:

$$
\mathrm{Y}_{0}^{2}=2.6 \times 10^{-8} \dot{\mathrm{f}}^{0.5} \exp \left(-\frac{3850}{\mathrm{~T}}\right) \mathrm{t}
$$

where $\mathrm{Y}$ is in $\mu \mathrm{m}, \dot{\mathrm{f}}$ in $\mathrm{f} / \mathrm{cm}^{3}-\mathrm{s}, \mathrm{T}$ in $\mathrm{K}$, and $\mathrm{t}$ in $\mathrm{s}$.

The addition of $\mathrm{Si}$ in the $\mathrm{Al}$ matrix results in an exponential reduction of IL thickness that varies with the Si content, and this effect depends on temperature. For the low-temperature RERTR-6 test, the Si effect is stronger and the IL reduction effect by Si additions is virtually saturated at 2 wt.\% Si (see Fig. 45). However, the high-temperature KOMO-4 test showed that the IL reduction effect continues up to $8 \mathrm{wt}$.\% Si without showing saturation. Fig. 64 shows a comparison of IL reduction versus the Si content for two different temperature regimes and data fit results given in Eqs. (15) and (16).

In order to model the Si effect, a hyperbolic decay function with the Si content is considered. Two different sets of constants were fitted for two temperature regimes as follows:

$$
\begin{aligned}
& \mathrm{Y}^{2}=\mathrm{Y}_{0}^{2} \frac{1}{1+4.89 \mathrm{~W}_{\mathrm{Si}}} \text {, for } \mathrm{T}<120{ }^{\circ} \mathrm{C} \text {, } \\
& \mathrm{Y}^{2}=\mathrm{Y}_{0}^{2} \frac{1}{1+1.51 \mathrm{~W}_{\mathrm{Si}}}, \text { for } \mathrm{T}>120{ }^{\circ} \mathrm{C} \text {. }
\end{aligned}
$$

where $\mathrm{Y}_{0}$ is the IL thickness for pure-Al-matrix cases obtained in Eq. (15) and $\mathrm{W}_{\mathrm{Si}}$ in wt.\% is the Si content in Al. Using Eqs. (14), (15), and (16), the correlations for the Si-added samples are:

$$
\begin{aligned}
& \mathrm{Y}^{2}=2.6 \times 10^{-8} \dot{\mathrm{f}}^{0.5} \exp \left(-\frac{3850}{\mathrm{~T}}\right) \mathrm{t}\left(\frac{1}{1+4.89 \mathrm{~W}_{\mathrm{Si}}}\right), \text { for } \mathrm{T}<120{ }^{\circ} \mathrm{C}, \\
& \mathrm{Y}^{2}=2.6 \times 10^{-8} \dot{\mathrm{f}}^{0.5} \exp \left(-\frac{3850}{\mathrm{~T}}\right) \mathrm{t}\left(\frac{1}{1+1.51 \mathrm{~W}_{\mathrm{Si}}}\right), \text { for } \mathrm{T}>120{ }^{\circ} \mathrm{C} \text {. }
\end{aligned}
$$

where again $\mathrm{Y}$ is in $\mu \mathrm{m}, \dot{\mathrm{f}}$ is in $\mathrm{f} / \mathrm{cm}^{3}-\mathrm{s}, \mathrm{T}$ in $\mathrm{K}$, $\mathrm{t}$ in $\mathrm{s}$ and $\mathrm{W}_{\mathrm{si}}$ in $\mathrm{wt} . \%$.

The correlations given in Eqs. (17) and (18) are for the regime where the Si addition is effective in reducing the IL growth rates. 


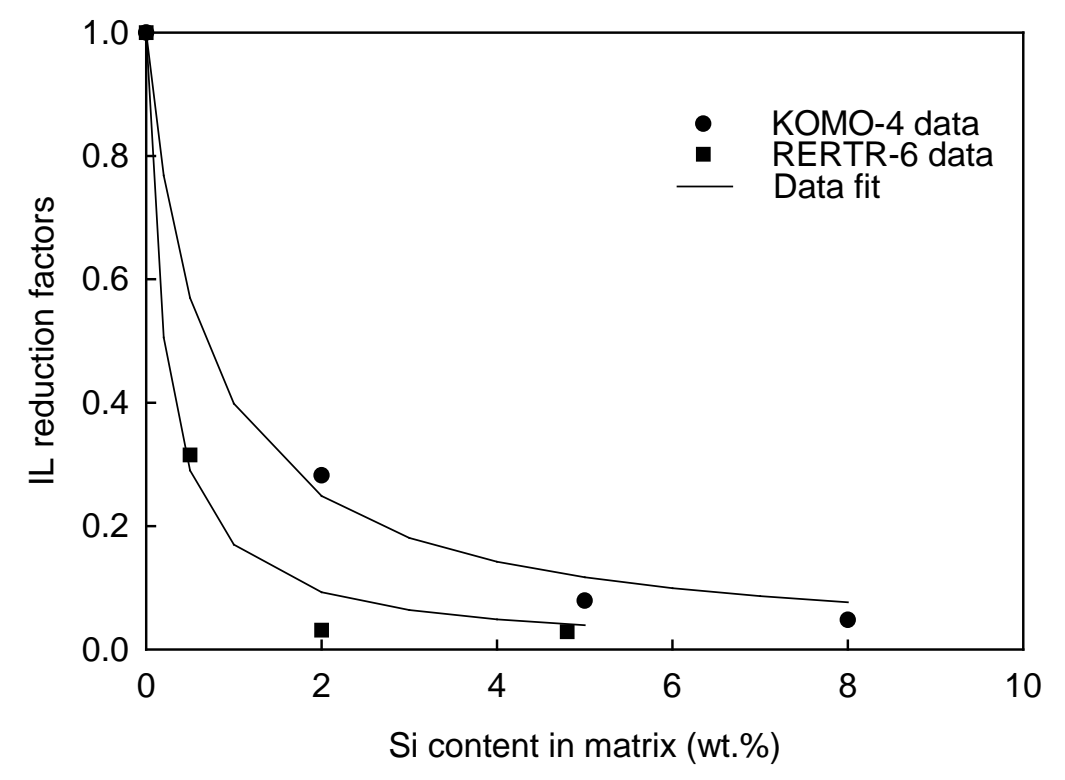

Fig. 64 Comparison of IL reduction factors obtained for the low-temperature RERTR-6 test and the high-temperature KOMO-4 test, where IL reduction factor is defined as the square of IL thickness divided by the square of IL thickness for pure $\mathrm{Al}$ matrix at the same irradiation condition.

Eqs. (17) and (18) are applicable for U-7Mo fuel particle dispersions. For other cases, a Mo content factor is considered. In the current PLATE modeling [81], the effect of the Mo content in fuel particles is considered such that the IL decreases linearly with the Mo content in the range of $6-10$ wt.\%. A similar factor is used for the current modeling. Prediction for the samples using other than U-7Mo should be adjusted by multiplying the following factor to Eqs. (17) and (18):

$\mathrm{f}_{\text {Мо }}=1.35-0.05 \mathrm{~W}_{\text {Мо }}$

where $\mathrm{W}_{\mathrm{Mo}}$ is the Mo content in fuel particles in wt.\%.

Other parameters such as fuel loading and particle size are also important, but they are considered implicitly in fuel temperature. Therefore, these parameters do not appear as variables in the modeling. 


\section{Section 7 Remedy with other element than silicon}

As Si has some reprocessing problem, other element that can be added in the $\mathrm{Al}$ matrix have been sought. In the literature [82,83], Bi and Be received some studies to reduce Al diffusion in $\mathrm{U}$ and Fe. Both appear to be promising. However, these two have very limited solubility in Al for the fuel operation temperature range.

Heats of formation of binary alloys were estimated with the Miedema model and the results are shown in Fig. 65. Be and Bi have large negative heats of solution with U. A slight difference between $\mathrm{Bi}$ and $\mathrm{Be}$ is that Be has very smaller positive heats of solution with $\mathrm{Al}$ than $\mathrm{Bi}$ does. This indicates that $\mathrm{Bi}$ is less soluble in $\mathrm{Al}$ than $\mathrm{Be}$. In fact, the phase diagrams show that both are almost insoluble in Al. From this thermodynamic assessment, it appears that Be is a good candidate for an alternative element to $\mathrm{Si}$.

Diffusion coefficients taken from Ref. 82, compared between U/Al, U/AlSi and U/AlBe in Fig. 66, show that the Al-Be alloy has lower reaction with $U$ than Al-Si does with $\mathrm{U}$. This is a promising result from out of pile tests; however, a real efficacy should be examined only by an irradiation test.

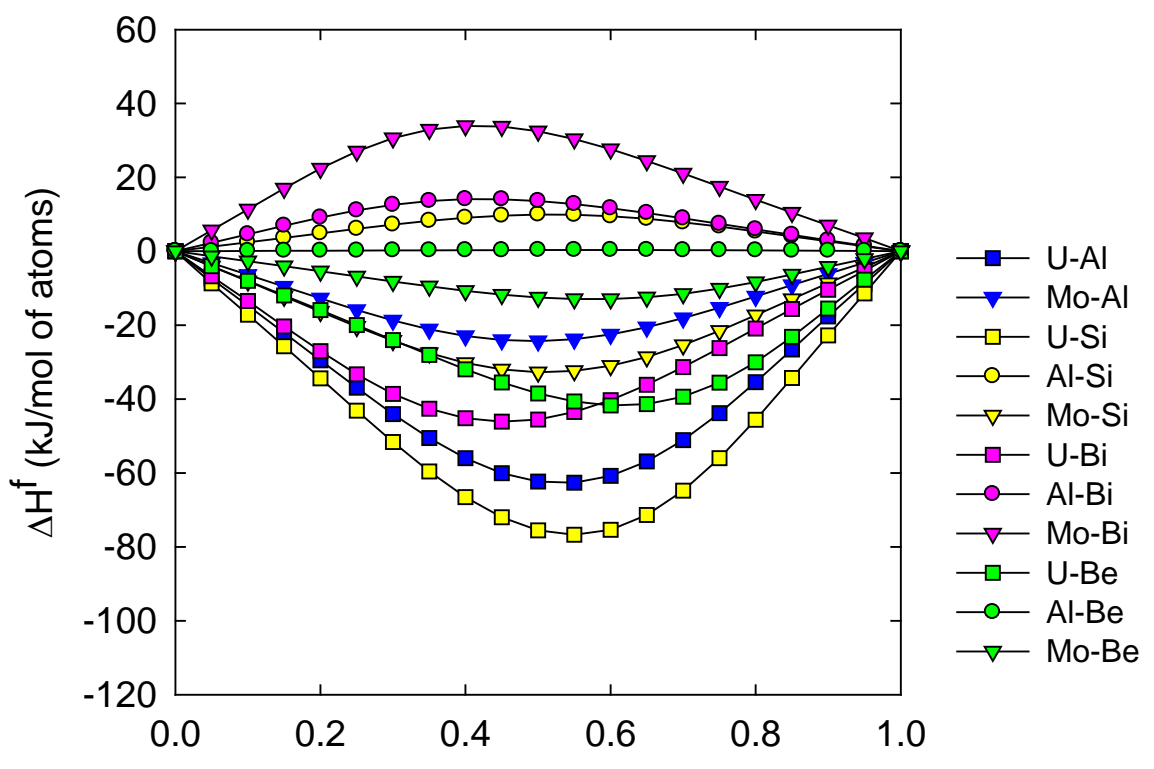

Second element concentration, atom fraction

Fig. 65 Comparison of heats of formation of binary alloys of candidate elements with $\mathrm{U}, \mathrm{Mo}$, and $\mathrm{Al}$. 


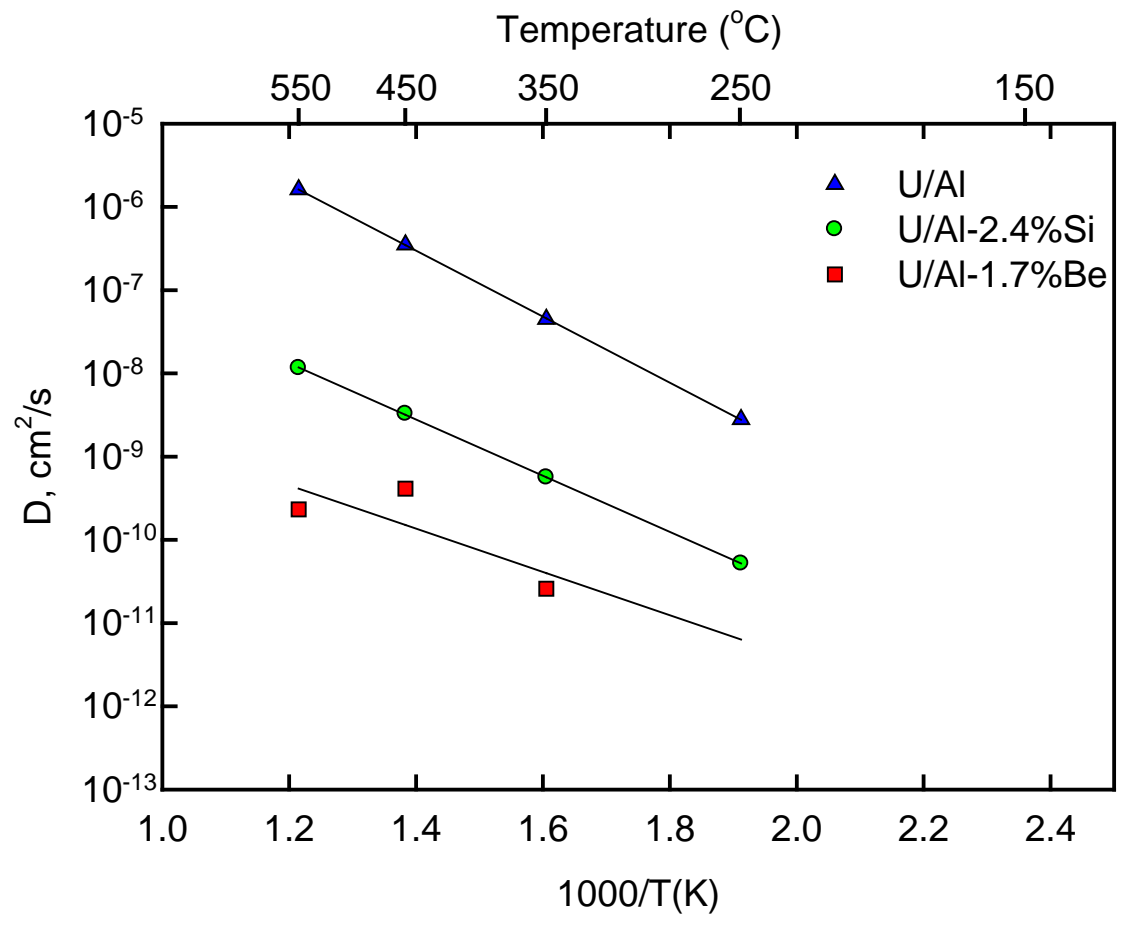

Fig. 66 Comparison of diffusion coefficients of U/Al, U/Al-Si and U/Al-Be diffusion couples.

At ANL, the effectiveness of Be addition in $\mathrm{Al}$ was heating tested. Several plates of U$7 \mathrm{Mo}$ dispersion in $\mathrm{Al}-\mathrm{xBe}(\mathrm{x}=2-8 \mathrm{wt} \%)$ were tested. However, because of the segregation of Be from $\mathrm{Al}$, a definite conclusion could not be drawn. A modified test using an Al-Be alloy powder instead of mixing two element powders is planned. In addition, an analysis of the preliminary test to quantify the effectiveness of the Be addition is underway.

Jungwirth et al. [84] tested the effectiveness of Bi addition in Al. A U-Mo dispersion in Al-Bi was irradiated with heavy ion beam. However, they observed an inconclusive result. The high oxygen affinity of Bi caused the improper contact between the fuel particles and matrix. 


\section{Section 8 Conclusions}

1. Out-of-pile tests revealed that the Si addition in the $\mathrm{Al}$ matrix reduced the IL (interaction layer) growth and also reduced the $(\mathrm{Al}+\mathrm{Si}) /(\mathrm{U}+\mathrm{Mo})$ ratio, showing a promising effect of $\mathrm{Si}$ addition. The higher the Si content in the matrix, the stronger the effect was observed.

2. Out-of-pile tests also showed that the lower $(\mathrm{Al}+\mathrm{Si}) /(\mathrm{U}+\mathrm{Mo})$ ratio, in other words a denser IL, was the key in reducing the IL growth. Higher diffusion of Si than Al occurred during heating as predicted theoretically that resulted in Si accumulation in the IL and a Si depleted zone.

3. Out-of-pile tests of $\mathrm{Zr}$ or $\mathrm{Ti}$ addition in the U-Mo showed that the addition is commonly effective in reducing IL growth, but $\mathrm{Zr}$ addition increased instability of the meta-stabilized $\gamma$-phase of the U-Mo whereas Ti addition did not seem to decrease the $\gamma$-phase of the fuel.

4. Like the out-of-pile tests, in-pile tests of Si addition in the matrix also showed drastic effectiveness by decreasing the IL growth. Like the out-of-pile tests, the IL growth was progressively reduced as the Si addition content increased.

5. Si diffuses in the IL with a slower rate than Al. This is attributed to the slower activation of Si by fission fragments than Al. However, Si diffusion to the ILmatrix interface was higher than that of Al. This resulted in a Si accumulation at the IL-matrix interface.

6. The effect of Si addition appears to take place by reducing the activity of Al (the effective concentration) at the IL-matrix interface where the U-Al reaction occurs.

7. The presence of high Si content in the IL is not the pre-requisite for Si addition to be effective. Since Si was depleted from the zone around the U-Mo particle during the pre-heating, additional Si migration to the IL could not occur during irradiation and the Si concentration was diluted as the IL grows.

8. The addition of Si in the matrix also showed that it delayed the formation and development of pores in the IL. However, a different kind of pores formed at the fuel periphery. At higher burnup close to full LEU burnup, pores started to form in the ILs.

9. The tenuous Si content near the U-Mo particle surface appears to establish a Si deficient condition. As a result, the IL stability decreases below such a level that the pores form.

10. Be and Bi have been studied to explore their effectiveness to suppress IL growth. An analysis of the preliminary test to quantify the effectiveness of the Be addition showed that $\mathrm{Be}$ is slightly better than $\mathrm{Si}$. However, a further examination is 
necessary to confirm the effectiveness. A German study found an inconclusive result to decide the effectiveness of $\mathrm{Bi}$. The difficulty regarding the test with $\mathrm{Be}$ and $\mathrm{Bi}$ lies in the limited solubility of these elements in Al. 


\section{Section 9 References}

[1] G.L. Hofman, Y.S. Kim, Nucl. Eng. Technol., 37 (2005) 299.

[2] G.L. Hofman et al., Proc. Inter. Mtg. on Reduced Enrichment for Research and Test Reactors (RERTR), Budapest, Hungary, Oct. 3-8, 1999, available on the web (http://www.rertr.anl.gov).

[3] G.L. Hofman, Y.S. Kim, M.R. Finlay, J.L. Snelgrove et al., RERTR Meeting, 2003. Available from http://www.rertr.anl.gov/

[4] P. Lemoine, J.L. Snelgrove, N. Arkhangelsky, L. Alvarez, RRFM 2004. Available from http://www.euronuclear.org/meetings/rrfm2004/index.htm

[5] W. Dienst, S. Nazare, F. Thummler, J. Nucl. Mater., 64 (1977) 1.

[6] G.L. Hofman, Nucl. Technol., 77 (1987) 110.

[7] H.J. Ryu, Y.S. Han, J.M. Park, C.K. Kim, S.D. Park, J. Nucl. Mater., 321 (2003) 210.

[8] M.I. Mirandou, S.N. Balart, M. Ortiz, M.S. Granovsky, J. Nucl. Mater., 323 (2003) 29.

[9] D.D. Keiser et al., Scripta Mater., 51 (2004) 893.

[10] F. Mazaudier, C. Proye, F. Hodaj, Trans. RRFM-2006, Sofia, Bulgaria, April 30-May 3, 2006. http://www.euronuclear.org/meetings/rrfm2006/index.htm

[11] H. J. Ryu, Y.S. Kim, G.L. Hofman, D.D. Keiser, Proc. Inter. Mtg. on Reduced Enrichment for Research and Test Reactors (RERTR), Cape Town, South Africa, Oct. 27 - Nov.1, 2006, available on the web (http://www.rertr.anl.gov). See also H.J. Ryu, Y.S. Kim, G.L. Hofman, J. Nucl. Mater, 385 (2009) 623.

[12] F. Huet, J. Noirot, V. Marelle, S. Bubois, O. Boulcourt, P. Sacristan, S. Naury and P. Lemoine, Trans. $9^{\text {th }}$ Internat. Topical Mtg on Research Reactor Fuel management, 2005, Budafest, Hungary, ENS, pp. 92-97.

[13] A. Leenaers, S. Van den Berghe, E. Koonen, C. Jarousse, F. Huet, M. Trotabas, M. Boyard, S. Guillot, L. Sannen, M. Verwerft, J. Nucl. Mater., 335 (2004) 39.

[14] Y.S. Kim, G.L. Hofman, H.J. Ryu, J. Rest, Proc. RERTR Meeting, 2005.

[15] H.J. Ryu, Y.S. Kim, G.L. Hofman, J.M. Park, C.K. Kim, J. Nucl. Mater., 358 (2006) 52.

[16] I. Barin, Thermochemical Data of Pure Substances, $3^{\text {rd }}$ Ed., Weinheim, VCH, 1995.

[17] S. Van den Berghe, W. Van Renterghem, A. Leenaers, RERTR Meeting, 2007. Also S. Van den Berghe, W. Van Renterghem, A. Leenaers, J. Nucl. Mater., 375 (2008) 340.

[18] O.A. Golosov, V.B. Semerikov, S.H. Boganov, M.S. Lyutikova, RERTR Meeting, Prague, Czech Republic, Sept. 23-27, 2007. http://www.rertr.anl.gov/index.html

[19] B. Bethune, “Transmission electron microscopy of $\mathrm{U}_{3} \mathrm{Si}$-effect of irradiation,” J. Nucl. Mater., 40, 205 (1971).

[20] J. Bloch, "Effet de l'irradiation par les neutrons sur les alliages uranium-fer a faible teneur en fer,” J. Nucl. Mater., 6(2), 203 (1962).

[21] S. Klaumunzer, "Ion-beam-induced plastic deformation: A universal phenomenon in glasses,” Rad. Effect Defects Solid, 110, 79 (1989).

[22] G.S. Grest and M.H. Cohen, "Liquids, glasses and the glass transition: A free-volume approach,” Advances in Chemical Physics, I. Prigogine and S.A, Price, Eds., John Wiley and Sons, p.469, New York (1981).

[23] G.L. Hofman, Y.S. Kim and M.R. Finlay, J.L. Snelgrove, et al., Trans. Internat. Topical Mtg on Research Reactor Fuel Management, Munchen, Germany, ENS, Mar. 21-24, 2004. 
[24] G.L. Hofman, M.R. Finlay, Y.S. Kim, RERTR Meeting, 2004.

[25] D.R. Green, "Diffusion of uranium and aluminum-silicon eutectic alloy,” HW-49697, Hanford Atomic Products Operation, 1957.

[26] T.K. Bierlein and D.R. Green, "The diffusion of uranium into Aluminum, Hanford Atomic Products Operation,” HW-38982, Hanford Atomic Products Operation, 1955.

[27] I.S. DeLuca and H.T. Sumsion, "Rate of growth of diffusion layers in U-Al and U-AlSi couples,” KAPL-1747, Knolls Atomic Power Laboratory, 1957.

[28] N.V. Chi and D. Berner, "Diffusion of Mo and W in Al," Proc. Int. Conf., DIMETA-82, F.J. Kedves and D.L. Beke, Eds., Tihany, Hungary, 1982, Trans Tech Publications, Switzerland, 1983.

[29] J.J. Blechet, A.Van Craeynest and D. Calais, J. Nucl. Mater., 27 (1968) 112.

[30] M. Ugajin, M. Akabori and A. Itoh, "Capsule irradiation tests of U-Si and U-Me (Me=Fe, $\mathrm{Ni}, \mathrm{Mn}$ ) alloys for use in research reactors,” JAERI-M94-042, Japan Atomic Energy Research Institute, 1994.

[31] W.C. Thurber and R.J. Beaver, "Development of silicon-modified 48wt\% U-Al alloys for aluminum plate-type fuel elements,” ORNL-2602, Oak Ridge National Laboratory, 1959.

[32] H.E. Exner, G. Petzow, Metall.23 (1969) 220.

[33] A.K. Chakraborty, R.S. Crouse and W.R. Martin, "Factors affecting the swelling during degassing of compacts containing uranium-aluminum intermetallic dispersed in aluminum,” ORNL-TM-2800, Oak Ridge National Laboratory, 1970.

[34] T.R.G. Kutty, C. Ganguly, N.C. Jayadevan and D.H. Sastry, J. Nucl. Mater., 230 (1996) 295.

[35] P. Chiotti and J.A. Kateley, J. Nucl. Mater., 32 (1969) 135.

[36] G. Bozzolo, Annual Progress Report to ANL, 2005.

[37] G. Bozzolo, R. D. Noebe, J. Ferrante, C. Amador, J. Computer-Aided Mater. Design 6 (1999) 1.

[38] G. Bozzolo, J. Morse, ADWTOOLS, Ohio Aerospace Institute, Cleveland, OH, USA, 2004.

[39] J.E. Hatch, Aluminum, American Society for Metals, Metals Park, Ohio, 1984.

[40] A.E. Right, C.F. Leitten and R.J. Beaver, In Proc. Research Reactor Fuel Element Conf., Gatlinburg, TN, 1962.

[41] W. Dienst, S. Nazaré and F. Thümmler, J. Nucl. Mater., 64, 1, 1977.

[42] G.L. Hofman, J. Rest, J.L. Snelgrove, T. Wiencek, S.K.V. Groos, RERTR meeting, Seoul, Korea, 1996. Available on the internet http://www.rertr.anl.gov

[43] C.K. Rhee, S.I. Pyun, I.H. Kuk, J. Nucl. Mater., 184 (1991) 161.

[44] A.E. Dwight, A study of the uranium-aluminum-silicon system, Argonne National Laboratory, ANL-82-14, 1982.

[45] A. Leenaers, E. Koonen, Y. Parthoens, P. Lemoine, S. Van den Berghe, J. Nucl. Mater., 375 (2008) 243.

[46] T. Komatsu, K. Matusita and R. Yokota, "Volume changes during the structural relaxation and crystallization in Fe-Ni based metallic glasses,” J. Non-crystalline Solids, 69, 347 (1985).

[47] S. Klaumunzer, H. Ming-Dong, G. Schumacher, L. Chang-Lin, Proc. of Mater. Research Soc., Los Angeles, March 1987.

[48] R.C. Birtcher, J.W. Richardson Jr., M.H. Mueller, J. Nucl. Mater., 230 (1996) 158.

[49] R.C. Birtcher, J.W. Richardson Jr., M.H. Mueller, J. Nucl. Mater., 244 (1997) 251. 
[50] F.R. de Boer et al., Cohesion in metals - Transition metal alloys, North-Holland, 1998.

[51] O. Kubaschewski, C.B.Alcock, Metallurgical Thermochemistry, $5^{\text {th }}$ ed., Oxford, Pergamon Press, 1979.

[52] R.F. Domagala, T.C. Wiencek, J.L. Snelgrove, M.I. Homa, R.R. Heinrich, Ceramic Bulletin, 65 (1986) 1164.

[53] J.M. Park, H. Ryu, G. Lee, H. Kim Y. Lee, C. Kim, and Y.S. Kim and G.L. Hofman, Proc. of the $27^{\text {th }}$ Inter. Mtg. on Reduced Enrichment for Research and Test Reactors (RERTR), Boston, USA, 2005, available on the web (http://www.rertr.anl.gov).

[54] M. Mirandou, S. Arico, L. Gribaudo, and S. Balart, Proc. Inter. Mtg. on Reduced Enrichment for Research and Test Reactors (RERTR), Boston, USA, 2005, available on the web (http://www.rertr.anl.gov).

[55] C.A.W. Peterson et al., UCRL-7824, TID-4500 (34 ${ }^{\text {th }}$ ed.), University of California, National Technical Information Service, US DOC, 1964.

[56] M. Mirandou, M. Granovsky, M. Ortiz, S. Balart, S. Aricó, L. Gribaudo, RERTR Meeting, 2004. See also: M. Mirandou, S. Arico, M. Rosenbusch, M. Ortiz, S. Balart, L. Gribaudo, J. Nucl. Mater., 384 (2009) 268.

[57] J.M. Park, H.J. Ryu, S.J. Oh, D.B. Lee, C.K. Kim, Y.S. Kim, G.L. Hofman, J. Nucl. Mater., 374 (2008) 422.

[58] J.M. Park, H.J. Ryu, J.S. Park, S.J. Oh, C.K. Kim, Y.S. Kim, G.L. Hofman, RERTR Meeting, 2007.

[59] C.K. Kim, K.H. Kim, Y.S. Lee, S.B. Park, G.L. Hofman, RERTR Meeting, 1999.

[60] R.T. DeHoff, F.N. Rhines, Quantitative microscopy, McGraw-Hill, New York, 1968.

[61] G.L. Hofman, Y.S. Kim, H.J. Ryu, D. Wachs, M.R. Finlay, Proc. RERTR Meeting, 2006.

[62] Y.S. Kim, H.J. Ryu, G.L. Hofman, S.L. Hayes, M.R. Finlay, D. Wachs, G. Chang, Proc. RERTR Meeting, 2006.

[63] G.L. Hofman, Y.S. Kim, H.J. Ryu, M.R. Finlay, D. Wachs, RRFM Meeting, 2007.

[64] Y.S. Kim, G.L. Hofman, A.B. Robinson, RRFM Meeting, 2009.

[65] Y.S. Kim, G.L. Hofman, P.G. Medvedev, G.V. Shevlyakov, A.B. Robinson, H.J. Ryu, RERTR Meeting, 2007.

[66] S. Van den Berghe, presentation at IFDWG meeting at RERTR meeting, 2008.

[67] J. Jue and D. Keiser, RERTR Meeting, 2008.

[68] F. Huet, V. Marelle, J. Noirot, P. Sacristan, P. Lemoine, in: Proc. International Meeting on RERTR, Chicago, IL, USA, Oct. 5-10, 2003. http://www.rertr.anl.gov.

[69] A. Leenaers, S. Van den Berghe, Private communication, SCK-CEN, Belgium, 2008.

[70] D.D. Keiser, A.B. Robinson, J.F. Jue, P. Medvedev, M.R. Finlay, Trans. Intern. Topical Meeting Research Reactor Fuel Management (RRFM 2009), Vienne, Austria, Mar. 22-25, 2009. http://www.euronuclear.org/meetings/rrfm2009/

[71] G.L. Hofman, Y.S. Kim, H.J. Ryu, M.R. Finlay, D.M. Wachs, Trans. Intern. Topical Meeting Research Reactor Fuel Management (RRFM), Lyon, France, Mar. 11-15, 2007. http://www.euronuclear.org/meetings/rrfm2007/

[72] P.E. Repas, R.H. Goodenow, R.F. Hehemann, Trans. ASM, 57 (1964) 150.

[73] K.C. Russell, Progress Mater. Sci., 28 (1984) 434.

[73] J.M. Park, H.J. Ryu, Y.S. Lee, B.O. Yoo, Y.H. Jung, C.K. Kim, Y.S. Kim, RRFM Meeting, 2008.

[74] J.M. Park et al., to be presented at RERTR meeting, 2010.

[75] H.J. Ryu, J.M. Park, C.K. Kim, Y.S. Kim, RERTR Meeting, 2008. 
[76] M.A. Dayananda, Def. Diffus. Forum, 95 (1993) 521.

[77] F. Rossi, M. Nastasi, M. Cohen, C. Olsen, J.R. Tesmer, C. Egert, J. Mater. Res., 6 (1991) 1175.

[78] M.V. Akdeniz, A.O. Mekhrabov, T. Yilmaz, Scripta Metall. Mat., 31 (1994) 1723.

[79] D. Wachs et al., RERTR Meeting, 2006.

[80] H.J. Ryu, Y.S. Kim, J.M. Park et al., Nucl. Engin. Technol., 40 (2008) 409.

[81] S.L. Hayes et al., RERTR Meeting, 2003.

[82] R.O. Williams, CF-50-7-160, ORNL, 1950.

[83] D.O. Gittings, D.H. Rowland, J.O. Mack, Trans. Am. Soc. Metals, R.T. Bayless, ed., Vol. XLIII, Am. Soc. Metals, 1951.

[84] R. Jungwirth, W. Petry, H. Breitkereutz, W. Schmid, et al., RRFM meeting, 2010. 


\section{Acknowledgments}

This report contains information gathered for a long expansion of the study from circa 2003 to the present, in the RERTR program (also known as the GTRI-Conversion program) and also in the foreign fuel development programs. In particular, the KAERI test results that have been given by Drs. J.M. Park and C.K. Kim are greatly acknowledged. The contributions from Dr. H.J. Ryu from KAERI and Mr. M.R. Finlay from ANSTO that were made while they worked at ANL as visiting scholars in different periods of time are gratefully acknowledged.

There have been many contributors for the RERTR irradiation tests, of which information is used in this report. To name a few, for the irradiation tests of RERTR-3, -4, -5, and -6, test plates were fabricated by T. Wiencek and PIE by late R. Strain at ANL. Later tests RERTR-6, -7, -8, and -9 were designed by D. Wachs, test plate fabricated by T. Wiencek, C. Clark and G. Moore. The PIE data from these later were collected by A.B. Robinson at INL. 


\section{Appendix}

The one-dimensional continuity equation for Al diffusion for the spherical coordinates is

$$
\frac{\partial \mathrm{C}}{\partial \mathrm{t}}=-\frac{1}{\mathrm{r}^{2}} \frac{\partial\left(\mathrm{r}^{2} \tilde{\mathrm{J}}\right)}{\partial \mathrm{r}}
$$

where $\mathrm{C}$ is the $\mathrm{Al}$ concentration and $\mathrm{J}$ is the $\mathrm{Al}$ flux. If we assume the Boltzmann parameter, $\lambda=\mathrm{r} / \sqrt{\mathrm{t}}$, is applicable, the variables in Eq. (A.1) can be transformed by

$$
\mathrm{dt}=-\frac{\mathrm{t} \sqrt{\mathrm{t}}}{\mathrm{r}} \mathrm{d} \lambda
$$

$\mathrm{dr}=\sqrt{\mathrm{t} d} \lambda$

If Eq. (A.2) and (A.3) are substituted in Eq.(A.1), we obtain

$\frac{\mathrm{dC}}{-\frac{\mathrm{t} \sqrt{\mathrm{t}}}{\mathrm{r}} \mathrm{d} \lambda}=-\frac{1}{\mathrm{r}^{2}} \frac{\mathrm{d}\left(\mathrm{r}^{2} \tilde{\mathrm{J}}\right)}{\sqrt{\mathrm{t} d} \lambda}$

which leads to

$$
\frac{r^{3}}{2 t} \frac{d C}{d \lambda}=\frac{d\left(r^{2} \tilde{J}\right)}{d \lambda}
$$

Dropping $\mathrm{d} \lambda$ from both sides and integrating Eq.(A.5) gives

$$
\int d\left(r^{2} \tilde{J}\right)=\frac{1}{2 t} \int r^{3} d C
$$

By noticing $\tilde{J}=0$ at $\mathrm{r}=\mathrm{R}$ where $\mathrm{R}=$ average radius of the U-Mo particles, Eq.(A.6) can be rearranged as

$\tilde{J}=\frac{1}{2 t} \frac{1}{(R+r)^{2}} \int_{C(R) \text { or } C(R+Y)}^{C(R+r)}\left(r-r_{0}\right)^{3} d C$

where $t$ is the test life, $\mathrm{Y}$ is the IL thickness, and $\mathrm{r}_{0}$ is the radius at the Matano surface location, at which the total $\mathrm{Al}$ amount on both sides is equal. $\mathrm{r}$ varies in the range of $0 \leq \mathrm{r} \leq \mathrm{Y}$. For convenience of calculation, $\mathrm{R}=125 \mu \mathrm{m}$ is taken from powder fabrication data.

Note that the Al flux calculated by Eq. (A.7) is a life-averaged value. 
The effective interdiffusion coefficient of $\mathrm{Al}$ is defined as $\tilde{D}_{A l}^{\text {eff }}=\int_{\mathrm{r}_{1}}^{\mathrm{r}_{2}} \tilde{\mathrm{J}}_{\mathrm{Al}}(\mathrm{r}) \mathrm{dr} /\left[\mathrm{C}\left(\mathrm{r}_{2}\right)-\mathrm{C}\left(\mathrm{r}_{1}\right)\right]$, where $\tilde{\mathrm{J}}_{\mathrm{Al}}(\mathrm{r})$ is the Al interdiffusion flux at $\mathrm{r}$ in the IL, and $r_{1}$ and $r_{2}$ are the radii at IL boundaries Detailed discussion of this formula can be found in Ref. 76. 


\section{Argonne}

Nuclear Engineering Division

Argonne National Laboratory

9700 South Cass Avenue, Bldg. 208

Argonne, IL 60439-4842

www.anl.gov 